Florida International University FIU Digital Commons

$11-24-2003$

\title{
Making the grade : the perceived impact on Floridas A+ plan on the learning environment of one elementary school
}

Robin L. Behrman

Florida International University

DOI: $10.25148 /$ etd.FI14050473

Follow this and additional works at: https://digitalcommons.fiu.edu/etd

Part of the Curriculum and Instruction Commons

\section{Recommended Citation}

Behrman, Robin L., "Making the grade : the perceived impact on Florida's A+ plan on the learning environment of one elementary school" (2003). FIU Electronic Theses and Dissertations. 1461.

https://digitalcommons.fiu.edu/etd/1461 


\title{
FLORIDA INTERNATIONAL UNIVERSITY
}

Miami, Florida

\section{MAKING THE GRADE: THE PERCEIVED IMPACT OF FLORIDA'S A+ PLAN ON THE LEARNING ENVIRONMENT OF ONE ELEMENTARY SCHOOL}

\author{
A dissertation submitted in partial fulfillment of the \\ requirements for the degree of \\ DOCTOR OF EDUCATION \\ in \\ CURRICULUM AND INSTRUCTION \\ by
}

Robin L. Behrman 
To: Dean Linda P. Blanton

College of Education

This dissertation, written by Robin L. Behrman, and entitled Making the Grade: The Perceived Impact of Florida's A+ Plan on the Learning Environment of One Elementary School, having been approved in respect to style and intellectual content, is referred to you for judgment.

We have read this dissertation and recommend that it be approved.

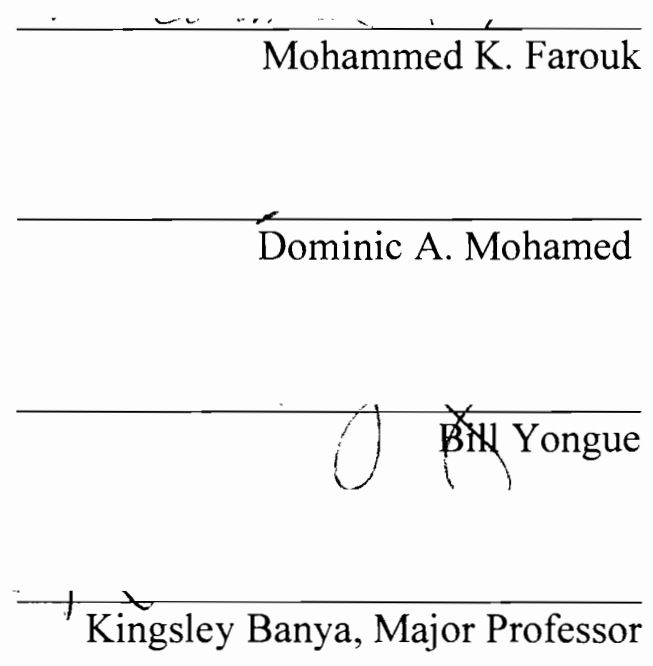

Date of Defense: November 24, 2003

The dissertation of Robin L. Behrman is approved.

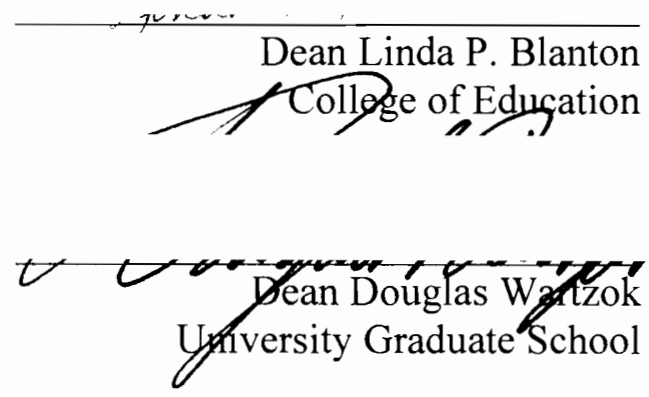

Florida International University, 2003 
(C) Copyright 2003 by Robin L. Behrman

All rights reserved. 


\section{DEDICATION}

I dedicate this dissertation to my mother and the memory of my father. Without their commitment to education and desire for the best for their family, the completion of this document and my degree would not have been possible. In addition, this dissertation is dedicated to my husband Andrew and my daughters Jennifer and Allison. Their patience, support and love have given me the strength to see this project through to the end. 


\section{ACKNOWLEDGMENTS}

I wish to thank the members of my committee, Dr. Mohammed Farouk, Dr. Dominic Mohamed, and Dr. Bill Yongue, for their time, assistance, and commitment in making this achievement a reality. As I progressed through the program, I was fortunate to come in contact with many faculty members who helped me successfully complete the process to earn this degree. My most heartfelt thanks go to Dr. Kingsley Banya who was a consistently positive influence. Without his support and direction, completing this program would not have been possible.

To my friends and my family, I'd like to say that all of you have been wonderful. I am truly the luckiest person alive to have the support system that I do. To Andrew, Jennifer, and Allison, my dearest husband and daughters, I want to let you know how much having you by my side through this endeavor has meant to me. Without your selflessness, I would not have been able to accomplish my goals. 


\section{ABSTRACT OF THE DISSERTATION \\ MAKING THE GRADE: THE PERCEIVED IMPACT OF FLORIDA'S A+ PLAN ON THE LEARNING ENVIRONMENT OF ONE ELEMENTARY SCHOOL}

by

Robin L. Behrman

Florida International University, 2003

Miami, Florida

Professor Kingsley Banya, Major Professor

The purpose of this study was to ascertain the perceptions of educators at one elementary school regarding the changes in the teaching and learning environment and their related effects following the implementation of Florida's A+ high-stakes accountability system. This study also assessed whether these changes were identified by participants as meaningful and enduring, in terms of the definition by Lieberman and Miller (1999). Twenty-one educators, including 17 teachers and four administrators, at Blue Ribbon Elementary school were interviewed. Data were inductively coded and categorized into four major themes: (a) teaching and learning environment consistency, (b) changes in the teaching and learning environment since the implementation of $\mathrm{A}+$, (c) effects of the changes, and (d) significant and enduring change. Findings fell into three categories (a) identified changes since A+ implementation, (b) effects of changes, and (c) what participants believed was significant and long term change, which included those characteristics of the school that had been identified as consistent in the teaching and learning environment. Statements of the participants explained their perceptions about 
what instructional decisions where made in response to the A+ Plan including the modification of curriculum, the addition or omission of subject matter taught, and the positive or negative impact these decisions had on the teaching and learning environment. It was found that study participants felt all changes and their effects were a direct result of the A+Plan and viewed many of the changes as being neither significant nor long term Analysis of the educators' perceptions of the changes they experienced revealed the overall feeling that the changes were not indicative of what was necessary to make a school successful. For the participants, the changes lacked the characteristics that they had described as vital in what constituted success. This led to the conclusion that, by Lieberman and Miller's definition, the majority of changes and effects that were implemented at the school as a result of the mandated A+ Plan, were not meaningful and enduring for effective school reform. 


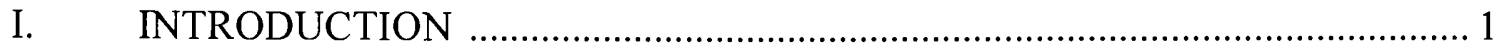

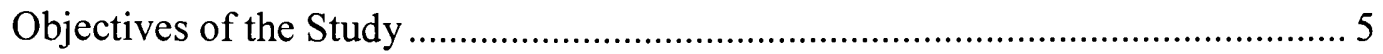

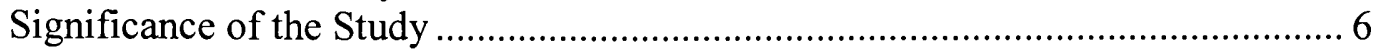

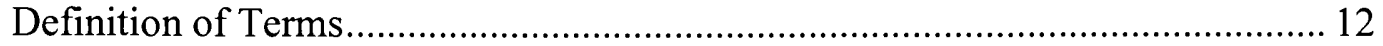

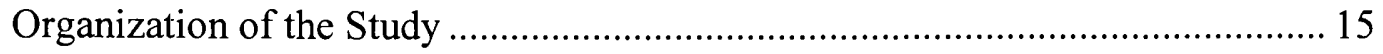

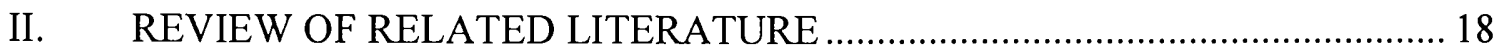

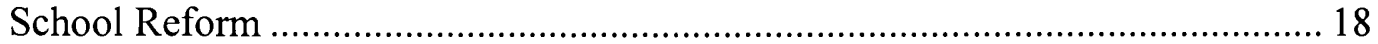

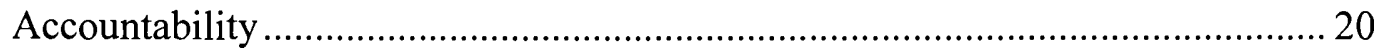

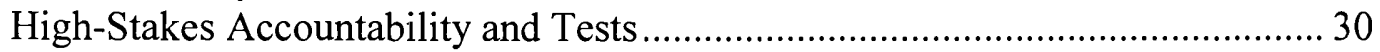

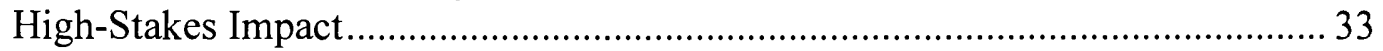

Conceptual Framework ..................................................................................... 45

Approaches to School Transformation ………….............................................. 46

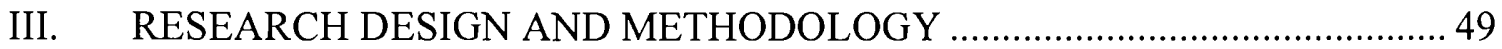

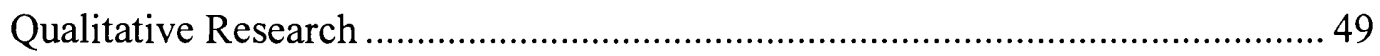

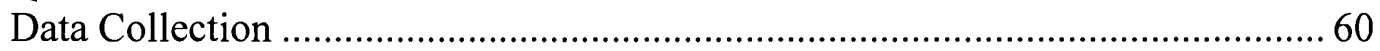

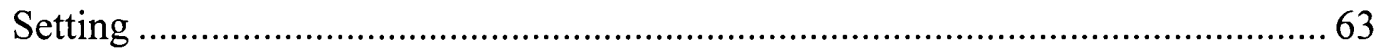

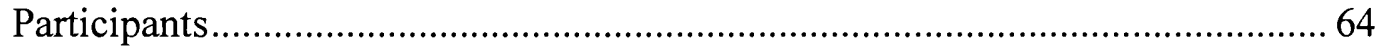

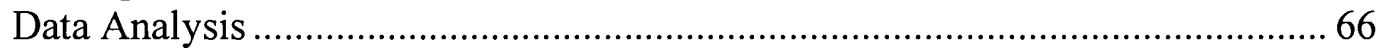

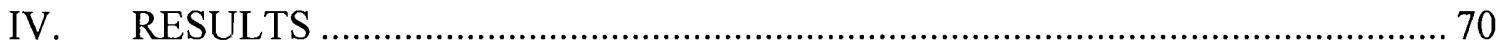

Teaching and Learning Environment Consistency ........................................... 70

Changes in the Teaching and Learning Environment........................................ 79

Effects of Change on the Teaching and Learning Environment.......................... 98

Significant and Long Term Change ............................................................... 124

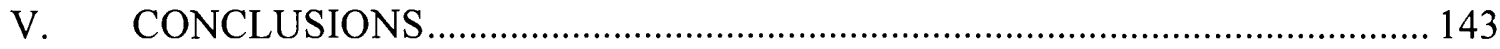

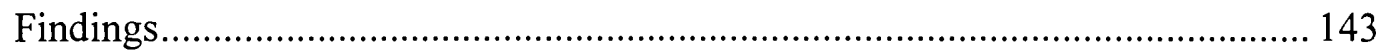

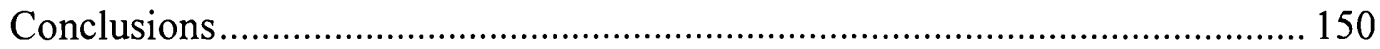

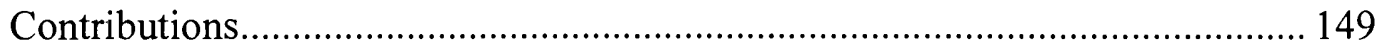

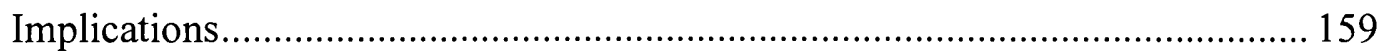

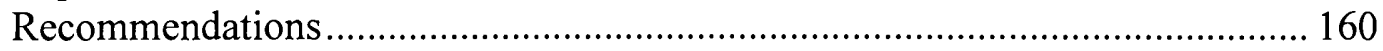

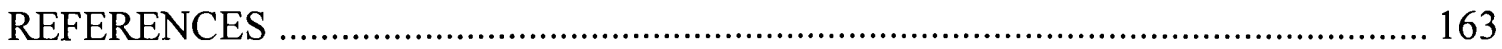

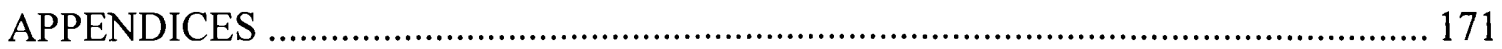

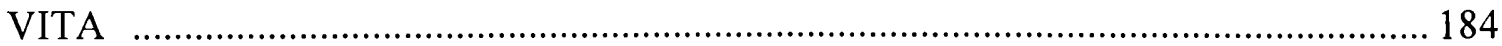




\section{CHAPTER I}

\section{INTRODUCTION}

The words school reform consistently seem to be linked with public education. The specifics are in a constant state of flux. Philosophies and theoretical underpinnings may vary from one reform theme to another. Proponents of educational reform seem to jump on the bandwagon at one turn and hop off at the next. Educational researchers have commented that many shifts in ideologies are strongly supported by local or state governmental mandates (Kohn, 2000b; Natriello \& Pallas, 1998).

The past fifty years have seen assessment and accountability together play a prominent role in numerous reform efforts (Linn, 2000). The appeal of linking assessment and testing with accountability lives on today. More and more states seem to make high-stakes tests, those externally mandated from which important decisions are made (Schleisman, 1999), the backbone of their school-improvement strategies (Wolk, 2000), and much of the discussion and deliberation surrounding standards reforms has focused on testing (Coleman, 2000). States such as Oregon (Conley \& Goldman, 1998), Kentucky (Kentucky Institute for Education Research, 1995), Los Angeles (Bradley, 2000), North Carolina (Manzo, 2000), and a host of others have made high-stakes test results the center of school accountability systems.

One evident utilization of standardized tests in determining school accountability is demonstrated in the Governor's A+ Plan for Education in the State of Florida. This program, enacted by the Florida Legislature in 1999, defines the fundamental premises of the state's education policy. The A+ Plan contains three major parts. The first addresses accountability and the improvement of student learning. Section two speaks to improved 
training for educators. The final section addresses improved school safety and the reduction of truancy (My Florida, 2001).

The high-stakes portion of the plan, one of the most visible pieces of Florida's system of School Improvement and Accountability, calls for an assignment of a school performance grade based primarily upon student achievement data generated from the Florida Comprehensive Assessment Test or FCAT. These school grades are used to communicate achievement and effectiveness of individual elementary and secondary schools. The grades are determined by the school's collective student performance in reading, writing, and math as indicated by the Florida Comprehensive Assessment Test (FCAT Briefing Book, 2001).

The grades that are assigned to schools are supposed to communicate to the general public how well each educational institution is performing relative to the Sunshine State Standards (SSS). These standards, developed by the Florida Department of Education (DOE) in 1994, were created to provide all education stakeholders a clear awareness of what skills and competencies Florida students should have in the areas of mathematics, language arts, social studies, science, the arts, foreign languages, health and physical education, at specific stages of their public schooling (My Florida.com, 2001).

Results from the FCAT are further used as the primary criteria in the state's calculation of school improvement ratings, rewards, levels of recognition, and performance-based funding. However, in addition to the FCAT scores, attendance, discipline, and dropout rate data have been used in designating school performance grades. 
Where does this stress on assessment and accountability lead? According to the headlines in local newspapers and educational publications, which provide a great deal of information to the general public, this increased emphasis on testing has produced a flurry of controversy. Proponents of high-stakes student testing contend that the risk of strict penalties pressures students, teachers and other school-site personnel to improve performance (Wolk, 2000). They further point out that tests are relatively inexpensive to administer compared to the implementation of changes in class time or class size. They can be mandated externally by states or districts, can be rapidly implemented, and the results are almost immediately visible (Barton, 1999). National and state polls suggest that the general public stands behind the push for standards-based education and seems to be supporting high-stakes testing (Archer \& Hoff, 2000).

Opponents of testing do not frown on the use of these assessments for monitoring student learning, but disagree with the way in which the results are utilized to define a successful school. Those who oppose the way in which test scores are used believe that no high-risk decisions affecting students, teachers, and schools should be based primarily on test scores (Coleman, 2000). As the stakes rise and money and jobs are put on the line, the pressure to teach to the test and even to cheat grows (Boser, 2000; Hoff, 2000). As an educator directly involved in addressing the mandates of a high-stakes assessment system, it seems as if the accountability microscope focuses more and more on testing as a means of gauging success in public schools and as a result, the teaching and learning environment goes through a continuous transformation. It is the need to better understand the essence of this change that is the driving force of the research involved in this study. 
During the 1998 - 1999 school year, the State of Florida began the implementation of the high-stakes A+ Plan for Education. The Florida Comprehensive Assessment Test (FCAT) became the primary means of grading Florida's public schools. I believe that the extent of the ramifications of this program was not well understood by those in the education community until later on in the program's implementation. During the beginning stages of the implementation of the A+ Plan, a time when I was a teacher at the school focused upon in this study, the faculty and others understood the FCAT to be an assessment that would aid in the alignment of the state standards to what was being evaluated and would help drive district curriculum alignment with state standards. The idea of school grading was not emphasized by the State of Florida until later on in the process.

Natriello \& Pallas (1998) found that nationally there has been little agreement on the impact of high-stakes testing and accountability on students and their learning, educators and their teaching, schools and their levels of achievement, and the general school community's perspective on education. Since the inception of calculating and reporting individual public school grades across the state of Florida, the news media has described various negative effects of test preparation and school grading on students, teachers and staff members at many schools. News reports have also focused on the intense preparation, motivational techniques, and disappointments connected with FCAT scores and school grades.

The purpose of this case study was to ascertain the perceptions of teachers and administrators in a specific elementary school, which is located in a middle class 
neighborhood in the northwestern section of Miami-Dade County, regarding the changes in the teaching and learning environment, including instructional methods promoted, school activities held, and professional development opportunities presented since the implementation of the Governor's A+ Plan for Education. All of the participants had been at the school before the implementation of the A+ Plan. Questions that guided the research included: How do educators at the research site believe the accountability measures of the A+ Plan have affected school practices? How have school educators and administrators viewed and responded to the A+Plan accountability measures and the changes in teaching and learning that have occurred? Has "making the grade" become an all-consuming quest of teachers and administrators? Are these changes, as reported by school staff, indicative of what Lieberman and Miller (1999) describe as meaningful and enduring?

Objectives of the Study

This inquiry investigated educators' perceptions of changes in the teaching and learning environment of one school community as teachers and administrators there worked to raise FCAT scores and the school's grade reported by the Florida Department of Education. It relates individual experiences and decisions educators had as participants in an overall process of "making the grade."

There were two main objectives of this study: (a) to inquire into the perceived effects on the teaching and learning environment, of "making the grade," on the school community and (b) to ascertain if the changes and their perceived effects, as indicated by school professional personnel, fit the Lieberman and Miller (1999) model of enduring change in a teaching and learning environment, i.e. containing the elements of 
transforming curriculum and instruction in order to improve quality and promote equality, changing the structure of the school, adoption of a two-pronged focus: students and teachers, formation of connections outside the school, and encouragement of increased participation of parents and the surrounding community. Lieberman and Miller's model defines change that focuses upon an enhanced teaching and learning environment and not just on the one isolated aspect of student achievement.

\section{Research Questions}

1) What changes have educators at the school site reported about the school's teaching and learning environment since the inception of the A+ plan?

2) What perceived impact have these changes had on the teaching and learning environment?

3) Do adult stakeholders at the school site perceive the changes as "meaningful and enduring" as defined by Lieberman and Miller (1999)?

\section{Significance of the Study}

Over the past decade and continuing on into the twenty-first century, school reform has been billed as a "standards and accountability" movement. Berliner and Biddle (1995) explain that the belief of many individuals that American schools are failing, due to the fact that students and educators are perplexed or because they lack the capability or the motivation to engage in focused education, has resulted in numerous state programs detailing specific standards for student conduct, effort, and achievement. Many of these programs then tie funding for schools or educators' salaries to performance indicators on standardized tests. Kohn (in Lindsay, 2000) points out that the 
control of the classroom has been put in the hands of politicians and business executives, and standardized tests have become the definitive driving force of learning.

Lindsay (2000) reports that as the new century gets into full swing, no other school reform initiatives can equal the size, speed, and momentum of the standards movement. In almost every state in this country, there have been designations of what children should know, and many of these states have produced tests to measure pupil and school performance. Some states use test results to reward success and punish failure. Many base their educational rating systems primarily on the outcomes of high-stakes tests.

The widespread emphasis on current high-stakes tests and school ratings has produced a great deal of fallout. Reports of teacher and administrator cheating ("Cheating to the Test," 2000; Feldman, 2000; Hoff, 1999; Kleiner, 2000; Olson, 2000) have increased as test scores are utilized at an ever-increasing rate to determine everything from teacher job security to student promotion and graduation. Educators and parents recount stories of children who cannot sleep, vomit on test days, and complain about school (Jehlen, 2001). Teachers complain about anxiety, feeling the pressure and even hearing a change in the tone and content of their own vocalizations (Feldman, 2000). Ultimately, reactions to high-stakes accountability influence what happens in the teaching and learning environment.

Studies have shown that a frequently emphasized consequence of high-stakes testing and accountability is the narrowing of the curriculum, a practice commonly known as "teaching to the test." Pressure to show better scores and higher school ratings forces teachers to spend much time, sometimes even months, on drilling students on the 
content and formats of the various tests (Feldman, 2000; Wallace, 2000; Willis, 1999).

Evidence of this practice occurs throughout many schools in the State of Florida;

instructional and curricular foci are placed on the Florida Comprehensive Assessment Test and the effects of the test's scores on the grades schools are given via the media.

In newspaper article after newspaper article, reports are made concerning the localized effects of the FCAT's presence. In South Florida, newspaper headlines allude to the repercussions of high-stakes testing and school accountability. The Miami Herald has run headlines such as "FCAT Preparation Reaches Fever Pitch in Area Schools" (Ferrechio, February 5, 2000), "Anxiety Heightens as FCAT Nears" (Ferrechio, February 14, 2000), and "Scores Have Teachers Jumping for Joy" (Nazareno, Brecher \& Robinson, 2000). Similarly, The Sun Sentinel has reported stories entitled "Educators Express Fears of Teaching 'to the Test"” (Gold \& Talalay, 1999), "Teachers Flee Failing Schools" (Hirschman, 1999), "Pressure, Tension Fuel FCAT Drills" (Hirschman, Hall, \& Patrick, 2000), "FCAT Focus Draws Flak" (Marshall \& Hall, 2000), and “'I Don’t Think Anybody Can Relax or Let Up"' (Hirschman, 2000). Each article ultimately points to the various negative effects of the FCAT and the grading of Florida's public schools. In addition, teachers' union newsletters and flyers and newspaper editorials have continually touched upon the fact that things around the school and community have changed, quite often negatively, due to Florida's A+ Plan's call for school ratings. The titles and content of these stories subtly indicate that changes in the teaching and learning environment have taken place. How stakeholders perceived these changes in turn have influenced what took place, on a daily basis, at different school sites around the state. It is the need to understand the alterations that have evolved and their perceived effects on the teaching 
and learning environment that has become the driving force behind this research and the interest in the results that found.

This study goes beyond what the media have reported as to the procedures that are being followed by educators in a specific school as they strive to meet the requirements of the current school reform initiative in the state of Florida. It offers insights into how a school reacts to a high-stakes accountability system, the effects of the implemented changes, and their relationship to meaningful and enduring change as described by Lieberman and Miller (1999), since as of this time the researcher was unaware of any published literature that focuses upon Florida's A+ Plan, high-stakes testing, and changes in a specific school's teaching and learning environment. Lieberman and Miller outline five building blocks for effective and lasting change that help build a successful teaching and learning environment.

This research also provides data that relates to the perceptions of educators concerning the relationship of changes to the school grading involved in the A+Plan and whether or not these changes are relevant to all types of school reform or germane only to the A+Plan. The study focused upon procedural changes or the ways in which teaching and learning take place and principled changes, those that rely on values, in the teaching and learning environment observed by the researcher and described by teachers and administrators.

The study also provides new insight into how a group of educators and administrators make instructional decisions, how they modify curriculum, extracurricular events, and other specific activities in their efforts to improve student performance on a high-stakes test in an attempt to raise the school's grade. Providing rich detail about what 
happened in this school as a consequence of its implementation of new accountability programs provides specific tangible examples that will augment understanding of how curricular and instructional concentration on tests can and do impact teaching and learning. In addition it explores the possible divide between what is intended by the State of Florida's implementation of a high-stakes test and what in fact is the actual effect (Moss, in Schleisman, 1999).

Although school reform literature speaks to current trends, negative and positive effects of high-stakes testing and the standards movement, and the increased public perception of a need for a higher level of accountability, there is not a large body of research concerning the specific changes that a school goes through in order to meet the demands of its respective state's reform criteria. In addition, there are reports that allude to the fact that teachers, students, administrators, and parents have an emotional investment in what goes on during times of intense reform; but specific accounts of the perceptions of key stakeholders are lacking. These perceptions give insight as to the level of support the school community gives to the ongoing reform. This is important to understand as the community helps to perpetuate the perception as to whether or not a school is successful in educating its students.

The impact of this study may be far reaching. According to Scott Willis of the Association for Supervision and Curriculum Development (1999), current accountability systems involving high-stakes tests have become more of morale busters than motivators. These high-stakes systems focus on the public's and politicians' distrust of the education community's professional capability to assess student performance and development. Willis says that instead of focusing upon the failures of schools, the successes need to be 
emphasized. In addition, he believes that accountability for student success and failure need to be spread to other segments of society besides schools and educators; a sentiment that those in public education have been voicing for quite some time. Eisner (2001) states that listening to what a school community has to say about the effects of highstakes testing and school ratings may lead accountability in a more positive direction. A more informed awareness of what impacts schools puts all stakeholders in a better posture to improve them.

An increased discussion on the linkage of salary and student achievement, opportunity scholarships (vouchers), and a host of other by-products of school ratings as determined by the A+Plan and other similar types of school reform movements around the country have been reported. The impact of these and other perceived effects of school grades on teaching and learning by one school's educational community can assist others with an understanding of the personal reality of key stakeholders about these changes and the roles they play during educational innovation (van den Berg \& Ros, 1999). An understanding of what changes go through a school during times of increased emphasis on standards and high-stakes tests and whether those changes are viewed as encouraging or detrimental by educators is relevant in determining whether or not a school is truly successful in terms of providing significant and enduring change. This success encompasses the entire teaching and learning environment as opposed to focusing upon only one aspect, in this case, student achievement indicated via standardized test scores.

This research is intended to strengthen the voices of the people deeply involved in a specific educational community, as it allows the educational stakeholders a chance to 
express their understandings of the impact of the A+ Plan and the FCAT on their teaching and learning environment. It is a vehicle to understand the frustrations and celebrations that surround "making the grade." McNeil (2000) explains:

It is only by understanding the differential effects of accountability systems on varied groups of students, on teachers, on parents, and on communities that we can know whether they serve our children and our goals for public education well. And it is only by going inside schools and inside classrooms that we can begin to build that understanding at a deeply informed level (p. 734).

State educational policymakers' knowledge of participants' perceptions of the strength, weaknesses and other effects of the Florida A+ Plan may contribute to the improvement of this high-stakes accountability system and/or assist in the development of other systems of educational assessment. As professionals in the field of education, the participants' contributions may help to strengthen the accountability process and promote buy-in among educators. This study may also help those involved in the design of Florida's educational accountability system plan to ameliorate the possible discrepancies between reform aims and what actually takes place at a particular school site.

\section{Definition of Terms}

For the purpose of this study, the following words and phrases have special meaning as set out below. Other terms that are not frequently used but which require definition are explained as they are introduced.

A+Plan for Education. This is the current wave of school reform for the state of Florida. It contains three major parts - one to address accountability and improving student learning, one to raise standards and improve training for educators, and one to improve school safety and reduce truancy (State of Florida, 2000). The grading criteria have changed on an annual basis. 
Accountability. According to the Association for Supervision and Curriculum Development (1999), the accurate meaning assigns responsibility to a variety of agents for creating the necessary conditions and providing the resources and opportunities crucial for the success of all students. In most areas of this study, however, accountability will refer to holding educators totally responsible for students' performance, specifically on high-stakes tests because this use reflects both the way it is used in the literature and was used by school level educators at the research site.

Florida Comprehensive Assessment Test (FCAT). Criterion-reference test created and utilized by the state of Florida to measure mastery of the Sunshine State Standards.

High-stakes Tests. These are tests, such as the FCAT, used by school districts and states to base decisions concerning things such as student promotions, school ratings, and teacher compensation.

School Grading Plan. Performance grades assigned to Florida public schools based primarily upon student achievement data from the FCAT.

Standards. Goals outlining what students should know and be able to do at various grade levels; clearly defined statements specifying knowledge, skills, and behaviors.

"Teaching to the Test". Daily instruction dealing with the content assessed on a standardized test including the utilization of test preparation materials. This usually takes the place of substantial subject matter content; in essence, the test becomes the curriculum. Increasingly, instruction moves away from the content and more toward the format of the test so that students will be ready to "take the test." 


\section{Delimitations of the Study}

This study is limited to one elementary school learning community in which the researcher holds the position of assistant principal. While the findings were site-specific, the results will increase the public knowledge of changes that took place due to the implementation of a high-stakes accountability system and enhance readers' understanding of the perceived impact those changes have had at a particular school site.

Within the community, teacher participants were chosen according to a willingness to participate in the research. The data reflect the insights of those who responded and had been an educator at the school at least one year before the FCAT. All the people who volunteered and had been members of the school staff at the inception of the A+ Plan were interviewed. The principal and the three assistant principals who have been part of the school site for at least the past four years were also interviewed. This was important to the study, as all of these individuals were part of the staff both before and after the commencement of the A+ Plan.

As both the researcher and an assistant principal at the selected school site, the character of the relationship between the researcher and school personnel might be construed as a limitation to the research. It is this relationship, though, that is a strength of this study due to the trust that had been built as a peer while I was a fellow teacher and has continued throughout present assistant principal - teacher relationships. An example of this bond was exhibited by the large number of individuals who were willing to be part of the study and who stated that they trusted my integrity and were comfortable with the idea of me interviewing them. All participating teachers and administrators had the 
opportunity to go over transcripts and reported findings during the process of member checking.

The findings of this study are site-specific. There is a possibility of transferring the findings to similar elementary schools where FCAT testing takes place, as the testing embodies a large portion of the criteria that determine every public school's grade in the state of Florida. Another person may be able to utilize this study by bringing its research and interview questions to another site and comparing the findings to those that were expressed as a result of this particular study to see if similar changes and effects have occurred.

\section{Organization of the Study}

Chapter I is an overview of this research project. It provides an introduction to the investigation as well as the statement of the problem, objectives of the study, significance of the study, and explicit and implicit influences of the investigation. In addition, this chapter presents the definition of terms, delimitations of the study, and a short summary.

Chapter II focuses upon a review of the literature. Topics reviewed include the current standards movement in school reform, the rating of schools by individual states, and the increasing utilization of high-stakes tests. Lieberman and Miller's concepts of meaningful and enduring change are explored as the basis of the conceptual framework of the study.

Chapter III examines the research design and methods used in the investigation. The setting and participants are described. Methods of data collection and analysis are specified and explained. 
Chapter IV presents the case study data from the interviews with the participants. It also provides an analysis of the data collected. Comparisons are made between the responses of the different groups of teachers and administrators. Findings from the interviews are examined in light of the teaching and learning change model described by Lieberman and Miller (1999).

Chapter $\mathrm{V}$ provides conclusions drawn from the research findings. It explains weaknesses and strengths in the study and offers recommendations for changes in practice as well as suggestions for further research.

\section{Summary}

Education reform in the United States is in full swing. The standards movement has taken a front seat in school reform and along with it has come the dependence upon high-stakes testing to rate schools. Throughout classrooms and school buildings across the country, teachers, students, administrators and parents are feeling the pressure caused by the emphasis on testing. In some places, teaching to the test has replaced a wellrounded curriculum, which includes subject areas not covered on the assessment. In others, people have resorted to cheating to escape the punishment associated with a low school grade. In all places, the public listens for news of test scores and where their community schools lie in relationship to the others in the district.

The Florida A+ Plan and its focus on the Florida Comprehensive Achievement Test have triggered changes across the state as reported in previously cited media reports. Programs to address the standards covered by the test have been instituted in public schools and have affected all stakeholders. It is the goal of this research to understand and explain teachers' and administrators' perceptions of these changes in the teaching 
and learning environment in a particular elementary school learning community in Miami-Dade County. The researcher hopes that the findings of this investigation may lead readers to a better appreciation of the effects on those individuals touched by this current form of high-stakes school reform.

In addition, it is anticipated that those who develop and require this reform will look at the results and possibly use these findings to understand how stakeholders view the effects of the changes that have occurred in the teaching and learning environment, which will in turn lead to an adjustment of the criteria necessary to achieve a passing grade as delineated by the A+ Plan creating a chance for educators to buy-in to the accountability process. Finally, by identifying what characteristics participants believe truly define a successful school and how relating these characteristics to the changes that have taken place since the A+ Plan, a better understanding of whether or not the teaching and learning environment fits Lieberman and Miller's (1999) model for meaningful and enduring change may take place. This framework focuses on the researcher's beliefs that educators are at the hub of all school improvement efforts and that without their involvement and guidance, any attempt at school reform is destined for failure. 


\section{CHAPTER II}

\section{REVIEW OF THE RELATED LITERATURE}

Educational literature abounds with writing concerning standards-based school reform, high-stakes testing, accountability, and the possible effects of these trends in education. Even though quantitative studies have been carried out to look at the implications these issues have at the school site, there are few qualitative studies that probe stakeholders' understandings of the emotional, procedural, and environmental changes that occur in a school community. The study focused on the perceptions of a school community as to how these trends have impacted teaching and learning in their school.

\section{School Reform}

The United States has encountered major social movements during the latter half of the twentieth century, and this trend continues into the twenty-first century. Civil rights, anti-war movements, gay rights, and others have begun as the discussions and campaigns of a few and spread to the public as a whole. As fervor for these issues has intensified, the direction of politics has changed, policy has been shaped, and adjustments in human behavior have tended to follow (Wolk, 1999).

School reform movements tend to follow a different pattern. According to Gratz (2000), statements of educational problems are more intense and specific than the proposed solutions. Reform innovations promise the world, but often fail to meet expectations. Implementation may be too quick, too rigid, and too sterile. Wolk (1999) reports that school reform movements differ from other social actions, as they are predominantly top-down. Political figureheads, business and other leaders respond to 
what they deem dismal test scores and evidence of an increase in mediocrity by producing volumes of directives and legislation in an effort to pressure schools to change. It has become more common in the last quarter of a century for state governments to establish large-scale reform initiatives in education. While the goals of these reforms have seemed to focus on student learning, there has not been an overall consensus as to whether policies should work to change teachers, schools, governance and accountability methods, or some combination of all (Fuhrman, 1993 in Conley \& Goldman, 1998). As a result of the lack of consensus, standards-based school reform and accountability have become the most recent phase of educational innovation as a result of a push to standardize public education.

According to Lindsay (2000), no recent type of school reform can equal the immensity, impetus, and velocity of the nation's educational standards and accountability movement. This development has become prominent across all academic levels and infused in almost every discipline. Assessments are one of the major policies being practiced as a primary intervention in the nature of teaching and learning in educational institutions (Moss \& Schutz, 2001). A broad spectrum of individuals and groups, from business executives to newspaper editorial boards, from foundations to politicians, has endorsed the ideas encompassed in this popular reform.

The emphasis on having standards has evolved out of long time arguments over tracking, the impact of educator expectations, the struggle for educational equity, and the never ending desire for highly skilled employees to power the country's economic machinery (Gratz, 2000). Reports and initiatives such as A Nation at Risk, SCANS, and 
Goals 2000 have addressed what their writers felt was wrong with American education; the standards were not high enough.

The movement toward the redesigning of curriculum to meet world-class standards has brought with it a component of assessment and accountability. Consequently, assessment and accountability have become reliant on high-stakes tests (Berliner \& Biddle, 1995). It is with this focus and thrust on accountability and testing that the debate between educators and other involved in the education of children, over the standards movement, has been set into high gear (Gratz, 2000; Kohn, 2000; \& Lindsay, 2000).

\section{Accountability}

Accountability is the rallying call of the latter part of the 1990s and continues into the new millennium (Holdzkom, 1999), although issues linked with accountability have held a major place in educational reform in the United States since the unveiling of "A Nation at Risk" in 1983 (Bauer, 1999). The early part of the twentieth century saw accountability as pressure for a higher degree of consistency in classroom design, curriculum, and instruction. It also evolved into the scrutinizing of states, districts, and schools for fulfillment of the mandates of particular laws. Recently, administrative or conventional approaches to school accountability have been put forward as part of a lengthy agenda for performance-focused reform, with compensations and penalties ascribed to school improvement or the lack thereof. Holding schools accountable is seen as the impetus that will push schools forward to meet the goals for student achievement and school improvement, gauged predominantly by test scores, which are established at the state level (Wheelock, 2000). Accountability requires a responsibility to a superior, 
being held to justification or being required to answer to a higher authority, such as a state board (McNeil, 2000).

In the past and today, the aim of standards formulation and performance measurement was and is to "systematize and standardize so that the public will know which schools are performing well and which are not" (Eisner, 2001, p. 367). According to many (Knowles \& Knowles, 2001), today’s discussion of educational accountability signifies that educators will be held responsible for how successfully students read and for their scores on achievement tests. Rewards and punishments will be dependent upon the school's ability to bring students up to or above grade level. Although accountability systems have been, in name, designed to help schools improve and students learn, standards and accountability, as implemented in most states, appear to be devised principally to identify and castigate schools and educators for poor performance (Gratz, 2000). The emphasis on accountability highlights sameness and fails to take into consideration that children are different (Knowles \& Knowles, 2001).

\section{National Picture of Accountability}

Boser (2001), in Education Week's Quality Counts 2001, explains that more states than ever before have made a mad dash to implement accountability measures in order to monitor public schools. Test scores are the sole basis of school ratings in twenty-seven states. Only sixteen of those twenty-seven states utilize other information in the formulas for school ratings. There are some states that assess schools by gains on test scores over a period of time. Others apply the same, definitive standard to all schools. Some states look at the total population within a school; others scrutinize the achievement gaps between all subgroups and punish those that register large discrepancies. 
School accountability is further defined (Quality Counts, 2001) according to the criteria for evaluations and ratings, assistance, rewards, and sanctions. As of January 2001, seventeen states assigned ratings to all of their schools and ten identified only those schools that were deemed low-performing. Four states assigned ratings in 2002, one will do so in 2004 , and one sometime in the future.

Evaluations and ratings of schools are currently based upon a combination of some or all of the following criteria: student test scores, attendance rate, dropout/graduation rate, course taking data, site visits or interview, and other information. States set the performance cutoff for low-performing schools in one of three main ways: schools are compared with each other, schools are compared to set standards or a cutoff point, or schools are compared with their past performances. At this time, very few states address achievement gaps. In addition many states impose sanctions, rewards, assistance, or some combination based on school ratings. These rewards and sanctions take on various forms including the infusion or withdrawal of money, personnel, autonomy, and restructuring.

Florida's High-Stakes Accountability System

According to the Florida Department of Education (2000), the state set into motion the School Improvement and Accountability Act in 1991. This occurred largely in reaction to the U. S. Secretary of Labor's comprehensive study of American businesses and the work force. Released in 1991, the findings of the Secretary's Commission on Achieving Necessary Skills (SCANS) Report basically stated that schools must be reworked into high performing institutes, preparing students to develop a new repertoire 
of proficiencies and foundation skills to be thriving adults in a successful national economy (Promoting Continuous Improvement, 2000).

Almost a decade later, according to the Department of Education and the Florida Governor's office, improvement in student achievement was not sufficient to meet the state's needs. In response to these concerns, the 1999 Florida Legislature increased standards and accountability for the state's students, educators, and its public schools. In turn, Governor Jeb Bush's A+ Education Plan went into effect.

The A+ Education Plan expanded upon the concept of school performance ratings that began with the 1991 Accountability Act and the adjustments made in 1995 and 1998. The plan provided Rule 6A-1.09981 of the Florida Administrative Code, which established letter grades (A-F) for assessing schools and created School Improvement Ratings. In essence, student achievement data from the Florida Comprehensive Assessment Test (FCAT), a state developed exam, would be used to establish both competence levels and annual progress for students, schools, districts, and the state. The results of these tests would further be used as the primary measure in calculating school performance grades, improvement ratings, and rewards and recognition (FDOE, 2001).

During the 1998-1999 and 1999-2000 school years, a school's grade was determined by student achievement on the FCAT and other performance information including, but not limited to: attendance rate, dropout rate, school discipline data, and student readiness for college. The $2000-2001$ school year accountability grades were once again based upon the results of the FCAT Criterion Referenced Test writing assessment in grades four, eight, and ten, reading assessment in grades four, eight, and ten, and mathematics assessment in grades five, eight, and ten (Appendix A). Data 
including attendance and dropout rates were also utilized, but the criterion of outdoor suspensions was eliminated. Beginning in 2001-2002 and thereafter, student learning gains as measured by the FCAT will determine a school's grade, along with other performance data utilized in the past (My Florida, 2001).

The Governor's A+ Plan is an example of what high-stakes accountability encompasses. Florida statutes, in Title XVI, Chapter 229, Statute 229.0535 provide for the intervention of the State Board of Education in the operation of a school system when one or more of its schools have received an "F" grade for two years in any four-year period. Opportunity scholarships, commonly referred to as vouchers, are provided for students who attend those schools that have been graded as an " $F$ " twice within a four year period of time (Florida Statutes, 1999). Schools receiving an "A" are rewarded with monetary bonuses, deregulated status, and greater budget authority. Recognition is given to schools that improve one or two letter grades. Intervention is provided for schools not meeting standards in numerous ways. Additionally, statewide student promotion and graduation decisions are tied to the FCAT assessments. If a student does not meet a minimal score, there is the possibility of retention or no graduation.

School grades and improvement ratings are required to be published on an annual basis by both the Florida Department of Education and the individual school districts. Parents and/or guardians of public school students are guaranteed by law a straightforward report which highlights data on both the school grade and rating of the school in which their child is in attendance. The news media also plays a major role in disseminating information concerning the high-stakes accountability the schools in the state are facing. 
Accountability and assessment have played major roles in numerous reform efforts during the past fifty years. Assessment, specifically testing, has been the center of controversy and the sweetheart of politicians and policymakers (Linn, 2000). Unlike other reform movements, which only transform pieces of the educational system, testing goes to the core of the soul of education. It dictates what students should know and be able to do. Tests have continually been used as a means of determining whether schools have been successful in their respective missions (Rothman, 1995).

Testing for accountability purposes actually dates back to the mid-nineteenth century. According to Rothman (1995), Horace Mann, serving as the secretary of the Massachusetts State Board of Education, and his ally Samuel Gridley Howe asked the Boston School Committee to replace teachers' oral examinations with a uniform written examination administered to the city's schoolchildren. Mann and Howe rationalized that the written test would make available objective information on the merit of teaching and learning in the city's schools. With the results of these exams in tow, Mann and Howe armed themselves with news of the seemingly wide gaps of knowledge among students, and proceeded to ally city and state officials, calling for a desperately needed change in the school system.

As support of the new instruments grew, Mann systematically began to promote the regular use of tests to scrutinize the quality of schools and allow comparisons among teachers and schools. As the focus of tests became increasingly geared toward use as a means to inform the public on school success, the more criticism grew and the question 
of fairness arose. As this example shows, the outside-of-the-classroom roles of tests have become more evident and often have high stakes attached to their utilization.

The use of tests as the basis for school reform has come in several waves since World War II. During the 1950s, emphasis was on the role of tests in tracking and selection. The use of tests for curriculum accountability was the theme of the 1960s. Minimum competency testing programs were the push of the 1970s. Testing in the 1980s saw a return to accountability of schools and school districts, and the 1990s brought a further measure of accountability utilizing standards, which continues today (Linn, 2000).

With each new reform, both the nature of the tests and the roles that they play in reform endeavors have changed (Linn, 2000). The wave of testing for accountability began in the 1960's and has continued to peak to today. According to Rothman (1995), there have been two factors that have aided in the constant force behind testing for accountability. The first was a keen interest among policymakers in education in theories derived from business and public administration that stressed revamping systems toward a goal. In response, numerous state legislatures passed legislation that held schools responsible for raising student achievement.

As lawmakers made a push for testing for accountability, educators and the general public grew more anxious about what was perceived as the lack of student achievement. The public outcry was for a move back to what was considered basic education, and with this move came a stronger demand for more testing.

The testing movement continued to grow as a response to the 1980 s release of $A$ Nation at Risk (Barton, 1999; Rothman, 1995). As government policies on education and accountability spread through the eighties and nineties, the amount of testing grew. As a 
result, what is taught in schools is increasingly driven by what is covered on an external test. In addition, test taking skills instruction continues to take the place of subject matter not covered by these tests.

While there have been serious efforts to improve the business of testing, according to Barton (1999), there has not been much change over the past two decades. Linn (2000) cites several reasons for the great appeal of tests to policymakers as an instrument of reform. First, tests are comparatively inexpensive when compared to other actions such as increased class time, decreased class size or the provision of substantial professional development for educators. Second, states or districts can externally order tests. It is extremely difficult for state policymakers to mandate change inside a classroom. Third, a test can be swiftly implemented. This can be quickly accomplished within the term of office of elected officials. Finally, test results are visible. They are reportable to the media. In addition, policymakers can show they have had an effect when an increase in scores is reported to the public, and a rosy picture is painted to help assure reelection. Lee-Smith and Fey (2000) also report that tests provide standardization over teaching and learning and that the general public reasons that schools and students should be responsible for outcomes as measured by tests as well as those imposed by sanctions.

Alfie Kohn (2000a) reports that there are numerous, related hypotheses to explain the passion for standardized tests. It may be a conscious attempt to further a conventional, back-to-the-basics approach to instruction. There may be a desire to view public schools in the worst possible light as a way of validating a privatization crusade. Tests are also quite profitable for those companies that produce and score them. The drive for profit gives these companies the impetus to back testing and the momentum to 
produce and sell teaching materials designed to raise scores on the tests they publish. Kohn (2000b) also believes that testing is a means by which politicians show they are concerned about school achievement and resolute about getting strict with teachers and students. Finally, it is reasoned that the popularity of externally mandated testing in schools relates to our cultural fondness of attaching a quantitative value to things. As a result, tests have become powerful political devices whose outcomes are used to mold educational policy and practice (Suarez \& Gottovi, 1992).

State School Accountability Systems

The emergence of high-stakes accountability is evident as more and more scholars, educators, news media personnel and political figures are quoted in debates over whether or not state-mandated assessment is a useful tool for changing educational practice for both teaching and learning (Bauer, 1999). Journals, books and newspaper articles tout the achievements of the high standards school accountability reform measures, and yet others delineate the negatives of what this current wave of "school improvement" creates.

Current accountability and rating systems from various states indicates that highstakes, standards driven reform is the predominant thread throughout school innovation. The following are examples of selected state accountability systems.

- California - In 1999, the Legislature and Governor established the state's school accountability program. Rewards are offered to schools and educators whose student high-stakes test scores improve by a prescribed amount. Academic progress is measure by an Accountability Performance Index, which is dependent upon test scores (Helfand, 2000). 
- Georgia - In 2000, Governor Roy Barnes convinced the legislature to pass his A+ Education Reform Act. Under this system, schools will receive two grades based on student achievement (Jacobson, 2001).

- Kentucky - Due to a state Supreme Court decision, the state's public school system was declared unconstitutional. Thus evolved the Kentucky Education Reform Act of 1990 (KERA). The Kentucky Instructional Results Information System (KIRIS) is the assessment and accountability component of KERA (Wolf, Borko, Elliot, \& McIver, 2000). Results of the KIRIS are converted into a school score, which the state utilizes to determine rewards or sanctions for administrators and teachers. If expectations are exceeded, then personnel may receive bonuses. If the score is below standards, or does not improve over time, then personnel can be put on probation, and the school can be put under the control of the state (Jones \& Whitford, 1997). KIRIS is designed to supply information for school accountability rather than individual student accountability. The most noteworthy debate that has arisen in Kentucky is that school progress is determined by different groups of students being tested each year and compares one group to another (Whitford \& Jones, 2000).

- Massachusetts - The Massachusetts Comprehensive Assessment System is in its fourth year of implementation. The number one indicator of this standards-based accountability system is high-stakes testing (Gehring, 2001). During the spring of 2000, a new regulation was added that requires math teachers in middle and senior high schools to take a math content knowledge test if they work in a school 
with a math program that has been defined as low performing (It's your fault, 2000).

- North Carolina - Public schools in this state must perform to standards of a very high-stakes accountability program called The New ABC's of Public Education, the fifth major state reform system implemented in the past decade. Schools are rated based on the End of Grade (EOG) testing program. (Holdzkom, 1999; Jones, Jones, Hardin, Chapman, Yarbrough, \& Davis, 1999).

- Tennessee - The Tennessee Value-Added Assessment System is the method utilized to measure accountability. Scaled score gains from annually administered national student achievement tests form the basis of teacher and school accountability (Young, 1996). The school reform law, which called for the formation of tests directed to supply greater school accountability, permitted the state's standards-based program to progress. Schools attaining scores in the bottom third of all state public schools were publicly announced in 2000 (Coles, 2001).

- Texas - The Texas Assessment of Academic Skills (TAAS) is the current accountability system. In 2002, this system required more of students and schools than before. The ranking of schools has been part of the accountability system for the past seven years (Keller, 2001).

High-Stakes Accountability and Tests

To require accountability is to agree with a political justification to order a particular individual or institution take on some responsibility and exhibit it in a certain form. Although there are numerous forms of accountability in education, the term has 
come to signify the duty of a school, school district, or student to the general public, parents, or government to produce high achievement test results (Lee-Smith \& Fey, 2000). For many years, states have been amassing testing requirements, which their decision makers have chosen. "Despite considerable evidence that high-stakes testing distorts teaching and does not give very stable information about school performance, test results have become the dominant way states, politicians, and newspapers describe the performance of schools" (Dorn, 1998, p.2).

The most recent wave of school reform maintains the emphasis on accountability, but adds some important new characteristics. The inclusion of high-stakes accountability devices for schools, teachers, districts, and students is not necessarily new, but what is different is the pervasiveness of this performance-based accountability (Linn, 2000).

High-stakes testing has now become a catch phrase. Although many educators criticize tying one test's scores to critical decisions as promotion or graduation, the practice is commonplace (Moores, 2000). In general, high-stakes testing refers to any assessment utilized for accountability containing significant consequences. As previously mentioned, it can affect important decisions concerning students. When applied to schools and/or districts, high-stakes testing can be used to determine which ones will receive awards for high performance or extra investment of resources due to low scores. On the other hand, low performing schools may lose accreditation, be reorganized, or even shut down. Test scores may even be solely used to hold teachers and administrators accountable for student achievement and determine salary schedules (Lewis, 2000). 
The country's understanding of a performance ethic for schools has led many states to rank their schools via test scores. The tests can differ from state to state. When the same tests are used, the standards used by states as cutoff points may be different (Moores, 2000). Yet, as now implemented in most states, high-stakes accountability is used by state boards of education and politicians to leverage some desired change in the educational system. These policymakers declare that the purpose of high-stakes accountability is to improve student achievement, expand bureaucracy, and appears to be designed primarily to identify and punish low scoring schools and students (Gratz, 1999; Ramirez, 1999).

The appearance of high-stakes accountability procedures has intensified the argument whether state-mandated assessment is a useful tool for changing education procedure (Bauer, 1999). According to Ramirez (1999), the underlying assumptions driving high-stakes accountability systems include the ideas that students are apathetic and need more immediate repercussions linked to their learning and teachers are not adequately skilled or are missing the motivation to inspire students to higher levels of achievement. It is also assumed that local school districts are not aware of what students should be learning or to what degree they should be learning the information and accountability via testing will compel the system to improve. Finally, a supposition is made that state government officials and corporate leaders know what is best in this realm of educational policy.

The most common way test results have been turned into high-accountability systems is the simple publication of results. In 1984, then Secretary of Education Terrell Bell annually released a "wall chart" attempted to show how the states of the union 
ranked in education performance. Federal and state officials created a new national report card in 1991 in order to exhibit state and national progress toward the national education goals created by President George Bush and the governors of the nation. Now, states and school districts have raised the stakes by attaching consequences to test results. Despite a perceived limited impact of the reports on the public by policymakers, the report cards have succeeded in making schools place even greater emphasis on highstakes tests (Rothman, 1995).

The prominence of high-stakes accountability systems and tests has raised many questions as to what impact and effects are really felt in schools. In addition, key stakeholders have begun to speak out concerning their perception of the roles high-stakes tests are playing in contemporary efforts at reforming education.

\section{High-Stakes Impact}

By their nature, high-stakes accountability and testing systems lend themselves to a barrage of effects, which may be viewed both positively and negatively. Proponents of the testing and accountability movement underscore the positive impact of this trend of school reform, while opponents highlight the negative consequences.

\section{Proponents}

According to Hess and Brigham (2000), high-stakes testing "can set a clear and challenging hurdle for students and for schools" (p. 26). The desire to meet this challenge can motivate considerable educational improvement. There is the potential to increase equality of educational opportunities to all students across all school districts.

McColskey and McMunn (2000) report that research on the effect of high-stakes accountability policies and tests has found the following positive outcomes: more focus 
being given to state curriculum, higher expectations for student achievement, and more support for low-achieving students and schools. Additionally, test results can bring very significant policy and programmatic decisions up to date (Stiggins, 1999).

Performance-based rewards and sanctions attached to high-stakes accountability systems are perceived by those who promote this type of reform as stimulants to school improvement efforts and team building, especially in the elementary and low performing schools (King \& Mathers, 1997). It is believed that team-based rewards play a part in improving the skills of low-performing teachers, as stronger educators will place pressure on the poorer ones. High-Stakes accountability systems are also expected to raise expectations for newly hired educators. Furthermore, accountability systems based on high-stakes tests are often recognized as improving teaching and learning, compelling incompetent teachers to improve and putting uniformity of knowledge into place.

King and Mathers also report that sanctions and publicity tied to high-stakes testing and accountability serve as motivators. As an example, the consequences linked to Kentucky's high-stakes accountability system are given credit for motivating change. In addition, public awareness, along with media attention of the high-stakes consequences puts pressure on school site staff to shine.

Kohn (2000) theorizes that support for testing seems to strengthen as one moves away from students, following a path from teacher to school administrator to district staff to school board members to state education board members, state legislators, and finally the governor. He finds that those individuals who use classroom visits as intermittent stops for photo chances are the ones most expected to be super fans of testing and to present self-laudatory orations about the necessity for accountability. 


\section{Opponents}

Opposition to high-stakes accountability and testing results from the negative effects or unintended consequences that are seen as prevalent with the implementation of this type of reform. For example, Mary Lee-Smith and Patricia Fey (2000) address the variety of forms that test score consequences assume. They explain that a state attempts to hold teachers accountable to a standard curriculum by establishing their positions on a career ladder by their students' average scores. A school district and the state try to hold teachers and their respective schools accountable by publishing test score results in local newspapers. Districts may try to hold school administrators accountable by basing pay raises on the average gains students make in a school year. Finally, a state may implement an accountability system whereby a rating or grading system, which may lead to incentive pay or state takeover, ranks schools.

Sheldon and Biddle (1998) addressed the perils of a high-stakes testing approach. The first peril states that a major focus on testing can cause teachers to implement a narrowed curriculum, one that only covers skills on a test, which in turn subdues student interest and possibly inhibits critical thinking. One extension of this peril encompasses both the abandonment of subjects, topics, and outcomes that are not tested and an excessive use of instructional materials that mimic items on the state test (McColskey \& McMunn, 2000). Administrators have had to cut back or eliminate what are seen as vital components of a well-rounded education including programs in the fine arts, recess for young children, electives for high schoolers and discussions about current events (Kohn, 2001b). 
The results of a study completed by Young in 1996 indicated that educators disagreed with the idea that the high-stakes accountability system in Tennessee positively affected the curriculum, whereas state officials had opposing opinions. Similar findings by Beck (1995) and Tuch (1996) led to their conclusion that a narrowing of the curriculum is evident in high-stakes systems. Teachers participating in a study by Barksdale-Ladd and Thomas (2000) reported that activities that are seen as pleasant for the educator and students, provide in-depth comprehension of content, which include collaboration, independence, and higher order thinking skills, and have goals such as attitude development and development of good citizenry had to be discontinued. In essence, teaching to the test has become the method in many classrooms and teachers have abandoned the ways of teaching that they highly value including an active, studentcentered type of instruction (Kannapel, Coe, Aagaard, Moore, \& Reeves, 2000; Kohn, 2000b).

The second peril (Sheldon \& Biddle, 1998) describes how incentive systems tied to test scores often produce a more controlling type of behavior by teachers, which then undermines students' abstract learning, intrinsic motivation and interest in learning the subject matter, and wishes to pursue future education. Distortions in what and how students are taught may increase test score, while at the same time not have a positive correspondence in student learning (Shepard, 2000). Narrowed, test-taking teaching strategies become harmful to the extent that students may begin to oversimplify these strategies rather than deeply thinking about and responding to what they are learning (Kohn, 2000b). Once oversimplified, these strategies may not be able to be applied to more difficult tasks. The message that is sent to students is that what really is valued in 
education are test scores. The school climate has taken an "orientation to practice that emphasizes extrinsically defined attainment targets that have a specified quantitative value. This, in turn, leads students to want to know just what it is they need to do to earn a particular grade" (Eisner, 2001, p. 369).

A third peril focuses on the fact that the cure-all mindset of accountability systems distracts those interested in improving our schools from dealing with the real problems of education (Sheldon \& Biddle, 2000). Some proponents of high-stakes testing have not just ignored the distinct barriers to achievement in certain lower socioeconomic neighborhoods; they have deliberately dismissed them (Kohn, 2000b). As the real dilemmas of schools and the populations they serve are ignored, the standardized system of testing creates many educational losses for poor, minority, and special needs students (McNeil, 2000). Schools with a large percentage of poor and minority children are the recipients of the highest level of narrow and reductive instruction as a result of test preparation. These schools experience the negative effects more than advantaged schools and meaningful instruction becomes lost (Lee-Smith \& Fey, 2000). Students bring a multitude of issues pertaining to their everyday lives with them to the classroom that interfere with their power to learn and concentrate. According to Sheldon and Biddle (1998), when politicians use schools and teachers as scapegoats for underachievement, they are actually diverting attention away from the serious social problems in society that need to be addressed.

Negative consequences of high-stakes testing and accountability affect the entire educational community. There is a depersonalizing effect on students and teachers. Test scores ignore the social and shared aspects of learning for students. Teachers' 
pedagogies and instructional practices are replaced by the quantitative data representing pass rates for their schools. Professional expertise is silenced, and parental and public discourse is trivialized (McNeil, 2000).

As the pressures imposed by high-stakes testing and accountability systems increase, the response from teachers reflects a feeling of entrapment in these circumstances. As pointed out by Stiggins (1999), the intensity of teachers' anxiety will increase and they may become extremely defensive and frustrated, as to lead them to believe they should oppose all effort toward school improvement, or ultimately leave the profession. Opposition to school reform efforts is not embedded in an educator's longing to avoid accountability but instead is a resultant of the fear of being kept out of the conversation of what comprises success and being made the scapegoat for perceived low academic achievement (Marsh, 1999). With high-stakes systems being the result of topdown mandates, it is a common reaction of teachers to reject change at all (Datnow \& Castellano, 2000). The communication from some educators to their peers and the general public holds a bit of resentment as they feel that their work in schools has been judged a failure, thus making these high-stakes systems necessary (Slaton, Atwood, \& Shake, 1997).

In an environment surrounded by high-stakes accountability and testing, teachers and administrators may find the need to substantiate the idea that low scores were not their fault. It also may pit one against the other. Administrators feel that their schools are pulled in different directions, which undermines organizational capacity and their relationships with staff (Mitchell, 1997). Additionally, teachers are becoming disenchanted with the mixed up priorities, disrespectful treatment and pressure they feel. 
Some talk about quitting, or at least try to avoid teaching grade levels where test administration responsibilities lie. A teacher pressured by the Massachusetts Comprehensive Assessment System (MCAS) told the Christian Science Monitor (Clayton, 1999) that she did not want to teach fourth grade anymore because of the intensity of the testing.

Principals and other school level administrators also find themselves feeling these same pressures. It is becoming more difficult to find well-qualified individuals who will take positions as school administrators, while increasing numbers of those already holding these positions choose to leave. Administrators who are attached to lowperforming schools find it difficult to staff their schools sufficiently (Holdzkom, 1999). This dilemma has the effect of lowering standards (Kohn, 2000b); when those who teach in or administer schools with low-scoring populations decide to succumb to the incessant pressure to raise scores, it is expected at-risk populations to be unduly affected by the departure of these educators (Kohn, 2000a).

The increase of frustration and anxiety tend to be coupled with the de-skilling, deprofessionalization of teachers, and the denigration of teaching caused by external accountability testing (Shepard, 2000) lead to lower teacher morale. Conversations focus more on what students are lacking instead of on their strengths. Teachers look and act tired (Whitford \& Jones, 2000). Young's (1996) study on the perceptions of teachers, principals, superintendents, and state officials about the impact of the Tennessee ValueAdded Assessment System produced data that gave evidence for the idea that this highstakes system is not perceived as having a positive effect on morale. 
Teacher-student relationships suffer as a result of high-stakes systems. When a perceived low-performing child walks into a classroom, educators seem to become resentful as opposed to looking upon the student as a challenge (Kohn, 2000b). Pressured teachers pressure children (Gratz, 2000) and relationships based on limitation, control, and manipulation take the place of those that promote learning activities among educators and between educators and students (Whitford \& Jones, 2000).

The temptation to cheat is yet another by-product of high-stakes testing. Headlines such as "Cheating to the Test" (School Reform News, 2000), "N.Y.C. Probe Levels Test-Cheating Charges" in Education Week (Hoff, 1999), and "Test case: Now the principal's cheating" in U.S. News \& World Report (Kleiner, 2000) are examples of unethical attempts at dealing with high-stakes testing pressures that have been publicized by the media.

Other efforts made in order to deal with the pressure of performing well on highstakes tests include reports of schools around the country resorting to tactics such as removing students from school rolls and urging low-scoring students to stay home on testing days (Bracey, 2000). According to Kohn (2000b), that is not the worst effect on students. When the high-stakes directly affect students, it is expected that those individuals that belong to minority, low-income, and other at risk populations will be disproportionately denied promotion or graduation diplomas, or will display defeatist attitudes. This phenomenon will likely lead to students simply giving up or dropping out. Test validity is also affected by utilizing test scores in a high-stakes arena. First, the focus on scores for the sake of accountability diminishes the validity of the test and causes the results to be less valuable in following real gains and losses (Lee-Smith \& Fey, 
2000). Second, the more anxiety produced from test accountability, the less valid the scores become. Finally, an accurate picture of student learning is not realized and the characteristics of good learners are ignored (Kohn, 2000b).

The effects of mandated tests on students are documented in a few studies. Adams \& Karabenick (2000), in a paper presented at the annual meeting of the American Educational Research Association, reported that most of the teachers they interviewed described that many of their students have exhibited stress related signs or symptoms, at least once, in regard to participation in mandated testing sessions. Some of the symptoms of stress observed were: verbal expression of fear or concern, crying, acting out, illness, sleep problems (as indicated by parents), eating problems, and other troubles exhibited at school and home. Similar experiences are reported by teachers in response to a survey given by Jones, Jones, Hardin, Chapman, Yarbrough, and Davis (1999). Educators felt that students exhibited less confidence and a loss of "love of learning" during implementation of North Carolina's high-stakes testing program. In the data of another study, both parents and teachers agreed that children displayed high levels of anxiety and nervousness related to high-stakes testing and bouts of disappointment were apparent when results were received (Barksdale-Ladd \& Thomas, 2000).

As the implementation of high-stakes testing and accountability systems have grown, so too has the evidence of resistance by many educators, parents, and civil rights activists (Hoff, 1999a). In Gwinnett County, Georgia, a group called the Concerned Parents of Gwinnett, with a goal of reaching a compromise with school officials, formed over concerns of the effects of high-stakes tests on their children (Jones, 1999). The 
group, Parents Across Virginia boasts a membership of more than 1,000 people who are in opposition to their state's system of high-stakes accountability (Bayles, 1999).

In addition to parental involvement in protest activities, teachers have become involved in anti-high-stakes movements. The Massachusetts Teachers Association aired a commercial on television that criticized the Massachusetts Comprehensive Assessment System exam (Ghering, 2000). After a 29-year career, a veteran Chicago teacher was fired for resisting high-stakes testing (Ohanian, 2001). Lawsuits have also been filed by educators to challenge the legality of high-stakes tests. In other areas, petitions have been and are being distributed, politicians are being lobbied, and individuals are finding a variety of ways to challenge the system. These protesters are not only disturbed by the tests and accountability systems themselves, but are bothered by the negative impact that has been created and the nature of "a one-size-fits-all set of standards and assessment handed down from the state capital and imposed with the force of law" (Kohn, 2001b, p. $355)$.

The impact of Florida's high-stakes accountability system resembles what has been documented previously concerning other states' accountability systems. Proponents of the A+Plan confirm that indisputable learning gains may have taken place due to the pressure of the FCAT (Nazareno, 2000). Yet, the most vocal reactions center on the negative impact of the plan. One principal, who feared the consequence following a drop in test scores or school grade, decided against recommending a few academically talented children for a program at another school, as the loss of their scores would have affected the school's average (Rosenstein, 2001). Teachers are leaving school districts around the state due to the belief that their creativity is being destroyed by the state legislators' 
demand of accountability through excessive testing (Bell, 2000). Resistance movements by teachers have cropped up around the state. Ohanian (2001) reported that teachers in Pasco County and four teachers and a principal in Sarasota publicly refused to accept bonus money offered by the state. One teacher set up a website to honor test resisters, and the St. Petersburg Times challenged politicians in the state to take the high-stakes tests; no one accepted. In addition, parents have organized rallies in local districts and at the state capital in Tallahassee (O'Connor, 2000).

Although academic achievement may seem to be on the rise as indicated by higher test scores, high-stakes accountability impedes "progress toward creating a population of life-long learners who can adapt to changing needs and conditions" (Natriello \& Pallas, 1998, p. 3). High-stakes reforms may raise test scores but at the same time, the effects of restricted accountability may diminish the motivation of teachers and students. Ultimately the real loser is society.

\section{Perceptions of Change}

The factual characteristics of an innovation or school reform effort, such as the policies, regulations, and standards, are important for the beneficial results of that reform. Nevertheless, the insights of the key players involved in the implementation of these reform efforts and the effects on the school, classroom, staff, students, and school community may be even more important for the intended outcome of higher student achievement and a better education for all (van den Berg \& Ros, 1999).

Assessment systems in schools should fulfill many purposes. However, there is substantial discussion today concerning the benefit of high-stakes testing and accountability systems and their possible unfavorable effects on school curricula and 
pedagogy and including the impact of test stress on the school community (Adams \& Karabenick, 2000). Differences in a school's score can be attributable to many features, including the extent to which teachers have changed their practice (Whitford \& Jones, 2000). It is possible that mandated change results in what is viewed as a positive change in the teaching and learning environment, or as illustrated by Bailey (2000), directed changes may be negative in that they require an abandonment of the methods and materials that had been otherwise successful in the past.

Substantiation exists to support the idea that the higher the risks on a given test, the greater the concentration of teacher focus on test preparation and the more the likelihood of teaching to the test becomes the norm and harms other aspects of teaching and learning. Yet, there is still little data available on how educators are handling the requirements of current policies, standards, and testing requirements. What perceptions they hold about the effects on the changes in the teaching and learning environment of a school community by mandated high-stakes accountability systems is still largely unknown (Ladd \& Thomas, 2000). The answers to questions about the effects of highstakes accountability on teaching and learning must come from insights of teaching professionals, including teachers and administrators (Jones \& Whitford, 1997).

There are also not enough published reports describing parent perceptions and responses to the high-stakes accountability systems and standards that are mandated for their children. Ladd \& Thomas (2000) remind us that parents are an integral part of the testing culture and their views and perceptions about the current climate of school comparison and grading is of utmost importance. 


\section{Conceptual Framework}

Over thirty-two years ago a paper written by James Coleman and funded by the U.S. Office of Education concluded that public schools did not make a considerable difference. Instead, a student's family history was the main reason for the child's success in school. According to the Association for Effective Schools, Inc. (1996), the emergence of Effective Schools Research was a response to this paper.

A group of researchers that included Dr. Lawrence W. Lezotte and Ronald Edmonds conducted the original effective schools research in elementary schools where they undertook the task of identifying existing effective schools. These institutions were those that were successful in educating all students regardless of their family history or socioeconomic background. Out of this research, Edmonds first officially identified the Correlates of Effective Schools in 1982.

As time as passed, these correlates have been enhanced and expanded, but the basic principles have remained the same. As indicated by Dr. Lezotte (2001), all effective schools exhibit (a) instructional leadership, (b) a clear and focused mission, (c) a safe and orderly environment, (d) a climate of high expectations, (e) frequent monitoring of student progress, (f) positive home-school relations, (g) attention to time on task, and (h) the continued opportunity to learn. Together, these correlates provide a set of research-based characteristics of a school's environment related to improved and enhanced student learning (Association for Effective Schools, 1996). The correlates are identified research concepts that may be able to analyze the intricate social institution called a school in order to facilitate improvement to the entire teaching and learning environment. 
The links to the conceptual framework for the underlying analysis of the transformation of the teaching and learning environment, as explained by the participants, are explained by Lieberman and Miller's model of teaching and learning transformation through the combination of procedures and principles into building blocks that outline change (1999). Whether the impact of the changes noted in this study fit the description of what would be considered meaningful and enduring change, is a major concern underlying this study. If the impact of the changes is perceived as meaningful to those affected by them, then the chances of those changes becoming a long-lasting part of the school environment increases.

Lieberman and Miller describe that meaningful and enduring change in education is entrenched in the belief that the transformation of teaching and learning are intertwined and cannot take place in isolation. This change cannot take place solely through the mandates of educational and political policymakers. The researchers believe that "effective approaches to change might include establishing goals based on some significant values, standards, or beliefs; outlining the procedural means to accomplish these goals; and putting in place an organizational structure that provides continuous support and learning" (p. 2). It is difficult to create these conditions especially in today's environment where standardization appears to be the rule.

In order to facilitate the establishment of effective change in any atmosphere of accountability, Lieberman and Miller delineate building blocks for transforming teaching and learning. The five elements include rethinking curriculum and instruction to improve quality and promote equality, rethinking the structure of the school, adopting a two- 
pronged focus: students and teachers, making connections outside the school, and encouraging increased participation by parents and the community. The first building block, the reconceptualization of curriculum and instruction, according to Lieberman and Miller, should be the foundation of school wide change. Previous practices are questioned and new ways to characterize and assess student achievement are explored.

As the second building block, Lieberman and Miller advocate school structure rethinking that concentrates on the operation of the school and is founded on the principle that changes in teaching practices necessitate a change in the organization and administration of the school. Ongoing staff development and teacher leadership fall under this idea.

The third building block set by Lieberman and Miller is the focus on students and teachers; neither is mutually exclusive. Establishing a fruitful teaching and learning environment, for both educators and students is a critical piece in promoting positive change.

The fourth element, going outside of the school to form connections, promotes the idea of schools forming alliance with other educational institutions and organizations across the country as well as locally. These relationships provide the vehicles for sharing information and securing support for the efforts being made at the school site.

Finally, the encouragement of intensified school participation by the community and parents allows for greater open lines of communication about the work that the school is doing. In addition, parents have, for a long time, been left out of the loop on school reform. Without outside stakeholder (parent and community) involvement, a lack of true knowledge for the entire school community exists. 


\section{Summary}

Concern involved with school reform includes the attitudes, problems, and experience of the teachers, schools, and key stakeholders in the school community (van den Berg \& Ros, 1999). If the objective of the recent wave of high-stakes accountability is to enhance teaching and learning, then the current methods encompassing test scores and reward and sanctions should yield to a more comprehensive system that would include qualitative information entwined in quantitative data (Jones \& Whitford, 1997). There is a need for stakeholders in a school community to identify the effects of state high-stakes testing and communicate these effects to those who mandate the accountability systems (Barksdale-Ladd \& Thomas, 2000).

It is critical to know how high-stakes accountability programs affect instructional practices, how these programs shape education professionals' morale and attitudes toward teaching and learning, how they have impacted children's lives, and ultimately affected the teaching and learning environment (Jones, et al., 1999). Reform, highstakes or otherwise, ultimately makes its mark individual by individual, school by school, community by community. "Without the context of people and place, lessons are not learned and understandings are lost" (Whitford \& Jones, 2000, p. 44). Classroom-based and school-based research is needed to discover this personal context of high-stakes accountability and the relationship, if any, which exists with meaningful and enduring change. 


\section{CHAPTER III}

\section{RESEARCH DESIGN AND METHODOLOGY}

This chapter discusses the methods chosen for this research. Selection of the research site, the selection and description of the participants, and methods of data collection and sources of information are briefly discussed. The issues of validity, reliability, and ethics are addressed.

\section{Qualitative Research}

The qualitative case study method was chosen as the methodological framework of this study because of its advantages in addressing the research questions. The main focus of this thesis was to describe the impact of Florida's A+ Plan and high stakes accountability system on the teaching and learning environment in a specific elementary school community based on the perceptions of teachers and administrators about the changes they experienced in the teaching and learning at the school site.

Qualitative research is primarily concerned with process, rather than product, which in this study has to do with the perceived changes and effects of Florida's A+ Plan. It is also interested in how people make sense of their experiences, their lives, and their worldly environment; is richly descriptive; and facilitates the building of concepts, hypotheses, theories and abstractions from detail (Creswell, 1994). The study looked at how the educators at Blue Ribbon Elementary (B.R.E.), a pseudonym given to the school to help maintain confidentiality, made sense of the changes that had taken place in the teaching and learning environment upon the adoption of the A+Plan. This plan has called for the grading of Florida's public schools. Through the descriptions of the changes and their effects provided by teachers and administrators at the school setting, concepts and 
ideas about the relationship to a successful teaching and learning environment at this school were developed from details provided in the interviews.

The apparent changes that I have experienced in the teaching and learning environment at the research setting reflects a process that included a series of actions that were carried out by the staff in order to address the high-stakes nature of the A+ Plan. The perceptions of teachers and other administrators concern how they have made sense of the transformations that have taken place at the school site. Due to the nature of the research questions, the fact that variables regarding change and their effects due to the A + plan were difficult to identify, theories were not readily available to explain the actions of participants in relationship to what changes had taken place. The necessity of theories to be developed as to whether the changes were significant and lasting, the presentation of a detailed view of the issue of change and its sensed effect on the teaching and learning environment were essential. A naturalistic setting was critical in order to get an up close view of what was transpiring at the school site. My role as an active participant enabled a story to be told from the participants' point of view rather than as an authority. Thus, the qualitative method of inquiry becomes the research method utilized for this study.

Case Study as a Methodological Framework

Qualitative case study research involves exploring a bounded system containing patterned behavior over a period of time. In utilizing these key factors to understand the case, the inquiry becomes both the process of learning about the case and the product of what has been learned. The school community and its members represent the system in this study. This particular school site, an elementary school located in a middle class 
neighborhood in the northwestern section of Miami-Dade County, represents the bounded system. The changes and effects that took place reflect the patterns of behavior, and the period of change since the implementation of the A+ Plan signifies the time.

Stake (in Denzin \& Lincoln, 1998) identifies three types of case studies. An intrinsic case study is carried out for the purpose of better understanding of a particular case; that is the specific case is of interest. Instrumental case study is undertaken to provide understanding of an issue or the enhancement of a theory. In this type of inquiry, the case is of minor interest; it acts in a supporting role and facilitates understanding of the focus of the research. The case is quite often studied in depth, activities specified, and circumstances examined. The value of the choice of the case is the advancement of the understanding of the focus of the inquiry. A collective case study looks at a number of cases together in order to query into the experience, populace, or common circumstance. My study followed the intrinsic case study model, as it was the intention of the research to provide an understanding of how key stakeholders perceived the overall changes, specific changes and the impact of these changes on the teaching and learning environment at B.R.E. since the inception of the A+ Plan.

Through the utilization of interviews and reflecting upon my experience as the researcher in this study, the advantages of a qualitative case study were realized. As the research instrument, my prior and current experiences with the change that had taken place in the teaching and learning environment molded the shape of the study, as what I had come across and felt during the implementation of the A+ Plan became part of the results of the study and were integrated throughout the interview process, determination of the results, and the formulation of the conclusion of the research. 
The research occurred in a naturalistic setting, an elementary school in Miami, Florida. The focus of the research was on the way the participants made sense of their experiences in this school during a time of change. The qualitative research process begins with details and proceeds through an inductive process where the researcher is able to build abstractions, concepts, hypotheses, and theories (Creswell, 1994). In this study, changes in the teaching and learning environment had taken place due to the implementation of a high-stakes testing and accountability program. The teachers and administrators constructed their own meaning of the change and thus reacted accordingly.

Social researchers address the value-laden inquiry of human disciplines (Denzin $\&$ Lincoln, 1998). Since qualitative inquiry is interpretative, biases, judgment and values of the researcher become entrenched in the reporting of the research (Creswell, 1994). This involvement of the researcher may be seen in a positive manner, as approval of the information gatekeepers, study participants, may become more readily available as the comfort level of the participants with respect to the researcher increases. As both the researcher and a stakeholder of the school site involved in the study, my interpretations of the data reflected a broader base of judgments, values and biases. The existing relationships between the participants and myself made information retrieval easier. I have maintained positive, long-term relationships with the teachers and other administrators both as a teacher and administrator. We have been together in this setting for a minimum of four years. This familiarity and these relationships may lead to a better awareness of the change in the teaching and learning environment and the impact it had on the school community. 
Flick (1998) describes various issues encountered by the qualitative researcher. The individual conducting the inquiry faces the task of deciding which aspects of the data to include and which to exclude, as was the case during the time I was determining which participant statements to include in the reporting of the results. In making the decisions on what data is most relevant, the assurance that the loss of what is accurately reported remains minimal and justifiable is of great importance. By having the participants check on what had been transcribed from the interviews, I was able to maintain a high level of authenticity as to what had been said by those interviewed.

Concerning access to the field, another critical area, I approached possible participants with guarantees of confidentiality and the ability to leave the study if they so desired. Interviews are part of this access and involve the close interpersonal relationship between researcher and interviewee. Participants are subject to a certain amount of selfdisclosure, which cannot be easily controlled in advance. Researchers end up being in the field for longer periods of time, and from the standpoint of practicality, much more wide-ranging demands are placed on those individuals involved. My long-term relationships with the participants in this study facilitated a greater level of disclosure and thus extended the length of the interviews without adding discomfort for the interviewees.

Trusting and lasting relationships between the participants and myself had been previously established. The prior existence of these relationships might have been considered limitations to the study, but this concern did not materialize. In this study, relationships between the participants and myself had been in existence for at least a period of four years. At the time of the study, the longest relationship, between the 
principal and myself, had been ongoing for the past eighteen years. Articulation levels of the various participants differed as did the intensity of the relationships, but both the participants and myself viewed all of the relationships as positive.

Janesick (in Denzin \& Lincoln, 1998) speaks to validity, reliability, and generalizability as they relate to qualitative study. Validity is explained as having to do with description and clarification, and whether or not a specified account fits a given portrayal of information. In essence, the question is being asked as to whether or not the explanation is a plausible one. The reliability of information is processed through participant review of materials and involving outsiders reading field notes and interview transcripts. This process took place throughout my research. Participants were given copies of the interview transcripts to review for accuracy. Other individuals not involved in the study were provided with transcripts and drafts to read for understanding.

In speaking to the issue of generalizability, the entire history of research involving case study in the fields of history, anthropology, sociology, and education rests firmly on the intrinsic worth of the case. The significance of the case study is its distinctiveness, yet universality may become evident as methods and findings show possible transferability beyond a specific context. This study's uniqueness was exemplified by the school site's faculty longevity, yet the issues that surfaced throughout the interview may be similar to those at other school locations.

Rubin and Rubin (1995) explain that qualitative researchers critique the integrity of their own work by the three criteria of transparency, consistency-coherence, and communicability. Interviewing strategies, in good qualitative inquiry, are designed to attain these principles. Transparency speaks to the assessment, by the reader, of the 
strengths and weakness, partiality, and the diligence of the interviewer. This standard allows the reader of a piece of qualitative inquiry to see the fundamental processes of data retrieval. With the meticulous maintenance of records of what is seen, felt, and done and the presentation of a body of rich verbal data, the research becomes transparent to investigators and others. Interview questions for this study were designed to address these three areas in order to support the integrity of the study. The transparency of the data retrieval process was ascertained by having individuals not involved in this study read the draft and report to me their understanding of what was written.

Credibility of a final research report is shown (Rubin \& Rubin, 1995) when the investigator has reconciled ideas and answers that appear to be contradictory. In the case of this study, there were a small number of discrepancies among participants' statements concerning positive and negative changes. The goal here is not to eliminate what items are inconsistent, but understand why they have occurred. Coherence becomes involved when explanations are available for obvious contradictions in the premises that have occurred and what these contradictions mean. A positive result of investigating an inconsistency may be an additional understanding of the culture of the situation and a subsequent increase in credibility. This understanding was accomplished by going back to the teachers and administrators for clarification and further detail in order to understand why the discrepancies in whether the changes were reported as positive or negative occurred. Most often, the contradictions occurred when the statements were made in general about change. When specific changes were discussed, the perceptions of the participants as to whether they had a positive or negative impact were similar. 
The communicability of the body of research presented allows participants and readers alike to be able to be convinced of the authenticity of the material. The depth of detail, wealth of data, and clarity of the content help influence those who have not had first hand experience that the information is reliable. According to Rubin and Rubin, this is how qualitative interviewing studies acquire their credibility and answer the questions of reliability and validity. This study first addresses each of the areas through the types of questions asked of the interviewees. Questions asked covered areas of consistency and change in the teaching and learning environment. The impact of these changes and characteristics of a successful school were also areas covered by the interview questions. In addition, the reporting of rich data and the process of member checking as to allow similar research to take place at another site addressed communicability of this study.

In conclusion, the qualitative case study approach was appropriate for answering questions in this particular piece of research. The case study approach provided an indepth method to study and understand the impact of the State of Florida's high-stakes school assessment package on the teaching and learning environment of those most closely impacted by its implementation. The credibility of the study was enhanced by the availability of rich data, the interpretation of the data gathered through the interviews to identify prevalent issues and themes, and the use of data triangulation using data collected from the twenty-one participants in order to enhance the verification and interpretation of what information had been gathered.

\section{Role of the Researcher}

Self-awareness is a key component of qualitative research. The role of the qualitative researcher, according to Janesick (1998) incorporates a certain subjectivity 
where the researcher is cognizant of one's own self, one's senses, and the part they play in the total picture of the research project. The active involvement of the researcher encompasses communication within the environment being studied along with the interaction that takes place with those who are members of the environment. As a member of the staff of this school site for the past ten years, my experiences, perceptions and relationship with the environment were part of the subjectivity involved in this research. Analyzing this interface between the researcher, environment, and those being studied were part of the research process.

During the initial process of choosing an area of study, I needed to be aware of what I was interested in, since I would be spending a great deal of time with the topic. I thought about my initial reaction as a teacher to what took place when I was confronted with the A+Plan and the FCAT. The comments of fellow staff members relating to this accountability were also reflected upon while developing the focus of this study. I reflected upon what issues affected me most as an educator and focused upon the FCAT and how it impacted my teaching. It was imperative that I understood the biases pertaining to the A+ that I was bringing to the project, as feelings of anger, fear, and other strong emotions shaped the form of what was being researched. These emotions were documented in a journal kept throughout the research. During the interviews and the period spent analyzing the data, I returned to the journal to reflect upon what I had previously written and in order to be objective in the interpretation and analysis of what had been said by the participants. Even at the point when the topic had been chosen for its importance and appropriateness, personal reasons might have caused avoidance of the project (Rubin \& Rubin, 1995), but this did not turn out to be the case. 
During the course of data collection, the researcher must keep in mind that it is he or she who is the research instrument. Because of this, the investigator cannot adopt a neutral role. The actions and observations of the researcher reflect his/her impressions, feelings, irritations, and biases and thus become part of the data (Flick, 1998). This relationship helps to dictate the framework from which the data will be collected and analyzed. As a member of the school community chosen, for this study, for the past 10 years, I was aware of the partialities that I brought into the research. The emotions and preconceived ideas that I took into the study were those that led me to the questions being investigated and helped mold the direction of the research. As a teacher, I felt the intense emotional strain of preparing students for a new type of test. In the role of an administrator, I had labored over decisions that had been incorporated into the changes, which impacted the teaching and learning environment.

Since the researcher is not neutral, the investigator's understanding, ethics, emotions, and sensitivity become important tools of qualitative research. During discussions with the participants, the overall interview is affected by the researcher's presentation of questions, tone of voice, body language, and personality. In addition to understanding the self that is brought to the interview, the researcher must be aware of what he or she is trying to convey to the participants when asking questions, as emotions and biases influence the style and tone of the questioning utilized. How the interviewer listens is also fashioned by the philosophical background brought to the research environment. I had continually felt that the FCAT was an excellent assessment tool, but that it should not be the overall driving force in judging the success of a school. I believe that changing what happens in the teaching and learning environment should not be 
dictated by one test. What one hears is affected by the researchers' reactions to those they interview, and further questions are determined by the investigator's awareness of his/her reactions to what has been said (Rubin \& Rubin, 1995). As I proceeded with the interviews, I noted my reactions and those of the participants in my journal. I reviewed these notes before each subsequent interview to better manage my body language and reaction reflexes. As I listened to what participants had to say, how I perceived their statements had a lot to do with how I understood what they were trying to convey.

Interpretation of the data depends on the researcher's ability to be self-aware. The researcher's interpretive paradigm is constructed by his/her belief system (Denzin \& Lincoln, 1998). It is necessary for the investigator to check on whether his/her expertise and epistemologies match with the methods of analysis (Flick, 1998). This involves selfreflection and may lead to a change in the structure of the form of interpretation. Knowing that I came into this study believing that some of the changes had had a positive effect on the school, but that a lot had been negative, I needed to check if what was said by the participants really supported my interpretation of the data. If it did not, then I checked to see whether I had slanted the interpretation toward what I believed and revised the analysis to reflect what had actually been reported. Once my interpretations of what the participants reported had been developed, I gave each person the opportunity to read and reflect upon what I had stated.

In preparation of the final research findings, the investigator must again be aware of the role his/her beliefs play in the presentation of the data and results. The researcher must be cognizant of how much of the "self" is present in the final narrative (Creswell, 1998). In the preparation of the report, the researcher must make sure that words have 
not been put into the interviewees' mouths, which may be tainted by the investigator's biases and/or emotions. Quotations must be reported accurately (Rubin \& Rubin, 1995). From my journal notes, I reflected upon what my beliefs were and compared them to what I reported and to the reaction I received from the participants. The individuals who provided feedback concurred with what had been written and offered additional meaning to what they had spoken about. This feedback was further utilized in the analysis.

The entire qualitative research process is a reflection of the researcher's own personality. From the decision about which topic to investigate, to the final report of the research findings, it is of critical importance for one to be extremely self-aware and selfreflective when involved in qualitative research. It is this awareness and knowledge of one's self that brings authenticity and validity to the subject and findings being reported.

\section{Data Collection}

The sources of data used for this study were interviews with teachers representing different grade levels and departments and school administrators. Interviews were recorded and transcribed in order to retain the views expressed by the participants.

\section{Interviews}

The inquiry methods used during the interview section of the gathering of data were modeled after the six types of interview questioning strategies described by Janesick (1998). Initially, basic descriptive and experience/example questions were utilized. For example, participants were asked to describe the school environment at B.R.E. when they first arrived at the school. Once participants had been given the opportunity to reply to the initial questions dealing with experience with changes in the teaching and learning environment since Florida's high stakes accountability system had been put into place, 
then the other types of questions, follow-up, simple clarification, structural/paradigmatic, and comparison/contrast questions became part of the interview. The semistructured or focused format of interviewing, as described by Rubin \& Rubin (1998), was the approach that guided the interviews. I introduced the topic, and then channeled the discussion by asking specific questions (Appendix B). For the purpose of this study, each person was individually interviewed for approximately one hour. If clarification or more depth was needed, then a follow-up conversation was held with those respective participants. Approximately six of these follow-up interviews took place.

The interview questions were developed based on the following: (a) research questions proposed in this study, (b) theoretical frameworks about the nature of the model of meaningful and enduring change (Lieberman \& Miller, 1999), (c) previous discussions that had taken place with various stakeholders in the school community, (d) review of a variety of questions presented in other research looking at similar ideas, and (e) the researcher's own experience with a smaller pilot project and related to the current situation being explored. Some questions were adapted from conversations and surveys associated with colleagues at several meetings and workshops, as well as during a mini study conducted at the school site. Other questions were adapted from those published in studies conducted in different areas of the country where high-stakes accountability has been incorporated into public school reform.

Maintaining ethical obligations during interviewing was ensured by following steps delineated by Rubin \& Rubin (1995). Participants were given a form (Appendix C), which assured them of anonymity and confidentiality of their responses if they so desired. Prior to being interviewed, participants were alerted to the fact that agreeing to be part of 
the study would not hurt them. Interviewees were informed that the session(s) would be tape recorded unless directed otherwise by the participant. In addition, an informed consent statement was issued to each participant. All of the educators agreed to the taping. These statements outlined the purpose of the study, provided important information about the researcher, and defined the benefits and possible risk(s) to the participants. Also, the consent form contained statements addressing the sharing of results with the participants, the level of confidentiality of the findings, and the emphasis of voluntary participation.

Concerning the ethics of determining how intensely to pressure someone for information, the researcher's obligation is to get beyond cursory responses; it is not necessary to pressure an individual for minor pieces of information, but judgments by the researcher must be made and the use of other forms of questioning styles may be useful (Rubin \& Rubin, 1995). In addition to an explanation of the consent form, I explained to the participants the intent of the research, how they were protected, the opportunity to provide pseudonyms, the availability of interview transcripts and analyses for their perusal, and the right to refuse to continue in the study without any repercussions.

\section{Researcher Reflections}

Janesick (1998) describes interviewing as "an act of communication" (p. 29). It is a means by which the qualitative researcher is able to ascertain what others feel and believe about their environments. Through the qualitative interview process, one can begin to comprehend experiences and recreate events in which he/she did not participate (Rubin \& Rubin, 1995). Even though I had participated in some of the activities as a teacher, the impact of the change experiences were reported by each individual. The past 
two years have seen changes in some of the grading criteria and might have possibly affected me differently as an administrator than as a teacher.

\section{Setting}

In selecting a site for the case study, several criteria were utilized. First, I chose a single element of investigation. It was my intent to gain an understanding of a single school culture and its reaction to high-stakes accountability over a period of time. Second, I wanted to study a school that was available to me on a continual basis. Although the literature warns about being careful with studying your "own" group (Rubin \& Rubin, 1995), the longevity of the faculty and previously established positive interpersonal relationships helped me to decide to choose this particular elementary school used in the study. Third, since the commencement of the grading of schools via the FCAT and the other criteria outlined in Florida's A+ Plan, the school had shown steady improvement on test results and a raising of its grade by the State of Florida. In the three years prior to the study that schools had received a grade, this school site received two "C's" and then an "A." This was important since part of the study was to see if the changes were understood as meaningful and enduring, or were they understood as just being relevant to meeting the criteria of the current piece of school reform.

An additional vital condition was the supportiveness and cooperation of the principal in permitting the research to take place and giving me the opportunity to spend time during the school day to obtain data. Also necessary was the availability of teaching staff who had a history with the school, teachers who had been at the site both before the inception of the A+ Plan and were still presently part of the staff. Mobility of staff in a lot of schools is an issue, but the school chosen to be the setting of this study had a 
history of longevity of its faculty and a reputation for having a high level of trust among and within the faculty and staff. Finally, school community members that were willing to take part in the project abounded. In order to make the data credible, it was of utmost importance that school personnel did not feel compelled to participate. Appendix D highlights the demographics of this educational institution including location, composition of the student body and faculty according to ethnicity and gender, and student standardized test results.

\section{Participants}

In order to be able to fully understand the changes in the teaching and learning environment and the impact that the changes had had, it was necessary to interview school administrators and faculty. At the school site, the principal and all three of the assistant principals who have dealt with testing were interviewed. Prior to the beginning of the study, each teacher was given a letter with a brief explanation of the project and asked to submit a form at the bottom, which indicated if he/she would be interested in being a participant. Out of the 105 members of the instructional staff who were given a letter of possible participation, 27 returned the form that indicated that they would volunteer to be part of the study. These individuals represented both the grade levels directly affected by the criteria for the grading of the school and those that did not. Representation came from all special areas (art, music, etc.), counselors, and exceptional student education. Each person was given a survey (Appendix E), which included a question dealing with longevity at the school site. Out of the 27 , all 17 of the individuals that had been part of the school faculty since the inception of the $A+$ Plan were chosen as 
participants. Table 1 gives a snapshot of the teachers and administrators involved in the study. The subsequent sections explain the basis for the specific selections.

Table 1

Study Participants

$\begin{array}{lll}\text { Area of } & \text { Number of } & \text { Names of } \\ \text { Responsibility } & \text { Participants } & \text { Participants }\end{array}$

Primary Teachers

(Grades K-3)

Intermediate Teachers

(Grades 4-5)

Special Areas

(Art, Music, P.E.,

Spanish, Gifted)

Administrators
7

6

4

4
Rochelle, Carole, Lisa, Tracy, Julio

Chris, Peggy

Rouben, Linola, Mar

Barry, Gigi, Consuela

Carla, Leslie, Maria, Laura

Patti, Spring, Jo, Atalia

\section{Administrators}

The principal of the school site had been the educational leader throughout the time period involved in the study. She was ultimately responsible for key decisions made that affected the teaching and learning environment. Additionally, the specific assistant principals chosen as interviewees had each had the responsibility of being the test chairperson at some time. They had set the tone of meetings involving data distribution and the testing logistics and overseen changes necessary to be successful in meeting the requirements of the A+ Plan. 


\section{Teachers}

Of the teachers willing to participate in the study, those chosen had been part of the faculty before the implementation of the A+ Plan and constituted a majority of the entire faculty who fit this criterion. The 17 educators who were selected as participants for this research represented all six grade levels and all school departments. Each was selected according to his or her willingness to participate in the study and had to have been a member of the faculty for at least one year before the school received its first grade. The grades that test results for accountability are utilized encompassed third, fourth, and fifth grades. Teachers representing this group were directly affected by state mandates. Ultimately, teachers in special areas including the arts, physical education, gifted, and foreign languages, as well as those in kindergarten through grade two were affected as well. It was critical to understand the perspective of teachers located in different places on the change in the teaching and learning environment since the grading of the school affected the entire staff in some way.

\section{Data Analysis}

A key goal of qualitative research inquiry is the process of reducing data into a manageable model. As analysis continues, the researcher constructs effective models that describe the actions being studied and identifies relationships, explanations, and the significance of a variety of components in the models and validates these by referring to interview transcripts (Janesick in Denzin \& Lincoln, 1998). The transcripts from the interviews of the 21 participants were analyzed according to common statements. Relationships among the statements were then explored in order to further categorize the responses made by the educators. 
Analysis of the research data began while interviews were still being conducted. This allowed me to redesign questions in order to focus in on significant themes as the interviewing process continued (Rubin \& Rubin, 1995). As I noticed the direction that the first set of interviews had taken, I revised some of the questions so that more specific answers would be forthcoming and would also produce some explicit examples of events alluded to by the interviewees. After data collection had been completed, a general review, as described by Creswell (1998) took place. This involved scanning transcripts to find recurring words or phrases that focused in upon changes in the teaching and learning environment. This was done in order to acquire a sense of the overall information.

Part of the initial data analysis, including coding the transcripts, began during interviewing. The process of coding was undertaken in order to group the responses of interviewees into categories that linked similar ideas, perceptions, or topics that have been uncovered. Initially, thirty-five categories of information were identified. After reclassifying the data five times, four major coding categories were documented. Under each major category, various sub-categories were formed. Multiple copies of each interview transcript were made and each word, phrase, sentence, emotion expressed, paragraph, action, or example was marked. Patterns were established and the possible existence of correlations between two or more of the categories was investigated.

After the classifications were made and the subgroups were created, each interview transcript was cut apart and parts were sorted according to the categories and subcategories. An integration of similar ideas was completed. Finally, generalizations of a naturalistic form were developed. These were generalizations that intensified my 
awareness and understanding of the case (Stake in Denzin \& Lincoln, 1998) and were later clarified by the participants.

In order to diminish the chance of misinterpretation, the process of data triangulation within and among transcripts was one method employed in conducting the analysis. Triangulation encompassed the use of several perceptions from the different participants to refine meaning, allowed for substantiation of the repeatability of an observation or explanation, and clarification of meaning by distinguishing different ways the event(s) were being visualized (Flick, 1998). Additionally, participants were given the opportunity to read the transcripts of their interviews and clarify statements. They were also given the opportunity to review the study conclusions and offer feedback. Most participants wanted to hear a summary of the final report instead of reading the findings sections themselves.

The final process involved in analyzing the data and formulating the conclusions was the analysis of (a) the reported changes, (b) effects and (c) what the participants felt constituted positive significant and lasting change. This analysis was conducted through the lens of Lieberman and Miller's (1999) characteristics of meaningful and enduring change. The qualities of effective and long lasting transformation defined by these researchers provide a model that describes principles and procedures that give schools a chance for success under any type of reform.

\section{Summary}

Chapter III addresses the qualitative research methods including the specific methodological framework of this qualitative case study. The naturalistic nature of this study was explained. Through utilization of the interview process, a deeper 
understanding was pursued of the changes that have taken place in the teaching and learning environment of a school community since the inception of Florida's high-stakes accountability system, the A+Plan.

Selection of the research site and participants, ethics, reliability, validity and generalizability, and the role of the researcher were explained. Details covering data analysis, including coding, were given.

The findings of interviews regarding the effects on the teaching and learning environment since the establishment of the A+Plan will be described in Chapter IV. In addition, in Chapter V, conclusions and implications will be explored. 


\section{CHAPTER IV}

\section{RESULTS}

Four major themes addressing the research questions evolved through an analysis of relevant information provided by participants during interview sessions. These themes were (a) the consistency of the teaching and learning environment before and after the implementation of the A+ Plan, (b) changes in the teaching and learning environment since the implementation of the A+Plan, (c) the effects of the changes on the teaching and learning environment, and (d) the identification of meaningful and enduring changes that have taken place. This chapter is arranged according to the order in which the themes presented themselves during the interview process.

\section{Teaching and Learning Environment Consistency}

In reviewing the statements of interviewees, I found that there were eight areas identified where most participants reported consistency at the school site that existed both before the implementation of the A+ Plan and after the grading of schools became a reality. These steady practices and school characteristics were reported by primary and intermediate teachers, regular classroom and special area teachers, and by administrators. The order in which these areas are reported reflects the importance that most participants spoke of the consistencies that they believed existed.

Areas of No Change

Although many educators at B.R.E. described changes in instructional strategies, curriculum, parental involvement, and student learning as a result of the implementation of the A+ Plan, there were a number of individuals who expressed that no change was evident. When it came to teaching style, Linola stated, "I can't give up my philosophy of 
basically teaching them to learn certain things that I think are worthwhile in their life." Leslie explained, “I just haven't really changed much 'cause I'm stubborn.” Julio avowed, "I consider myself to be pretty hard working and I don't think it's going to change me regardless whether I have an FCAT or an ACAT or a BCAT, whatever CAT. I don't think it's going to change my style at all." Finally Lisa said, "I'm creative with my teaching style, and I'm still doing the same thing I did...I've always used multiple of teaching strategies because all kids learn differently, and so my ultimate goal is to make sure every kid learns." Participants were steadfast about their professionalism and emphasized that what they had done in the classroom all along worked best to promote achievement.

Parental involvement and school relationships were also indicated as places where no change was truly noticed. Atalia and Spring agreed, "You've always had your handful of people who've just been ready to come in and fight no matter what, and the majority of them have always been very supportive...the parents who were involved before are going to be involved now and the ones that don't care, don't care." Other topics cited as points of no change included the skills and knowledge of the students, time management and scheduling, major focus of funding, extra curricular activities, regular curriculum, style of administration, and staff development. These reports of no alterations tended to be in direct conflict of the perceived changes remarked upon earlier.

Administrators tended to identify change in the areas of scheduling, funding, and school with parent and community relationships in a more positive manner than those participants who had classroom duties. Teachers, on the other hand, pointed out changes in the areas of staff development, extra curricular activities, and curriculum. There did 
not seem to be any relationship between grade level and subject area taught and where the conflict in statements about changes existed. Most teachers and administrators felt that the level of parent involvement had not changed; the only thing that had changed was that the number of programs the school offered parents had increased. Additionally, both administrators and teachers believed that the skills and knowledge of students had not changed; they had just become better test takers.

Learning in spite of physical plant limitations and class size. Most teachers addressed the issue of too many children in each class and at the school, which housed too many students in general. Yet, each one of these staff members spoke to the point that despite the large number of students in each of the classrooms, which went as high as 35 pupils in each kindergarten class, and the enormous student population at the school, high standards and levels of learning have always been evident both before and after the Florida A+ Plan came into being. Teachers explained that the school even utilized what was designed as a storage closet for a classroom. According to participants, the school open space design has not impeded high quality education, even though the pod design did not lend itself to the use of some teaching strategies. All believed that no matter what barriers the building caused, the levels of learning did not change.

Care and concern. The second characteristic, which was reported by participants as being continued as a part of B.R.E., was the fact that care and concern on the part of the staff towards the children had been maintained. Many participants explained how supportive the faculty was and is of the students throughout all the programs that have come and gone. Both classroom and special area teachers spoke to the point that almost everyone's top priority is that the students "get it." 
In summarizing the words of the teachers and administrators, B.R.E. has always seemed to have had a positive environment. They maintained that it has continued to be a good school with a core of dedicated, committed, and devoted teachers and has repeatedly provided a caring and supportive atmosphere.

Instructional needs met. According to the participants, instructional needs included five areas: the academic needs of the children, the necessity for high standards, supplemental programming to target deficient areas, the critical need for an excellent school staff, and the availability of supplies and resources to fully implement a sound educational program. Teachers and administrators spoke to one or more of these five areas when discussing how meeting the instructional needs within the teaching and learning environment had been a steady practice both before and after the time since the school was graded.

According to primary teacher Lisa, the school has always tried to meet the needs of the children and has been extremely flexible in its approach. Intermediate teachers Barry and Mar explained how the staff targeted skills that needed to be concentrated upon and that the school offered programs such as Academic Excellence for students who did not meet the criteria for entrance in to the gifted program, but do need to be challenged. Special area teachers Laura and Maria explained that what the kids needed to learn was what the school has always shown as its focus. Maria stated, "We're the best, we make adjustments for all and work with their needs always."

Teachers in all areas, one assistant principal, and the principal agreed that the instructional program at B.R.E. has always been and continues to be strong. Teachers Julio, Mar, and Rouben verbalized that educators continued to teach toward high 
scholastic achievement; expectations have always been high and the push for excellence has always been in place. Mar stated that education at BRE has always been "serious business." Carole said, "The goals of the teachers are to teach and have the children learn." Administrators expressed similar views about the continuity of the instructional program. Assistant principal Atalia explained that the stress on reading, writing, and math continues to be a primary school goal, and assistant principal Jo made clear that the objective of the school has always been and will always be high. Supplemental tutoring programs existed before $\mathrm{A}+$ and remained a vital part of the instructional program. Several teachers and an assistant principal alluded to these classes.

Blue Ribbon Elementary faculty members believe that the school has prided itself on the fact that it has always had a good staff. This even held true today according to many of the teachers. Spanish teacher Maria validated this detail by saying, "I think we're the best. I think that we make adjustments and work everyday with the children and their needs." Barry's comments reflected those of Maria's. "What we've always had is a good core of dedicated teachers here." Peggy also stated, "I think this has always been a good school because I think we have a lot of very good teachers here." Over and over again, classroom teachers conveyed that B.R.E. has always been a good school with good teachers who worked hard, were serious, and dedicated themselves to student learning.

Participants made it known that availability of supplies were important to meeting the instructional needs of students. Classroom and special area instructors communicated that they have always been given the resources that they need to provide students with a sound education. Supplies have never been an issue in the past, nor have they been since the inception of the A+ Plan. 
Administrative support. Along with the infusion of high standards and sound instruction, many participants indicated that the support and leadership of the B.R.E. administrative team has remained a constant throughout changes in educational reform. Many participants pointed out that school administrators made them feel welcome and comfortable when they visited anyone of their offices. Rochelle described that when she really needed to speak to the principal, "I felt no hesitation in going to her office." Indications were that a sense of a positive attitude and open rapport has always been evident among the administration. Statements from participants that not only was there an open door policy among all administrators, but that concepts brought to the administration were listened to and discussed evidenced this idea. In addition, most teachers felt that they had always been treated as professionals.

Teachers reported that the administrators have done a good job without and with the A+ Plan. Several of them said that the school leadership has always worked hard and they have not seen this change. They believed that the leaders have always had high expectations, provided teachers with a lot of backing, been fair across the board with all grade levels, worked to maintain a positive environment, and have continued to be very organized and focused.

Respect and civility. Teachers expressed the need for respect and civility to be evident in a school in order to have a successful learning environment. These individuals indicated that this respect and civility has remained the same throughout changes in school reform. Rochelle stated, "It's a very good chemistry we have here. Everybody respects one another and that's good." Barry also addressed respect by saying, "Parents seem to respect education and what teachers do." All agreed that the majority of the 
children and parents have remained respectful towards school staff. They also specified that this respect and civility has been displayed by the administrators toward the staff, students, and community and that the educators at the school respect each other, the students, parents, and administration.

Camaraderie. Two primary teachers, one intermediate teacher, and one special area teacher expressed the idea that the school had always been and continued to be a close-knit family with cohesive groups. Rochelle stated that the faculty continued to work together, shared ideas and exhibited a wonderful chemistry. Tracy stressed that communication among staff members remained as a characteristic of the school. Carla believed that the friendly ambiance of the faculty has persisted over time.

Parental and community involvement. Consistency in the support and expectations of the parents and surrounding school community was seventh sub theme of the interviewees. Teachers and administrators expressed that parents have continued to be supportive of the school's educational goals, as the role of school reform has changed. Maria said, "I think that the parents have always been involved here." Tracy commented, "There has always been parent involvement at Blue Ribbon Elementary." A common perception among primary teachers seemed to be that the school has excellent parentteacher relationships and high levels of parent involvement. Intermediate teachers articulated that parents were concerned about the academic expectations and levels of the students. All agreed upon the fact that community involvement had increased over the years and remained an integral part of the school climate.

Working to make a good situation better. Many of those interviewed made it a point to explain how everyone was coping to make a good situation better. The eighth 
and final sub theme concerns comments participants made as they reported that the faculty and staff of B.R.E. have done their very best with the circumstances that they have been given. Everyone has tried to follow programs and make them work even against all odds. Barry explained how it was hard to improve, but that the faculty has continued to try and isolate the weaknesses in order to do better. Maria believed that everyone made adjustments and worked toward becoming stronger. Carla felt that we never stopped trying to make something good even better. Leslie understood that training had something do with making a good situation better. "I really think, in spite of all the things I was talking about, about the grouping of classes and that kind of thing, in spite of that I think we're successful because we're trained."

Positive teacher qualities were indicated factors that helped enhance the educational environment and further evolve it from a good situation into an even better one. "I think we still have really good teachers there, and I think our kids are good, and the, the teachers know how to make the kids want to learn, " stated Leslie. Carole declared:

I still see teachers at B.R.E. who really want to teach, because I feel that ninetyfive percent of our children are very enjoyable children, and they're still fun to teach, and they are children that can learn. So, I don't think that the goal of teachers to teach and have children learn has changed, but I think that the pressure has been put on the teachers....

Many study participants said that excellent teaching has been an ever-present commodity at the school.

Teachers believed that the school has always striving for excellence, a factor that has not changed with the implementation of the A+ Plan. According to Julio: 
We've pretty much been the same school, the same goals, the same standards. Maybe now we have more pressure because we're being measure and compared to the schools in our district and in the state, but I think this school is still as excellent as when I first started here. The same leadership, I don't think that has changed; the same goals, the same standards.

Consistency in striving towards high standards was also perceived by other participants to be in evidence both before and after school grades were assigned.

\section{Relationship to Meaningful and Enduring Change}

As explained by Lieberman and Miller (1999), there are five building blocks that are key in transforming the teaching and learning environment: (a) curriculum and instruction must be designed to promote equality and improve quality, (b) the organization and administration of schools need to be reexamined, (c) the focus must be on students and teacher, (d) schools must form alliances with organizations outside of the building, and (e) schools need to encourage a higher level of participation by parents and the community. For long lasting and effective change in the overall teaching and learning environment to be realized, these building blocks need to be addressed.

Participants' views about B.R.E.'s practices of care and concern, the meeting of students' instructional needs, availability of instructional materials, continual administrative support, and persistence of respect and civility fall within Lieberman and Miller's third building block of adopting a two-purposed focus upon students and teachers. Reports of the faculty's striving to make a good situation even better and the consistent high expectations with a push for excellence fall under the umbrella of the first building block of rethinking curriculum and instruction in order to improve the quality and equality of education. Interviewees' explanations of the continual support and expectations of parents and the school community reflect the criteria of the fifth building 
block related to the encouragement of increased participation by the parents and community in the education of students.

Statements by the participants concerning the importance of these practices and the conveyed evidence of their existence, both before and after the implementation of the A+ Plan, seem to suggest they hold attitudes toward the transformation of schooling and teaching consistent with the ideas of Lieberman and Miller.

Change in the Teaching and Learning Environment Since A+ Implementation

The second emergent theme concerned change, not consistency. In the six years since the Florida A+ Plan has taken hold, participants believed many changes have taken place and are still taking place at the state, district, and school levels. The interviewees indicated that these changes have resulted from decisions made by individuals and teams at all three levels. According to the statements of these educators, school level changes have been perceived as a direct effect of the A+ Plan.

Perceived Overall Change

According to the responses to questions asking about perceived change due to the implementation of the A+ Plan, there were four areas of overall change identified. These topics included how children were affected, the impact on teachers, the general transformation of the teaching and learning environment, and the effect on resources. It was noted that students seem to demand more one-on-one instruction with the increased pressures of the A+ Plan. In addition, participants felt that children now needed to grow up and face the reality of the consequences of their actions in school and in their everyday lives at a much quicker pace. 
Educators perceived that they have been impacted in many ways. First, the teacher assessment system has been changed so that all indicators are geared toward a more professional instructor. Yet, it was explained by one assistant principal that teaching and learning have become more structured since there needs to be a high level of readiness for the Florida Comprehensive Achievement Test, and this has led to instructional strategies becoming "teacher proof." A second area of impact on the teachers has been in the matter of staff development. Participants noted that workshop delivery has had to change. Julio stated that most training has dealt with language arts issues, how to provide documentation, and fill out forms. Two other individuals concurred with the issue of documentation and expressed their dissatisfaction with the amount of extra paperwork that has evolved in order provide a paper trail.

The teaching and learning environment has been manipulated in such a way that the emphasis has been on testing. According to Leslie, "Yeah, it's all FCAT. Everything that we do, everything we learn, every workshop we have, you know, geared to how we can improve our FCAT scores. I mean, even in science." Carole concurred, "Instead of learning being the goal, passing a test or a certain test score has become the goal." It seemed as if the test had become all encompassing.

Study participants indicated that they believed district mandates put a greater emphasis on developing reading and language arts blocks of instruction and a push towards a great change in the curriculum. Mathematics has become more problem oriented, reading and writing have taken the forefront and have been more fully integrated in all other subject areas, and higher order questioning has taken precedence over direct factual knowledge feedback. 
As a result of the change in curricular emphasis, the need has developed to find textbooks that are geared towards critical thinking and the FCAT. Both administrators and teachers expressed this idea. In addition, funding for these supplies was touched upon. Educators felt that money has become tighter. Administrators agreed and pointed out that specific funding was redirected for FCAT enhancement.

\section{Observed School Level Changes}

In most instances, school level changes were reported more as a direct effect of the A+ Plan and the administration of the FCAT than other school level changes in and among themselves. Alterations fell into categories, which include time, curriculum, administrative style, teaching style, grade level configurations, parent involvement, staff assignments, student needs, resource allocation, and staff development.

Curricular changes. Curricular issues were of great concern to many of the participants. The topic most often referred to was that the emphasis seemed to be on testing. Primary, intermediate, and special area teachers as well as administrators took this view. One assistant principal, Jo, related this to past practice.

I just don't think so much money went into test prep materials. We had like some archaic volumes of Test Ready or Test Best, and they never got even pulled out until a couple of months before the test. Then it was like the big hunt for where are we going to find this? Who has this? But that kind of rigid test prep in the lesson plans like we have now was not around.

The perception of the participants seemed to be that the curriculum had solely become teaching to the test.

Teachers and administrators reported that the curriculum in the intermediate grades has become more reading and writing centered for grades three and four and added emphasis has been placed on mathematics in grade five. Primary grade educators 
felt that the shift in the early grades academic program has forced teachers in kindergarten to replace centers and playtime to knowing color words, sounds and sight words and has applied more focus and pressure on reading comprehension and higher order thinking skills from second grade all the way down to kindergarten.

Special area teachers now have had to incorporate reading and writing in their art, music, and physical education classes as well as in their homework assignments. As explained by Patti, the principal, "Well you know the whole support staff is now focused toward teaching toward FCAT. P.E. is trying to incorporate reading; art and music are trying to do it." In addition, the teachers of the gifted program have had to change the focus of the gifted curriculum. Leslie, one of the three teachers in the gifted program stated:

I mean I teach science; I may teach, do a hands-on experiment, then I'll have them write up and emphasize paragraph structure and things that they need for the FCAT, Florida Writes and that kind of thing. I do more; I make sure that I do more math things where they have to graph, and they have to do things like that, that I know are FCAT type skills... The two partners that I work with didn't agree with me. They felt that it was important that we stop, and we stop teaching gifted and that we take a portion of the day, and we focus on FCAT skills and they have taken that on.

The feeling of accountability had been spread across the entire instructional staff.

In all subject areas, teachers felt that there needed to be an increase in the amount of homework given in order to address FCAT skills. At the same time, many felt that there was also a lack of subject matter being covered. Carole explained:

I think social studies has lost a lot. I think that gets pushed to the side because science is, science is emphasized and you can use a lot of the reading strategies with science...It seems by squeezing social studies in with reading or language arts that I don't think the children in fourth grade are getting enough Florida, and I know that the kids in fifth grade are not getting enough American history per se, as in a chronological, this is the way the country was developed, kind of order. 
Another teacher, Barry expressed the same idea this way:

I'm teaching the same amount of hours, and I teach math and science, and from September through March, through FCAT, although I'm supposed to do an hour of math a day, I find myself many days doing at least an hour and a half to the whole morning or the whole afternoon with just math. Because we have such a scope of skills to teach the children, and you have to do so much individual tutoring to get the kids who need a little extra help, they have a question, that the morning flies by; but when you look up at the clock, you haven't done science. And in years past, I would do math, science, and social studies.

A third educator gave her account in this way:

Okay, so instead of teaching anything else, any other subject, science or anything else, we just taught math for every minute we had...but that's just an example; we just totally did away with science so that we could teach, you know, teach what we were supposed to teach in math.

Study participants believed that what was not covered from the general curriculum was as important or held more importance than what was covered to address scoring high on the FCAT.

Changes in instructional delivery. Participants conveyed information about changes in personal teaching styles and strategies used in the classroom. Patti justified these instructional changes by saying:

For example in math, we have the planned activities to follow that they, in order to get all the FCAT tested material in before FCAT, we have a calendar that they have to follow. And basically the instruction has changed toward the material that the FCAT will assess.

Spring also stated, "But they've had to change because of the, in a sense, with the higher order thinking. The questioning, you know, strategies have changed in the way the teachers are asking the questions." Linola described, "It seems that instead of group work and cooperative learning groups and using manipulatives, we're doing less of that because we're basically using whatever has been published to prepare the students for the 
FCAT." Carole noted, "I see people incorporating instructional strategies just because everybody is doing that. That people are doing things because they've gone to workshops and because people are saying, when somebody comes in you have to have, for example, a word wall." I understood this to mean that participants believed that a shift in pedagogy had materialized.

Along with the change of instructional strategies has come the move toward more collaboration among teachers. The responsibility has moved away from the placement of the entire burden of academic achievement scores on just one teacher. People reported that they were more involved in working as a team. Carole stated, "I think we had fourth and fifth grade become a team and worked not so much toward teaching better, but focusing more on what the kids had to do to get a certain score." This team teaching was reported by educators at each level and subject area.

Changes in school goals. According to participants, it seemed that along with the implementation of the A+ Plan came a change in the goals of the school. Targeting the identified weak areas of students remained a constant, but now it was geared toward the A+ Plan benchmarks of receiving a particular grade. Rouben felt, "Of course there is one goal in mind now is just to do well on this test...I believe there's only one goal now; it's to get that successful grade... So we only have one goal and that's to get that good grade as a school." Carole's similar perspective was articulated in her comment, "I don't think that the goal of the teachers to teach and have children learn has changed, but I think that the pressure that has been put on the teachers because instead of learning being the goal, passing a test or a certain test score has become the goal." Leslie's comments concurred with the aforementioned statements; "Learning is not the focus anymore, it's 
FCAT scores, and let's get that A+." Linola's comments followed suit. "Well, the goals of the school just seem to be everything to make the children increase their scores on the test, that's it. Nothing else seems to be of concern." Primary concentration had shifted to being graded an A by the state.

Various school site practices were cited as being employed to meet the demands of the new interpreted goals. Some of these new procedures included fewer classroom enrichment activities, increased focus on attendance incentives, and students being pulled from special area and content area classes to give extra tutoring in the computer lab. The use of computerized programs for first through fifth grades such as the Accelerated Reader, use of phonics based motivational programs in kindergarten and first grade, and homogeneous grouping of classes where students of similar abilities were put together were also discussed. Additionally, looping students with the same teacher for two years, teachers teaching grade levels and subjects in their strength areas, utilizing FCAT practice booklets, and smaller classes for those students working below grade level were utilized to address the school's goals. Jo expressed an administrative point of view about these changes.

Well, the Saturday School, the before school, the after school, there's been a lot more emphasis on that as opposed to just helping kids that need help learning. It's which kids that are going to matter for the FCAT. Well, definitely the Academy of Reading Lab that the paras [paraprofessionals] that go in and help the kids brush up on their skills; that's another impact. The looping that we're doing and the way we've put our strongest teachers in third and fourth grade for reading and fourth and fifth grade for math; you know that two year continuity with the best teachers for the subjects that matter.

Interviewed staff members explained other systems that were put into place. Leslie exclaimed, "I never thought I'd see the day when we'd have an FCAT rally like a pep 
rally, and what is that? Rah, rah, rah FCAT? I don't know, I just, and I've seen that change."

Administrative changes. Transformations in administrative practices were noticed. These included less visibility of administrators, a change in administrative actions but not in the style of administration, and an increase in administrative communication. Linola articulated that the administrators were more involved in what curriculum was being taught and that more directives were given as to what to do and when. Mar stated:

I don't think they [the administrators] have changed. You know, they've always had the high expectations, they've had the workshops, they've had this, they've told us what we have to do to improve, whether it was SAT [Stanford Achievement Test] scores or whatever. So in that aspect, I don't see a lot of change. They do let us know more now, what we need to do to go from point $A$ to point B. They make an emphasis on that, but not necessarily that it's just added new; that they never did speak to us about it.

Shift in administrative practice was not identified as an area that had been clearly transformed.

Changes in resource allocation. Utilization of resources, monetary and personnel was another noted topic of change. Participants addressed the change in the jobs of paraprofessional and other support staff. Administrators and some teachers were at opposite polls when speaking to this issue. The principal stated:

Well, the money that we get from the state, we're using that specifically to prepare kids to take the FCAT. I mean we're using the money for paraprofessionals to man a lab to bring kids up to par in reading and aides to pull kids out for math instruction that are lower or remedial kids. And as far as the overall budget from the county, basically if there is a need for FCAT preparation that really comes before anything else.

Another administrator, Atalia confirmed that, " the issue now is looking at our budget again and looking at how we could allocate the money to help out third and fifth grade 
and looking also at a math program." She also said that there were aides in each fourth grade language arts classroom working alongside the teachers. In accordance with the administrators, Tracy, one of the primary teachers, felt that more resources were being given to the upper grades because that was where the emphasis needed to be. In opposition, Carole, who taught third grade, stressed her sentiments.

I'm going to be very blunt. Whenever the office got overwhelmed, we got more office helpers. When the remedial program was integrated with the computer lab, we got lots of people up there. When an administrator needed help, they got an administrative aide. Who helps the teachers, who comes and files?

Another teacher, Barry, questioned present allocations:

Do we really need a lot of teachers on special assignments? That money, I think you get a couple of experienced teachers together, and we might be able [to decide] how to better spend those funds; whether it's in actually tutoring kids that are sent there with specific skill that the teachers say they need to master, or taking those funds and putting them into "custodial" to keep the school cleaner.

Participants agreed that there had been a change in the way the funds had been reallocated, but maintained a difference of opinion about how spending had changed. Some believed that the reallocation was necessary to address the needs brought about by the school being graded, and others felt that the areas to which funds were reappropriated were unwarranted.

Changes in parent and community participation. Parent and community involvement and activities also appeared to have changed. Extra parent conferences, meetings, and communication have occurred. From an administrator's perspective Patti pointed out that in addition to what had been done in the past, "Well you know we send home stuff for the parents to work on with their kids and we have parent night activities for the kids and parents to help the kids prepare for FCAT. Parents are fully aware of the 
importance of the test." Atalia explained that parent workshops have been ongoing each month for the past two years. Spring added that parent calendars were also distributed. Teachers also alluded to the increase of parent involvement. Carole substantiated this by saying, "Yes, we have given workshops, and we have asked the parent to come to school for science workshops, for math workshops, for language arts work shops. We've had FCAT workshops. We have at least tried." Additionally, it was noted that there was increased community and business participation.

Additional changes. Other school changes focused upon were that of preferential scheduling given to those grade levels most directly affected by the FCAT and the shift in objectives written into the School Improvement Plan. The principal made clear that:

Basically we give the grade levels whose scores count toward the grading the preferential scheduling so that they'll be able to have their language art or their math or whatever in the morning before the kids get burned out. So, they have that two-hour block uninterrupted. And we want to be sure that those are the grade levels that have the cushy schedules, so to speak (D.H).

As to the School Improvement Plan, teachers observed that the objectives had become geared towards increasing the FCAT scores.

Perceptions of positive versus negative changes. School level changes were sometimes expressed as being negative or positive for students and staff at the time they were first being described by participants. Other times during the interview, participants brought to light whether certain changes had been viewed in a positive or negative manner by themselves or other educators. Not all transformations of practice, resource allocation, time management, etc. were viewed as either positive or negative, but were just described as modifications of which the interviewees were aware. 
Changes that were considered as negative by the participants included various instructional strategies, personnel changes, and other procedural adjustments. The major area of disapproval concerned staff positions and the manner in which they were utilized or were reallocated. Julio protested about the reassignment of paraprofessionals only to FCAT affected classes. He exclaimed:

When I had an aide two years ago who came to my class daily, it was great because whatever kids I had that were low, falling behind, those kids would get, even though it wasn't given daily, they would get extra help 'cause with first graders you can't do it alone. You can't do it all by yourself, and the help that we had before was really good. So, now the emphasis is on some other grade levels. I think that that change has been really bad for the lower grades, even for the other grades that don't have aides.

Carole expressed a problem with sacrificing an extra teacher's position for having someone in the technology lab where the use of those computers was for remediation only. She also took issue with staff not spending full days at their assigned positions.

My biggest problem with budget is the, how do I say this, I have to be very [careful], that there are staff people around the school that are not working full days and that there are not enough aides in the school. I think we're wasting our money on a reading leader, on a part time P.E. teacher, two part time P.E. teachers. That's a lot of money that's not helping anyone at all and that you could have how many aides? A lot!

The change in the utilization of support personnel did not seem to be viewed as a benefit for the entire school.

Participants communicated that instructional focus and methodology were the other areas of negative change. For many of them, one of the most distasteful points was that the whole focus of instruction had become a methodology of pinpointing ways to raise test scores and learning how to take a test. Leslie explained: 
Yeah, it's all FCAT. Everything that we do, everything we learn, every workshop we have, you know, geared to how we can improve our FCAT scores. I mean, even in science. Now they're, you know, this is going to be FCAT so, hey, hey, hey we're going to do this, this, this. And, you know, I think it's a shame.

Educators' statements seemed to indicate that pedagogy was now being dictated by the test.

Other teaching strategies that were at issue included having a pat formula for writing, eliminating a lot of hands on activities during testing preparation, implementing FCAT practice into the gifted curriculum which cut into true program time, and pulling kids out of special area classes to get extra FCAT skills infusion. From an administrative point of view, Jo felt:

I think one disservice that we're doing to the kids is that we are pulling them out of their special areas, in some cases, to get remediated. And, while I think they need remediation, I don't really think that we care what Michael Jordan's reading level was and that is a disservice, because there are kids that have an opportunity to shine and be successful in an area, and all we're doing is drilling them on an area where they're not successful. And I think that something's got to give, and I think that it really shouldn't be that.

Another teacher expressed the same perspective. Gigi stated, "About this pullout business, where the kids have been taken for additional tutoring, additional instruction, I don't think that it, that the results are what we intend them to be." It appeared that the staff members were dissatisfied with the swing in instructional strategies and methodologies.

Some individuals viewed certain changes as negative while others considered them to be positive. The emphasis on attendance and the consistent issuance of incentives was found to be counterproductive by one teacher and effective by two others. One educator felt that departmentalizing grades three through five was not a wise 
practice, yet Gigi. believed, “I think maybe one of the good things was putting strong teachers in their field of expertise or strength. Those teachers that teach at that level can convey much more than a teacher that is uncomfortable in a specific area." The implementation of the Accelerated Reader Computer program, which had students read a specific book at their level, take a test on the computer upon completion of the book, and earn points for their scores, was viewed both negatively and positively by teachers at various grade levels. Finally the looping procedure, where students stayed with the same teachers for two years, was identified as troublesome by one intermediate teacher, but as helpful by others including one administrator. Their responses did not fall along the lines of grade level or subject area taught or whether or not the person was a teacher or administrator.

Participants indicated that constructive changes included many alterations to teaching and learning procedures. Providing additional support to students with lower level skills, including after school tutoring was viewed as a plus. Developing a specialized curriculum reference manual and creating a pacing chart to help in information dissemination was lauded. It was believed that with these changes the weak teachers now had structure and made positive changes in their instructional methods.

Several changes that directly affected teachers were perceived in a positive sense. Block scheduling, which requires a continuous two hours of reading and language arts instruction and is part of the District's Comprehensive Reading Plan, along with the scheduling of common planning time were identified as two constructive adjustments. Consuela stated, "The group planning I think is good and should always be there." The other area with a direct effect on teachers, which was noted, was that of staff 
development and instructional support. These included teacher support from the reading leader and the more specific money expenditures on materials and subject area interventions. Mar clarified:

Well, what I'm aware of since FCAT started grading us is we've got more materials to help teachers and students perform better on the FCAT. I don't think they would have gone out and bought all these FCAT Advantage books and those reading book blasters, or something like that, unless we would have had that case. I think that money would have been spent elsewhere such as practice workbooks or anything like that. It's more targeted; it's more specific where the money is being spent.

Consuela was also in agreement. She said, "Additional materials, I know, are always good no matter what. Whether I would have spent it on FCAT books or something else different, the additional material is good." Money expended for academic enhancement was applauded.

Teachers felt that the increase of administrative communication helped them across the board. Two administrators believed that the number of attempts to reach parents created a feeling of acceptance for family involvement. In addition, the building of community partners to assist in the education of students was viewed as an encouraging area of growth for the school. Finally, it was stated by a few educators that all the changes they could observe were positive, although this was not the viewpoint of the majority of participants.

Discernment of intended versus unintended changes. When they spoke about which changes were perceived as anticipated by the State of Florida with the implementation of the A+ Plan, most participants referred primarily to the effects of the plan on the changes at the state, local, and school level. Items such as higher FCAT scores, more kids working and on task, increased monitoring of learning, and harder 
working and higher achieving teachers were cited as being intentional outcomes of the A+ Plan. According to Patti:

I think that what they [the state] intended to happen with the A+Plan is that they intended for more schools to be A schools so that it would look like the Governor's plan was improving schools. And, I think that that was their political agenda, and that's what happened, and I think that will continue.

Leslie addressed the notion of harder working teachers by stating, "I think, I'm not sure what the state was thinking. I think the general public kind of feels that teachers are lazy, you know, and maybe they don't work so hard. And, I have to say that prior to this, maybe there were some." Thoughts that reflected school level changes, which might have been construed as intended by the state, included the allocation of money toward helping students do better academically. Jo maintained:

I think most of the changes would be, that we mentioned, would be intended because they had to expect that you were going to do massive training and buy materials to support all of this kind of stuff, and I think that also the level of the training of teachers is some of what they wanted...And I think they would be glad to see less of the fun of school, you know what I mean?

Although some individuals had specific ideas of what the state was looking for in change, most seemed to be perplexed by what was really desired by the state as outcomes.

The perceptions of the participants as to what changes were not expected by the state included the expense of materials and training, pulling kids from special area and other classes to practice FCAT skills, and the looping for two years of students with the same teachers. Overall, one intermediate grade level teacher summed up the ideas of calculated and unplanned change in this way:

They [the state] planned on, of course, monitoring the learning; they planned on proving that everybody could learn regardless of your background, which we know is not a fair thing to say at all. They intended to see growth, equal growth among all the children, and that has not happened... So, it's unreasonable to think 
that each child, if they haven't come to you with the same, how can they possible all be equal.

I don't think they counted upon the expenses of all these materials and supposedly all this training that they want. I think they though that it was going to be very easy; just let's do this, we're going to go by these, these, these objectives and be tested on this, and this is going to make them critical thinkers and whatever, and we'll just grade the school on how good they're doing.

And the more, you know, we slap them on the hand, then those teachers will snap out of it, and everybody will just be wonderful A+ school. And, that's not the way it is. Reality is here. We're seeing it every single day, and they're not here to it. They must sit in a class and notice there's no way what so ever. (Consuela)

Whether what took place as a result of being assigned school grades was deliberate or unintended, I found that a negative attitude toward this reform consistently surfaced.

Necessary change. In addition to the changes sensed at the state, district and school levels, interviewees made it clear that many changes were still necessary. These adjustments were both related and unrelated to the implementation of the A+Plan and were at the school site as well as at the local and state ranks. Participants' responses identified the following areas as prioritized needs:

- Expose students to more things than just cramming for test taking sake.

- Give more support to the primary grades.

- Increase level of technology and computer programs and utilization of lab by all students.

- Give teachers more leverage in dealing with disruptive students.

- Increase the level of administrative presence in the classrooms.

- Better utilize staff including the reading leader and paraprofessionals.

- Place strongest teachers at grade levels affected most by FCAT.

- Form classes at each grade level using knowledge of chemistry among students to achieve maximum collegiality.

- Better utilize the media center across all curriculum areas.

- Employ a group method of working with parents.

- Offer parent workshops at more convenient times and teach parenting skills.

- Secure an intensive mathematics program.

- Focus on vocabulary at all grade levels.

- District should develop a grade between kindergarten and first. 
Participants believed that excellence would be enhanced with the injection of these changes into the teaching and learning environment.

The area that people saw as needing the most transformation was in the role of the teacher and the learning of children. Carla spoke about focusing on students' wanting to learn. "If we can go back and relook at things that will help connect these children to help them love it, they'll keep coming to school not only for the attendance awards, but for the learning." Following along in the same vein, Consuela believed, "We need to change our teaching style and go back to the way we know, teaching the way we know kids learn, the way they knew they learned. They may no have all learned equally, but they left learning something." These statements reflected educators' confidence in their expertise on what will motivate students to learn.

Class size was also a subject where many pointed out a change was essential.

Peggy emphasized:

My big thing is smaller class size, especially in the primary grades. I really, really think that $\mathrm{K}, 1$, even second grade; that's where they first come in. That's the foundation and everything, and I just think that teachers wouldn't be as stressed. I think that the whole environment, the children would benefit because you would be getting to all of them better.

In a concurring statement, Tracy articulated:

I think that what's happening now is with all the FCATs and the A+ and everything else, the kids are, there's expected a lot from them. Obviously would be lower class size, and I think that itself would improve test scores. But, that's my opinion and I know it's not going to happen. But, and I know that's what everybody says, but when you have a smaller class sized and you're able to work with these kids. And now that I'm packing and I see all this stuff that I used to do that's been put away in a cabinet 'cause I don't have time to do, 'cause the class is so big. 
I sensed that class size was a major issue as it was hinted at quite often when needed changes were brought up.

An assistant principal and an intermediate teacher elucidated two distinctive ideas about fundamental transformation. Jo, the assistant principal, clarified her idea for change.

I really think that if schools, and this is my own soapbox, if schools all over the county are really going to make a change, then those kids need to come out of the hospital when they're born with a letter from the principal saying, "Welcome, I am your principal. This is what you need to do to get your kids ready for school." And until we attack that, we're going to have a very tough time just making do with what we get, and not just us, because we have a pretty good population. We have what it takes to be successful, but there are many schools that don't.

And unless you're going to do something to target that, it's going to be, the plan is going to be very unfair.

In a laughing voice, Consuela expressed what changes she felt, as a teacher, needed to be made to make the school better. "Get rid of FCAT!" This was a familiar vocalization among interviewees.

\section{Relationships to Meaningful and Long-lasting Change}

The statements about change made by the study participants included information relevant to each of the five building blocks described by Lieberman and Miller (1999). Some of the responses represented what Lieberman and Miller describe as what works in transforming schools, such as increasing activities for parents and the provision of extra tutoring for students who demonstrated a need. In addition, some of the participants' perceptions also reflect what was in direct opposition to the building blocks of combination for content and process, the attention to the needs of students and teachers, and the maintaining of a balance between all areas involved in school transformation. These identified changes included moving paraprofessionals solely into FCAT affected 
classes, refocusing the curriculum on FCAT skills, and omitting instruction on nonrelated subject matter.

Participants addressed changes in general and at the school level that corresponded to the building block of the restructuring of curriculum and instruction to forward the ideas of equality and improved quality. Statements associated with an increased focus on subjects and grade levels covered by FCAT, the teaching of testtaking skills, an increase in homework, the creation of specialized curriculum manuals, teacher training on FCAT assessed subjects, and the elimination of instruction not directly related to the test were some of the areas covered by the participants. The majority of the accounts seemed to indicate that there were some improvements in the quality of certain aspects of the curriculum and instruction as in the creation of a curricular pacing chart. In contrast, there were some indications that curricular improvement and learning equity were lost with the low prioritization of subjects not tested on the FCAT and focusing curricular goals on getting a good school grade.

Other reported changes that correlated with Lieberman and Miller's ideas about transformation include statements concerning levels of communication, which correlate with the combining content and process building block. Statements concerned the levels of parent and community involvement, which correspond to the building block of participation by the community and parents; and issues covering the changes in personnel responsibilities including the reassignment of paraprofessionals. This affects the balancing of teacher and student needs, which Lieberman and Miller identify as something that needs to be addressed in order to transform schools effectively. 
Finally, issues of necessary change that were reported by participants covered all five building blocks identified by Lieberman and Miller. Additionally, these identified needed changes addressed what Lieberman Miller express as necessary elements in order to transform schools positively. The combination of process and content is alluded to by statements concerning the exposure of students to a broader body of knowledge, the increase in the level of technology and computer lab utilization, forming classes according to known student interactions, employing a group method of working with parents, and offering parent workshops at more convenient times. Providing attention to both the needs of students and teachers is indicated in declarations regarding giving more support to primary grades, providing teachers more leverage in dealing with disruptive students, and utilizing staff in a more effective way. The thread of maintaining balance between all areas runs through many of the ideas about change related by interviewees. Effects of Change on Teaching and Learning Environment In closely examining the responses of participants when questioned about the effects of the changes reported, I noticed that most individuals seemed to have related their perceptions of the effects in the same manner as they spoke of the actual changes. The effects fell into categories of those which were generally due to the A+Plan, effects of changes made at the school site, effects that were considered to be positive and/or negative, effects that were felt to be intended or unintended by the state, and those outcomes that were a direct result of just getting used to the A+ Plan system of assessing schools. 
Interviewees reported an array of results, which they believed to be directly related to the implementation of the A+Plan. These outcomes included alterations in curriculum standards, overall school atmosphere, school goals, teaching and learning environment, time utilization, allocation of resources, and delivery of staff development. In addition, effects on school staff, students, parents, and administration were noted. Final thoughts on political undertones were also expressed.

Two general effects of the grading of schools were reported to be that poor grades could lead to the downfall of a school and that even though no two schools are exactly the same, the A+ Plan treats all schools as if there is no difference among them, an idea that did not sit well with participants. "I don't like the idea of the fact that the whole way they treat different schools, because there's no way you can compare BRE to Little River. They have different needs than we do. You can't compare BRE to a school in Tallahassee or anywhere up north; it's just totally different" (Julio). Individuality of the learning environments was perceived to be of little value in the A+ Plan.

Many individuals reported an improvement in the level of teaching, higher standards, enhancement of test taking skills, and higher expectations of students as results of the school being graded. "To me, the curriculum has gotten a little tougher...it's higher expectations of the students," described first grade teacher Lisa. Kindergarten teacher Tracy's comments piggybacked on Lisa's.

Well, curriculum in kindergarten, like I said earlier, is we used to do centers and everything used to be very hands-on, now everything is book, board. I use a lot of overhead, but everything is very curriculum based. There's not that much handson even though we try, but there's not that much hands on. I also feel that kindergarten somehow along the line in the last four years, five years, has turned 
into a first grade. First grade has turned more like into a second grade, and I think we're trying to catch up the kids that we're just putting them up a whole grade... So we're expecting a lot from these kids, and I think second grade teachers are expecting a lot more because everybody's trying to get to those tests, and those tests are getting harder. So we're starting younger to catch them up.

Carla summarized that the FCAT and the A+ Plan have generally helped to raise the bar of education.

Goals. It has been sensed that the overall goals of B.R.E. have been changed to specifically meet the criteria of the A+ Plan. Mar clarified that, "The goals of the school have changed. You know we have criteria to meet, and we can't let one thing go and make ourselves look bad in front of everyone when that's just not us. Everybody wants to achieve and look well in front of the public." Consuela described goals that were now geared more towards the A+ Plan. "All school improvement plans are changing now to fit this little whatever way they want to be or want to look to be able to be the A+ school...many schools are just redoing their whole school improvement things based on that what they want to be." In conjunction with the goals, they believed that the school atmosphere reflected the idea of wanting a good reputation. "We want to have a good reputation, we want the public to believe in us," emphasized Leslie. There seemed to be a sense of relief when B.R.E. achieved an A grade; yet uncertainty remained due to the concern over how to maintain that ranking.

General school atmosphere. Other statements that focused upon the aspects of the broad school atmosphere included issues concerning the conflicting focus upon the fourth grade, the regimentation of the environment, the change of enjoyment level after the administration of the FCAT, and the utilization and lack of time. Laura described the 
fourth grade as being both privileged and cursed. She explained the conflict in this manner.

Fourth grade became almost like, I tell you, fourth grade became like a group that I couldn't do anything with because they were overwhelmed.... Nobody's booking fourth grade [for field trips] because they're untouchable. Nobody can get permission for them to go anywhere. Nobody can do any projects with them; they're so busy and overwhelmed in that year...I think there's a feeling that fourth grade is like a privileged grade. Not from the fourth grade teachers; I think they have a feeling that fourth grade is a cursed year, but from everyone else.

Carole described the regimentation of the school environment. "I think we've lost again the fun of learning, but the school environment, I don't want to say too regimented, too, I don't know, prescribed." Consuela's statement demonstrated the transition from the regimentation before FCAT to the nice part of learning after FCAT. "Right after the reading FCAT, they are enjoying so much. They are just so happy being out of that this copy and rewrite and do the other and all of that...they're just so happy." According to the statements of participants, effects of the grading of the school had taken a strong hold on how the school atmosphere had evolved.

Statements concerning the utilization and lack of time also mirrored the effect on the general school atmosphere. Notions of there being less wasted time, increased time spent on meeting the total curriculum before FCAT administration, a lack of true teaching time, and more time being given to testing individual students and document results were perceived by participants. "Now I don't have, the part that is sad that hurts me is the students that cannot read at all, I don't have time to sit down and teach them the beginning of reading. And those are the losers," clarified Rochelle. Peggy explained: 
I just think it takes away a lot of time, true teaching time, which I think they would get the FCAT skills if you were allowed to teach what is really true teaching... You know one of the things that teachers never have enough of is time, and then they take away more by doing this.

Consuela asserted, "If we're going to have three or four different subject areas (tested on FCAT), then where do you go from there? There's no way that we can do cramming in four subject areas, so teaching is not really teaching." Feelings were summed up in a declaration by Barry:

I have a whole set of challenging enrichment activities that I've used over the past years, and I've had to save them until after FCAT is done. I can stick a few in during September through March, but it's not a regular thing. I spend too much time going by the scope and sequence at the fast pace through March. And I felt like I was hired to teach for this test.

The adaptation of time to meet the demands of $\mathrm{A}+$ appeared to be evident to educators.

Resources and staff development. Participants referenced resources and staff development as two other areas of general school conditions. Educators maintained that more money was going into FCAT preparation and toward the purchase of textbooks with FCAT orientation. Linola believed, "We need textbooks that gear themselves towards critical thinking and the FCAT math books where they have questions that are similar to the questions on the test. So basically yes, you needed a whole new text of textbooks." Where staff development was concerned, it was alluded to that the A+ Plan brought about a need for more training especially in areas that centered on skills covered on the FCAT, including critical thinking.

Teaching and learning environment. Those who participated in the study noted numerous effects on the overall teaching and learning environment. In relationship to the issue of time, many individuals spoke to the fact that as educators, they were not able to 
get to everything in the curriculum that was desired or needed. Both teachers and administrators expressed this idea. The principal stated, "They [the teachers] feel more stressed right now to get through all the information they have to get through, that's going to be tested on FCAT and they feel, I think, more restricted in getting into other areas" (Patti). Related to this concept was the belief of several participants that teaching to the test occurred on a frequent basis, with cramming and not actual learning taking place. Atalia avowed, "What I'm really upset about is that our curriculum, unfortunately, has been thrown out the window. We're teaching to the test. No matter what anybody says, the reality is, we teach to the test." This point was reiterated by others and is summarized in the statement made by Julio. "It seems that we like kind of teach toward the test, to the test, and we concentrate just on FCAT. It's like everything is FCAT these days." Cramming for the FCAT to reach for the ultimate goal of an A grade was also mentioned as part of this impression that they are teaching to the test.

In following the line of thought, which placed an emphasis on teaching to the test, it was observed by those interviewed that the focus of teaching and learning had become achieving the score on the test that would lead to the highest grade possible instead of concentrating on the child. "Well, scores are important. Should it be the entire emphasis? No...the child is what's important. And not just scores, that's only just part of the child. It's just one part of the whole" (Leslie). It was felt by these educators that this concentration on scores led to a cookie cutter approach to teaching.

An expressed concern that had a commanding effect on the teaching and learning environment involved the belief that whatever had been done in response to the $\mathrm{A}+\mathrm{Plan}$ 
would not be able to be replicated due to the fact that the criteria of the accountability system was in a constant state of flux.

Well, I think eventually it's going to get old, but I also think that eventually the test will get harder, and the standards are getting harder, and what used to make an A school last year is not going to be what makes an A school this year. So, there is going to have to be changes done, and there is going to be more materials, and there is going to be change, and it's just going to continue to get harder, I feel. (Tracy)

This perceived feeling of exasperation was also expressed by Chris.

And I think they have the FCAT test, and when so many people did well on it, let's change it so that more people fail it. And so they turned around and made it more difficult and changed things so that as many people failed. And then they have the two F schools, and an F school gets two Fs and now we can go to private school. Then people that are investing in the private school will reap a reward; it's all money.

Teachers and administrators echoed this sentiment equally.

Influence on entire school community. Responses to questions dealing with the effects of the A+ Plan not only dealt with the school atmosphere and the teaching and learning environment, but comments also encompassed the effects on the teachers, students, administrators, parents, and school community. Remarks dealt with positive and negative impact on the key individuals at the school site. The majority of the accounts were comprised of topics affecting educators at the school site. Comments about what influenced teachers ranged from there being a less cohesive staff and educators second guessing themselves to stress, anxiety, frustration, and the exiting of people from the profession. Also expressed were impressions about a more structured, but better teaching force, where educators were always striving to do their best.

School personnel interviewed reported that the excessive reliance on testing felt like a slap in the face, in essence questioning the professional judgment of the individual. 
Some also felt that this emphasis on test scores gave way to a degree of tattletaling when certain teachers did not follow the specific subject matter tested.

Teachers reported that key issues that affected them were an increase of anxiety, undue stress, nervousness, pressure, and frustration. The words of several of the interviewees painted a picture of this phenomenon. Carla explained, "I think it $[\mathrm{A}+/ \mathrm{FCAT}]$ has promoted a lot of stressed out teachers. I think that the crux of it comes on the teachers. I think many times that the teachers are short with the students, that they don't really mean to be, but so much pressure filter down to the students." An administrative point of view was exhibited in this way:

It's like I said before, I just think the staff, as a whole, is very stressed. It's like I said before, there's less time for camaraderie, and people like to build relationships and just organize. You know before, we just seemed to be more of a family...but a direct result of the FCAT is the stress level of the teachers; they don't have time. They're constantly complaining about the kids. They're much more judgmental of the kids, you know telling us on an ongoing basis that these kids just can't make it, "I don't know how they're going to do on the FCAT." Before they'd tell you just that this kid can't read, but now they're more focused on "this kid's never going to be able to make it on the FCAT." (Jo)

Peggy agreed:

I would probably say the hardest thing on everybody is the stress level. The kind of profession that we're in is very stressful to begin with because you're working with children, and then with all of this it adds a tremendous amount of paperwork and sometimes things are just really not necessary...I think that everyone would benefit, especially the kids if we weren't so stressed. We pass that stress onto them, and that in turn the parents are stressed because the workload is tremendous. So, I would say stress is probably the hardest thing on everybody.

Interviewees expressed that the high stress level has prompted instructors to request to teach grade levels not directly affected by the FCAT. Patti stated, "Nobody wants to teach fourth grade any more. I've had teachers crying in my office asking me to please take them out of fourth grade." Special area teachers not directly responsible for student 
knowledge for the FCAT expressed the same ideas about stress and explained how the anxiety permeated the entire staff.

One of the most striking results of the stress of the FCAT and A+ Plan on teachers, as explained by the participants, was the desire of these educators to leave the profession. Educators stated that people are burning out, and they feel they're doing so much and don't see the results until the school grade is finally posted. Additionally, people have stopped considering teaching as a profession due to the excess stress.

The lack of creativity and freedom in covering curriculum and the loss of the fun and excitement of teaching were other perceived effects of the A+Plan. Teachers and administrators articulated that most people do not have time to address the teachable moments that arise unless they deal with something covered on the FCAT. All of the participants agreed that teachers had a lot more freedom to be creative before the implementation of the A+ Plan. They have conveyed that a lot of the fun of teaching had escaped them.

Positive statements about the effect of the changes on educators included the idea that teachers were on the same page and covering the same skills. Additionally, it was noted that all teachers needed to rise to the occasion and do their best.

Maybe, if there's one positive thing that I can say about the test, and about this whole grading thing is that maybe it's making us look at what we're doing and be more like reflective on what we're doing, be more defensive about what we're doing, and that's a good thing. Because, anytime you get complacent, maybe you don't push yourself as hard. (Laura)

Carla believed that with the A+Plan it has become extremely difficulty to be a dead weight teacher. 
The impact on students was another matter touched upon in the discussions with school staff members. Concerns included ideas that students were not developmentally ready for what was being pushed down their throats, that after testing, students gave up on learning for the rest of the school year, that children's thirst to know was destroyed, and that pupils were put under a great deal of stress and pressure and exhibited excessive tension.

I see the kids themselves are very stressed, you know. Before, when we did the Stanford, the kids knew the importance of the test, yes they did. But, now, you know, they're all afraid they're going to be retained because of this test, and you know we've had kids getting sick, and they're just very upset about the whole thing. You know, especially the older kids; the little ones don't really know, but the fourth and fifth graders are very, very stressed.

You know, school used to be just a place to come and learn and you had fun and you had a good time for the most part, especially with the great teachers we have here, but now you know school is stressful because we have to get these skills; and what if I don't have them, and if I fall behind, what's going to happen to me? It's just a lot of pressure, and it's trickling down from the administrators to the teachers to the kids, and it's affecting them. (Jo)

This sentiment was echoed throughout the responses of the other interviewees.

The perception of the A+ Plan having no real impact on students' learning was described along the lines that no true academic achievement was realized. Teachers reported that students seemed to be struggling more with the basics, which they felt were a prerequisite to the utilization of higher order thinking skills. Educators also believed that student differences were not being accounted for and that if pupils did not qualify for exceptional student education programs, they ended up falling through the cracks because of the state's failure to allow for individual differences. Carole summarized the effect on students by articulating: 
I think it's, my favorite saying was and is that education is not filling a pail, it's lighting a fire. And I think it's [the A+ Plan] dousing all the fires. I think we're destroying children's thirst to know something, that's fun to know, and then try to teach them how to find it out.

The overall outlook on the effect of the A+ Plan on students did not seem encouraging.

When illuminating the effect of the A+ Plan on administrators, interviewees spoke to two subjects. One area was the amount of time wasted in test material organization and session preparation. Atalia affirmed, "I have spent hours before the test administration putting together packets for teachers and putting labels on student booklets!" The other area was the degree of pressure felt by administrators. Consuela said, "I think the pressure is coming at them [the administrators] and then they of course have to pass it right on down." This pressure equaled that of teachers and students.

Parents and the school community were also reported as being affected by the parameters of the A+ Plan. Aggression, panic, unhappiness, and frustration were some of the characteristics reported as being displayed by parents in response to changes made by the grading of schools. The frustration may come from parents' lack of ability to help children in solving FCAT type homework problems and/or the anxiety caused by their children's stress levels. Some parents have resorted to removing their children from public school and sending them to private school. Leslie revealed, "I can remember getting a call from a parent before we were an A school and said she was taking her child out of the school in the south because it was an A school." In addition, a greater number of parents were reported to have sought one-on-one tutoring for students in order to better prepare them for the FCAT. 
According to those interviewed, the school community, including parents, has become extremely aware of the grading of the schools.

They're [the community] all more focused toward FCAT as well, and you know, along the lines of the grading... when we were a $\mathrm{C}$ school, that would be thrown in my face with the disgruntled parent. And yet, the very next year we're an A school and we're just teaching as hard as we've always taught, the kids are the same as they always were, but now everybody is applauding the fact that we're an A school. We're the same school we were before. (Patti)

Similar accounts were given by other contributors and contained details concerning the increase of transfer requests into the school since it received an A grade.

Political implications on schooling. The final effect of the A+ Plan, which was reported through the responses I heard from the study participants, surrounded the political realm of schooling. This notion appeared to be focused around the view that accountability in schools was really just part of a passing political agenda and that every effect produced by the A+ Plan was ultimately political.

I think the A+Plan is very, is just a political gimmick to begin with. That's just my personal opinion. What is its purpose as it's stated is, I would say that competition is good among schools; people respond well to competition to try to get up to that standard. Also, to try to get the schools at a certain level, and I think that by making it so public, it kind of infuses the notion of accountability. (Jo)

The extension of vouchers was considered part of this political agenda, which participants believed removed the separation of church and state. In addition, some participants believed that the criteria for grading a school was manipulated to change the effects of the A+Plan, so much so that in the eyes of Leslie, it might eventually lead to the death knell of public education as an ultimate effect. 
Many of the reported effects of the changes made at the school site were very similar to those described as effects of the A+ Plan. At times, participants expressed the two sets of effects as one and the same. Study participants delineated school change effects from general to specific instances. These covered the areas of curriculum, time issues, impact on the teaching and learning environment, stress levels, impact on teachers, students, administrators, parents and the school community.

General school outcomes that were illustrated included receiving the "A" grade as a result of looping and the increase of math scores as a possible result of utilizing FCAT practice books. In addition, participants noted that there was an increased level of paperwork due to more required documentation of student preparation tests and consistent skills practice. It was also noted that the school's higher attendance rate was an effect of the implementation of a variety of attendance incentives meant to improve student achievement.

Participants outlined a variety of instances of school level impact, which they believed to be consequences of the transformation of the curriculum to reflect the knowledge and skills required to be successful on the FCAT and the necessity to meet the goals of the A+Plan. They noted that the grades that were tested concentrated on specific skills, and there was less general material with which to work. According to these educators, this lead to isolated skill teaching and not being able to cover what was part of the curriculum not tested. In essence, they meant teaching to the test. "A lot of things are not being covered as they should...some things are just going to take a back seat and that's one of the effects on the curriculum," stated Mar. Rouben clarified that 
subject areas not tested were covered enough to make sure a grade could be assigned on the report card. Additionally, individuals felt that due to the refocusing of the curriculum, subject matter was not being taught holistically, that the material had to be forced down students' throats when they were not ready to learn it, and that teaching has become more structured and programmed.

I think that now it's, more strict is the word, or more structured. Before, it was a little more free. We were able to do more things on our own. I remember I had all my little themes, and even though now we try to incorporate themes, themes don't incorporate in everything we need to do. We incorporate science into language arts, but that little theme that we're going to do this, it's very hard to do when you have a certain curriculum you have to teach and get it through by the end of the year. (Tracy)

Educators seem to believe that the refocusing of the curriculum had lead to a sort of morphing of the teaching and learning environment. Numerous effects on the teaching and learning environment were identified as consequences of school level changes. Effects on teaching and learning. Perceived effects on the teaching and learning environment as a consequence of school level changes were numerous. Participants reported how time, programs, creativity, and student achievement in the classroom were impacted.

Rescheduling of class periods to favor grade levels directly impacted by FCAT produced concerns about choppy days for other grade levels, scheduling conflicts, problems for special area classes, and the reduction of time to cover all necessary subject matter.

Well, I know personally it's [the scheduling] hurt our P.E. program, which really doesn't affect me, but that's something that I know that's really been a problem with the P.E. department. Then, a lot of people say that if we're going to be an A 
school, we don't have to worry about physical fitness. But, I think that maybe we need to understand that we do because there are so many problems with obese children.

As far as scheduling, my day has become a little more choppy trying to deal with the schedule...I don't have, it seems like I have an hour in the morning and then my morning is split, and I also have to accommodate the computer lab. I have small groups that go to the computer lab, and I had that working well and then they tried to get more in. Then the computer lab became overcrowded, so then I had to change the way I sent children to the computer lab and then that made my day even choppier. (Carole)

It was also conveyed that the revamping of the schedules allowed maximized class time, and that departmentalization gave a little more time to teach.

The need to use more time to address the criteria of the A+ Plan, according to educators, also affected the cutting back of school programs including field trips, modifying gifted classes' projects, and replacing student attendance in special area classes with remedial work in weak areas.

I tell you, fourth grade became like a group that I couldn't do anything with because they were overwhelmed, which to me was sad because the kids, the more pressure that is put on them, the more they need their specials and the more they need outlets of expression and creativity, and it's just an untouchable year and it's not, that it's not just me. When I've gone to museum trips, and I've booked museum trips through the museum program, it's always third and fifth. Nobody's booking fourth because they're untouchable. Nobody can get permission for them to go anywhere. Nobody can do any projects with them; they're so busy and overwhelmed in that year. (Laura)

It was felt that with this limited range of school experience along with the fun and excitement of learning and teaching had waned.

Specific reading and math programs that were implemented at the school site were viewed as having an impact on student learning, although the participants didn't agree on whether the impact was positive or negative. Atalia applauded the Accelerated Reader computer program for bringing up low readers, while Leslie believed it caused 
students to choose poor literature. Having students write to different prompts in the same structured manner had Julio and Linola believing that students were becoming better writers for the writing portion of the FCAT. On the other hand, Mar and Leslie felt that this programmed writing harmed students in the long run. Both felt that students were no longer able to be creative when they wrote.

The utilization of ability grouping at B.R.E. was perceived as leading to no academic progress among weaker students. "There's nobody there to spark any interest or motivation because they think that everybody is like this," explained Linola. Maria cited a lack of academic growth among students who were pulled out of classes for extra help. "When you have a child who's already low, who gets pulled out for that special class, when that child comes back, he's back or worse than he was at the beginning." Others also believed that the pulling of students from classes kept them from getting their needs met. In addition, it was observed that focusing on FCAT skills and impacted grade levels, while eliminating hands-on activities, weakened the foundation students needed to be academically successful.

Effects on the school community. The participants also expressed beliefs that school level changes influenced the key stakeholders at B.R.E.. Teachers, students, parents, and were perceived to be directly affected by transformations that occurred at the school. The effect most often related by participants was that of increased stress and anxiety. All teachers and administrators described this phenomenon. Although stress was seen as a major effect from school level changes, specific changes were not alluded to when stress and anxiety were being spoken about. Instead, changes were put into a generalized category. 
The only thing that I thought, of course, is that everybody is stressed out to the max. I do think maybe there were some teachers that felt the pressure, were squeezed a little bit more to do better, and maybe that's why their kids did better, but I think there could have been other ways to do that. I think the stress level is so high that it's hairy, I mean even myself. I feel very stressed...

I do think that there are other ways to implement other plans and programs where if you feel like it's something you want to do, you will work hard 'cause it's something that you want to achieve or a goal that you feel is important. Like for instance the National Board or doing your Ph.D. It's gotta be very stressful, but because it's something you want to do, you know you're going to work hard for that. Where if somebody made you do something that maybe you didn't believe or something, then to me it's like you're going to do it because you have to do it, but it's not something you would be willing to do or you don't believe in it.

So, you're doing it 'cause somebody's making you do it, but it's not, I don't think it would accomplish the same goal as if you really wanted to do it and work hard for that. (Peggy)

Nothing positive was indicated in any participant's discussion about stress and anxiety concerning any of the stakeholders.

Effects on school instructional staff. Beyond stress, other consequences surrounding the educational staff were indicated. The placement of teachers with strong reading, writing and/or math subject area knowledge in respective grade levels had triggered these educators to want to change their teaching assignment, especially if that responsibility was for fourth grade reading or writing. The preferential treatment of grade levels that counted for the school grade had given way to bad feelings and some low morale.

Perhaps what I can say about this is maybe, I mean, what I've heard from other teachers is that maybe we're not as important as those grades. So, you know we don't count. We don't really count, you know. It's just them. It's whatever, they come first. So, maybe like the morale of the grades that are not affected by the score, I think it's lower than in previous years. (Julio) 
Furthermore, the focus on the scores and grade of the school had led some to believe that the educational staff is not a priority of the school.

Teachers are not the number one priority at our particular school and at a lot of schools. Because there is so much pressure on administrators to answer to whatever, but the teachers don't have enough help and then when they did have parents coming in, you had no parents coming in to help, but then the policy became - if a parent comes into your room the only thing they are allowed to do is read with a child. Excuse me, I went to college for four years, got a degree, got a degree in reading, you know, and I'm going to go file papers while she reads with my kids? What's wrong with that picture? (Carole)

Finally, the looping of teachers with the same students for two years gave educators a feeling of not being stuck on the same grade level for an extended period of time.

Other areas of impact on educators were defined, though specific changes were not referenced. It was noted that confusion occurred as to what to teach after the testing period was completed, feelings of being hired to teach the test were experienced, less freedom to be creative was available to teachers, and that educators had been doing things because they were supposed to but their hearts weren't into it. Also, it was supposed that teachers had become overworked and less likely to use teachable moments. After FCAT, according to some individuals, creativity seemed to increase. On the positive end, some people believed that due to the changes, teachers were better prepared and utilized more effective instructional strategies.

Effects on students. The alterations at B.R.E. have affected students as well. With the increase of skills practice, teachers have seen an increase in the size and weight of the backpacks students use. The curriculum focus on testing skills that has taken place until the completion of the FCAT assessment period each year has caused students to give up on learning once the test is over. Atalia gave an example of this trend. "There was a 
fourth grader who said to his teacher after the FCAT was over, 'Do we have to learn anything anymore 'cause FCAT is over?"' In addition, educators felt that students no longer had fun or exhibited the excitement over learning that the teachers used to see. By being pulled from special area classes to work on computerized tutorials, teachers fielded students' comments about missing out on a lot as well as the teachers having their own feelings about students missing out on the basics. According to classroom teachers, the combination of this extra reinforcement for weak skilled students and the intrinsic rewards for high achieving students had managed to leave a gap for the average student.

I feel like a lot of emphasis is placed on the score and teaching to get a better score, whereas the average child, the kid that is just going to be okay is sort of forgotten about. They like their high scoring kids, and they're going to work real hard with them, and they gotta work with those low scoring kids 'cause they're going to bring everybody down, and the average kid is just kind of, "Oh well, they'll be all right." (Leslie)

On the other hand, participants felt that the intensive concentration on FCAT skills had resulted in students becoming, for the most part, excellent test takers.

Study participants cited various other influences that school site changes had made on the students, although no explicit modifications were defined. Instead, transformations were grouped in general terms. It was noted that students had become scared of the FCAT, spoke about the test all of the time, and were quite aware of both individual and school scores.

The students are going to learn what they're taught or they're not, but the difference I would say in the students is they're more aware how they do on a test, which is very important, determines their future, the grading of the school and so they're more uptight about this testing situation, and they feel more pressure. (Patti)

Leslie also recounted the effect that changes had on the students. 
They talk about the FCAT. At first, before we were an A school, like the year before, the kids were so stressed out, the teachers were so stressed out, everything was focused on we gotta get these scores up and we want to be an A. I had kids, especially in gifted because those are the brightest ones in the school, they were crying, they were upset, they had stomachaches. It was awful, I thought it was awful. I thought it was just awful what it did to them.... I can think of a couple of them that were just headaches all the time and you know really worried and stressed. I had many of them worrying am I gonna flunk? Are they going to fail me you know if I don't do well on this? These kids that are smart, that should do well, but that's just the change I saw.

Students were also reported as exhibiting defeatist attitudes. Yet, when activities and time moved away from FCAT, teachers noticed an increase in student excitement and engagement.

An administrative perspective of the principal, Patti, detailed one specific outcome of a particular school change. She expressed that she had a lot of remorse over utilizing homogeneous grouping when forming classes.

You know, I've had a lot of guilt about that because even though I heard from the teachers that the higher kids really did really well, I feel like the lower kids got the short end of the stick there. I can understand that when there are no sparks there to move them along and I would feel very badly that the remedial kids didn't get as much stimulation as they should have.

Comments by teachers and other administrators underscored this concern.

Effects on parents. Changes at school brought were reported to have brought about changes among the parents. Interviewees felt that parent understanding of what education encompassed diminished with the increase of academic focus in the lower grades, the increase of daily and weekend homework, and the intensified focus on testing skills. Furthermore, participants noticed that parents exhibited distress when being confronted with their child's stress. Consuela explained her perspective.

I think parents, what I noticed, are more aggressive, and I think it's because they're experiencing this at home. These kids are going there with all these 
FCAT workbooks, and the parents cannot explain to them how to do it. I've had parents over and over every year come and say, "If I come after school can you teach me how to do it?" I think we've all been there. And so I think they're stressed out because what the kids are having to do, they have no idea how to do it themselves... and so they're becoming more aggressive we sense this year.

They're involved, but not involved in a good way. We're not seeing them involved; I think they're panicking. We see parents like of the gifted students, which like I think are panicking because of the kids. We've had kids crying, you know, during the testing, and then the parents very concerned over their child's going to be evaluated based on the, and they're just all very worried about how their kid is going to perform. Will they be up to, you know, par based on this new testing? Or if the kid cannot comprehend well, they're very scared about that.

It was felt, as a positive result, parents were taking education a little more seriously.

More conferences appeared to be arranged with parents, students, teachers, and administrators in order to manage the increasing fears of the parents.

Positive versus negative effects. Most of the effects described by participants were expressed in broad terms, usually with no significant indication as to whether the impact was perceived as positive or negative. Yet, there were certain statements about the effects of the A+Plan and school level changes that contained strong emotional implications as to the constructive or harmful nature of what was implemented.

With the implementation of the A+ Plan, interviewees expressed the conviction that the money the state provided for remedial students was a plus. They believed that the administration of the FCAT and the resulting scores gave educators another way to check a child's progress from year to year. The increase of the school's grade has been viewed by some as an impetus for improved self-esteem at the school. It was also noted that the most positive effect of the FCAT was that it was making teachers teach differently. "That's a positive effect because it's making us realize that we're not going to just have kids regurgitating information; that they've got to be able to figure stuff out" 
(Patti). In addition, it was viewed as a positive idea that the $\mathrm{A}+\mathrm{Plan}$ expected the schools to look at remedial students and work with parents to plan help for those students. There was a sense of appreciation that parents were now expected to work with their children.

Reported positive outcomes of school site changes included students' new understanding of how to explain the derivation of their answers to problems. According to Rouben, "When I went to school you just basically gave the answer and that's it. Now the positive I see from this test is basically we want to take it beyond and explain to us how you got the answer." This was seen as a direct effect of the change of instructional strategies and the teaching of higher order thinking skills. The shift in instructional strategies was also considered to have benefited reading comprehension. Looping with students for two years was perceived to have produced a positive outcome for both teachers and students as each know the other's expectations and characteristics and time was not wasted the second year relearning these attributes. Finally, the opinion was that students were learning more and intervention strategies for those students who exhibited weaknesses were begun earlier.

The number of negative effects reported overshadowed the number of positive ones. Participants articulated that most of the destructive impact came from the A+Plan and administration of the FCAT as compared to the effects of school level modifications. Leslie exclaimed, “ The kids were so stressed out, the teachers were so stressed out, everything was focused on the fact that we have to get these scores up and want to be an A!" Linola stated, "I think there is a lot of unhappiness. I just think the whole thing is just bad for the school." These influences were experienced by students, parents, and 
teachers and included frustration, ambivalence, negative procedural changes and alterations of curriculum.

Study participants explained that the state reform has discouraged teachers and pushed them to want to leave the profession as well as discourage others from joining teacher ranks. The focus on grades directly affected by the testing made some feel as though they were being left out. Julio said, "We don't have the same feeling as before of being part of the whole school and saying they count too, you know. Maybe they don't feel as important or part of the whole school." Morale seems to have been negatively influenced.

Participants believed that all stakeholders have become frustrated. It was cited by several interviewees that when the school was rated a C, parents looked to transfer some children to an A school. As explained by Rouben, "People outside the teaching community, they see that grade, and they base everything on that grade. They don't know how good that school is even if it is a C school." Patti also addressed this issue and stated,

The negative is the fact that we're getting a grade for statistics that are not necessarily valid or significant is very disturbing. The public is seeing or perceiving that schools aren't effective based on the letter grade that is not based on anything statistically significant. That's very disturbing.

Perceptions of test bias, pitting schools against schools and teachers against teachers, and negativity about public schools from the results compiled according to the requirements of the A+ Plan has "deflated the teachers' joy in teaching" (Carole) and promoted negative feelings among other teachers. 
Interviewees believed that in a lot of ways the A+ Plan and school changes produced suspicion changes were effective. Some felt that pullout programs had no effect on achievement, but gave some students extra free time. In general, though, they considered that change, whether positive or negative, is just change, and that with change comes more change. They seemed to have accepted this as reality.

Perceptions of state intended versus unintended effects. As with the expression of negative and positive effects, participants indicated their feelings on which effects they believed were intended to occur and which ones were not anticipated by state education policymakers. Educators thought that the pressure of the A+ Plan was supposed to lead to an improved level of teaching, see more schools improve academically as indicated by their grades, and improve the problem solving and reading skills of students, all of which they said had taken place at B.R.E. The effects on the school that the interviewees sensed were not intended included many students still achieving at low levels even after intense remediation and the continued exhibition of frustration and anger on the part of educators. They felt that the state expected every student on the same grade level to achieve the same standards at the same time.

Getting used to the system and criteria changes. One specific theme that emerged from the responses of the study participants in relationship to the effects of the A+ Plan and school site changes was that as time went on those affected became familiar with the changed curriculum. Additionally, statements alluded to the fact that educators became accustomed to the school grading system and were aware that the FCAT format and school grading requirements were forever in a state of relative instability. Educators believed that it might have been the effects of the changes at the school that lead to a 
higher accountability grade for the school. It could have been the greater level of comfort gained with using a curriculum for three years. Additionally, it was sensed that knowing the keys to the school grading system and understanding the format of the test automatically lead to improvement. Patti verbalized, "Once we're used to the test and teachers become more comfortable with the way questions are asked and with the teaching that they need to do to prepare the kids, it's bound to improve." Rouben also expressed a similar idea.

I think it took two years or so for the students to get accustomed to the test, number one. The same thing for the teachers, to get accustomed to the new system, cause I think the teachers are doing what they're usually doing. I think it's, just again, it was a change that they had to go to get accustomed to.

Experience with the reform, participants believed, seemed to effect the overall school outcome.

In contrast to comfort and familiarity with the expectations of the A+Plan and FCAT, interviewees expressed their awareness of the fact that the criteria has changed and is anticipated to change even further. They believe that this understanding also has had an impact. "What I know about it [the A+ Plan], uh, it changes. I don't have expectations from year to year, 'cause if I did, I'd go crazy, “ chuckled Rochelle sarcastically. Other participants considered similar ideas and felt there the changes and outcomes would need to be revisited.

In the case of the A+ Plan, changes at the school, district, and state levels may be regarded as the effects of the implementation of the grading of schools and directly related to the administration of the FCAT. Along with the variety of changes that were made at B.R.E., participants felt that the effects on the teaching and learning environment 
seemed to be specifically from the direct impact of the FCAT and the role it played. As explained by Jo,

Well, I think that they're (effects on the school), as an effect of the FCAT, but I think no mater what school the students would be in Florida, they would be affected the same way because what we've done at the school is just a reaction to the FCAT. So, it is a direct effect of the FCAT.

The effect of the change in the state's school reform has been change at the school site.

Significant and Long-lasting Transformation

The reported effects of the A+ Plan and school level changes correlate to the elements of Lieberman and Miller's five building blocks for effective and long-lasting change. Participants alluded to how time, programs, creativity, and student achievement were impacted. Many individuals spoke about favored grade levels, scheduling conflicts, and the reduction of time necessary to cover all necessary subject matter. These concerns are in direct opposition to the building blocks of promoting quality and equity and with that of a professionally supportive environment for teachers a rich learning environment for students. Other reported effects of the impact upon parents and the outside community relate to those connections outside of the school.

Many of the concerns and issues brought to light by the study participants reflect the statements of Lieberman and Miller dealing with the need to maintain balance between the content and process of change, the needs of students and teachers, and the impact of pressure and support and accountability and responsibility. The effects of the improvement in the level of teaching, the raising of standards and the higher level of expectations of students address the area of balance between focus on teachers and students. Equity and quality are referred to in statements covering the pulling out of low 
children from class and the fact that they fall even further behind when missing regular classroom instruction. Issues reflecting the balance between the change process and content are delineated in the declarations regarding the utilization and lack of time and the change in curriculum. It is the interaction between these various changes and effects that define possible long-lasting and meaningful change at the school site.

\section{Significant and Long-term Change}

When responding to questions about the changes due to the $\mathrm{A}+$ Plan and the effects that the plan and the changes had on the school, study participants spoke of changes and effects that they felt would more globally define success and be considered as significant and long lasting. Responses that defined important and lasting change fell into four clusters which included (a) characteristics of a successful school, (b) effective changes for all types of school reform, (c) the assignment of school grades versus real success in teaching and learning, and (d) other issues that were perceived as being vital for a successful teaching and learning environment.

\section{Characteristics of a Successful School}

The identification of the qualities that define a successful school was alluded to many times during interviews with participants. The ten areas that developed as encompassing these attributes included the need for respect and a safe environment, a positive approach to teaching rather than a lack of enthusiasm, staff cohesiveness rather than isolation, a focus on a total school curriculum instead of a concentration on curriculum for specific grade levels, a positive supportive administration rather than one that is inflexible, the preparation of students for real life, staff development as opposed to a lack of knowledge, high expectations for all, increased parent and community 
involvement, and continued assessment of changes that have been implemented with an adjustment if necessary.

The evidence of respect was repeated many times as an indication of a successful school. This respect was expected across the board and was viewed by some to be part of B.R.E.'s success. Rochelle reported that she had seen students being respectful of each other and staff members getting along well. One part of respect was the valuing of the opinions of teachers by educational policymakers along with complimenting their work and treating them as professionals. Peggy explained, "Let me start with fair. I guess where all the staff is treated professionally, equally professionally, and that professional meaning not only treated professional, but also where their input is important." Barry also addressed this area. "You [administrators and educational decision makers] should encourage them (the teachers) more...just a good word, you're doing a good job is worth a lot to anyone." Another facet of respect was expanded upon by Carla "Our biggest aim is to educate the individual and make the child believe in themselves and most importantly make the parent believe in our schools. And unless you do this on an individual basis, we're not going to go any place." Thus, respect of all stakeholders was deemed an ingredient for success.

A positive approach to education rather than a lack of enthusiasm was indicated as another component of ensuring long lasting positive change. It was expressed that putting all into what teachers do, using the idea of meeting the needs of children, and maintaining high morale and a positive outlook were key to achievement. Rochelle articulated, "I think they should let teachers make teaching enjoyable, make children enjoy coming. I'm positive. Being negative is not going to help. I can't fight the 
system." Barry believed that you had to look at a school and see if there was a core of teachers that enjoyed what they were doing. He also maintained that these teachers have shown a lot of enthusiasm for what they're doing and have been able to pass that on to students and parents. Laura's comment followed that line of thought. She said, "I'm more impressed if I go into a classroom, and I see the teacher enthusiastic and the kids enthusiastic and learning is taking place. You can see by the interaction." The importance of a positive outlook was also expressed by Gigi. as she explained what had been taking place at B.R.E..

I think that a certain group of teachers really did care, and really did try to put wholeheartedly everything that they could into it. I think that the teachers have taken a serious view of it. They may not agree with it, but have done the very best that they could possibly do with the circumstance and everything, but that they have tried to follow the program and tried to make it work, even against all odds. I do think that the teachers have bent over backwards for it.

In summary, Carole remarked, "We always want to be moving upward. We always want to be improving." This was the essence of carrying forward a positive approach.

Another earmark of school success was defined as the cohesiveness of the group with the ability of working together. Carole's statement expressed this sentiment.

We're all in this together, and these are our goals, and this is where we're going. And I'm going to help you, and I'm going to do this for you, and I'm going to let you know how we're going on' you have to. You have to let people know that they're part of it and that what they are doing is very, very important.

Participants believed that this togetherness facilitates cooperative and collaborative planning and improves the skills of beginning teachers. Consuela asserted this idea in the following way:

I saw the importance of how working as a group, regardless of whether you like the person or not, but I mean working as a group there's so many resources and things you bring into it; what you think of that maybe someone else doesn't, or 
what they have you might not. And I think that it was just a wealth of information whenever we got together as a grade level, and I think it was good for the children because they were all on the same page, per se. We were all doing the same thing.

Collaboration and cooperation were also cited as aiding in making a large school seem smaller, facilitating communication among all stakeholders, and producing a feeling of buy in to what ever change has been implemented. Carole explained it in this way:

Teamwork. People working together. First the teachers buying into making the year a success with a strong leader who they know that they'll get support from. And then bringing the kids into the team. Once the teachers know what their goal is and that they're going to do it as a team, then making the children feel like they're part of the team. And going from there.

Participants agreed that if all of those who have a vested interest in the education of the children at a school do not work as a team, there will be no way to be successful.

The fourth component of a successful school was connected directly to a total school curriculum focus as opposed to a focus on curriculum that dealt with testing issues at specified grade levels. By concentrating on curriculum that pinpointed test covered skills in specific grade levels, interviewees felt that students received a narrow education, and children not directly affected by the FCAT were losing out on some skills altogether. Laura concluded, "We ought to do what we feel betters education because trying to hit the target of the test is like a crapshoot." Atalia pointed out:

These kids are getting, I keep saying this, a very narrow education. They're not getting a broad education, especially in elementary school where they need to be exposed to so much. There's so much to teach them in the six years that they're here.

Instead of narrowing the educational program and giving attention to a few grade levels, participants deemed the best way to ensure achievement to be concentrating on all grades and provide a solid foundation from the beginning. Laura promoted a vertical curriculum 
that included a focus on vocabulary integration across grade levels. Carole insisted that more school-wide activities built into the total curriculum would increase learning. Most were adamant that all grades, starting at the beginning, should be concentrated upon and the total curriculum needed to be examined.

A positive and supportive administration was viewed as a key factor in building a successful school. Most participants believed that success began with school leadership starting with the principal. What defined an administration as constructive and supportive were traits such as "leaders as well as listeners, and not only caring about the educational process that's going on and new and innovative ways to improve it, but also the people within the building as well," described by Carla. A strong administration was also depicted as one who had open lines of communication, was organized, was consistently visible, and instilled confidence and self worth in staff members by validating decisions that were made.

The preparation of students for real life and the concentration on the total child were two more indicators of school success according the responses of participants. "The child is what's important. And not just scores, that's only just part of the child. It's just one part of the whole," emphasized Leslie. Each student's individual progress and the evidence of growth were stressed. Clarification was given that each child learned differently and an appropriate response must be given according to this piece of information. In addition, a comparison was made between what goes on at school and in life. Consuela claimed, "Life is all about a test, we know that. Life is one test after another...So how do you monitor? By just listening to them, hearing them, that 
knowledge they have up here that they've acquired." Preparation for more than just a test seemed to be an area of importance.

Building a knowledge base for educators was an important element for achievement. A variety of workshops that improved content knowledge and pedagogy were viewed as crucial. If educators did not avail themselves of staff development opportunities, the consensus was that individuals would become lost and ineffective and that would impact students learning. Attending these workshops also kept people from becoming stagnant. Jo acknowledged that training was crucial. "I think the teacher training; I think beyond anything else, no matter what materials you buy or what extra things you do, it all comes down to that teacher in the classroom." Teacher training equaled success.

High expectations for all stakeholders were another part of the reported key elements of school accomplishment. Interviewees believed that these elevated standards were not only for students, but also for all individuals who played a major role in the teaching and learning environment. The following statement reflected this idea.

I think a successful school is always about promoting excellence, about going above and beyond. And that goes from the top down, including the students. I think you need to make sure that there's an atmosphere of high expectations that all children can learn, and all people are important to the process. (Atalia)

Elevated levels of professionalism, goals, and improvement were also indicated as part of what was expected. "I think you should always strive to be better. I think you should always look at what you did last year and say 'can't we do better?"' stated Carole. It was about making good things even better. 
Continued and enhanced parent and community involvement in the teaching and learning environment were also noted to be part of a successful school setting. Gigi indicated that studies have shown that student strength was directly related to the parental relationship and involvement in the school, since if parents were not involved; they were lacking the knowledge of how they can support their child in school. Many participants felt that unfortunately, parental involvement is not what it should be and at times, when there have meetings, parent nights, or conferences, the attendance was disappointing. This concern did not seem to be the primary focus, though. Basically, the need for additional workshops for parents to help with parenting skills and how to assist children were suggested. The needs of the community and the students have been considered when adult education for parents was offered and when these individuals were invited into the school. Peggy related the following:

I know that in my experience, all the years that I've taught, whenever I have students that the parents are involved, they always do better... We tend to, as teachers, get an attitude where we always feel that the parents, they're over there and we're over here, and the classroom belongs to us... We kind of put up a wall, I think, sometimes and make the parents feel like they're outsiders...Y You know the parents, a lot of them are willing to help, even the ones that don't, that don't have as much time cause they work.

Sustained education and involvement of the school community were seen as imperative.

The last theme that I understood to be considered by the participants as necessary for success was the consistent monitoring and assessment of the other success characteristics that were previously identified. It was related that student learning should be continuously monitored along with where the year started and ended and what growth was realized. Shifts in curriculum, programs and other types of changed were specified as needing continual assessment. Maria believed, "I think with any type of change, you 
have to see the measurements of it. So, it doesn't hurt for maybe the staff and the administration to come together to see what has worked and what needs improvement." Assessment of success was considered necessary to be successful.

Many characteristics of a successful teaching and learning environment were touched upon. Gigi concluded:

A successful school is one that has a structural core that provides for every level to be consistent and to have a pattern of growth where you're not totally overlapping but not missing gaps in between. So it has to be one where the curriculum, number one is understood by the teachers, followed through, that there is some type of accountability as to how the teacher has to execute it, and at the same time have leeway for special circumstances that come up during the course of the curriculum. There has to be, I wouldn't say rigid, but a strong power at the top, and even though a lot of things have to be delegated on to others, there should always be some type of central control to know that everything is happening in all areas; whether it's in the curriculum, whether it's in office staff, custodial, every area of the school.

Because what happens is that when things do not mesh in each area, something falls through, and I believe that the person in charge needs to have knowledge of everything that's happening. It has to have feedback, and not through a process of snitching or you know what I mean, but have some type of, through surveys, through meetings, through questions, whatever, for that person to know that everything is happening the way it should be happening and not just lose focus on a lot of things that go on in the school and not be aware of those things.

Interviewees determined success to be an integration of many features.

The characteristics of a successful school, interpreted by study participants, reflected many of the traits of high quality sites as delineated by Lieberman and Miller. Some of these include teacher collaboration, the impact of leadership at the school site, parent involvement, the opportunity for multiple forms of staff development, and the valuing of the input of all stakeholders. 
In conjunction with the identified successful school characteristics, a set of general and school site changes were portrayed by study participants as being effective for all types of school reform initiatives. Some of them were applicable to alterations that could be made at the state, local, and school level, while others were specifically geared toward one or the other.

Participants considered three ideas necessary for effective change. The first was that the entire focus of education should be on the individual child and his or her progress. Second, each school should be viewed as an individual entity instead of constantly comparing one against another. Third, educators believed that lowering class size and possibly adding another grade level in between kindergarten and first grade were issues that needed attention. When addressing the subject of focusing upon the individual child, it was stated that it was important to look at a trend of improvement, not just the score on one test. "You want to see a trend, you don't want to necessarily see that they reached a certain level; I think you need to see a trend of improvement. I wouldn't want to say, 'You have to be at this level,' because not all schools are created equally and not all kids are created equally," related Atalia. To look at where children started at the beginning of the year and ended each consecutive year was considered to be a valuable change at the state level.

Another indicated useful general change was that state officials, in order to indicate school success, should visit school sites and as Barry pointed out "get a feel of the place to know that these people enjoy working with young adults; these people enjoy 
working with other teachers. And that's something you can't do on a test." Lisa

communicated a similar viewpoint.

Come in, come in and see. The need to come in and visit, come in and observe some classrooms and observe and look at some students' work from when school started up until maybe the middle of the year, and then maybe at the end. Let's compare, compare and contrast the kids' work. Sample the children's work and come in and observe teachers.

This belief stemmed from Lisa's and others' ideas that success encompasses what the teacher does in the classroom and that cannot necessarily be ascertained from test scores. In addition, teachers and administrators spoke about accountability, saying it should be considered more at a local level and that school and student demographics should be analyzed.

I think it should be more of a local thing...Y You've got people of different backgrounds up there and they can't really relate to what's down here. It's a totally different situation. To group all of the counties together and compare them, you really can't do that. It's unfair. (Chris)

Essentially, an individualized approach to each child's and school's success was a change that participants felt needed to be introduced.

At the school level, effective changes that were relevant for all types of school reform were categorized by participants as those that were already in place and those which needed to be implemented. In some instances the changes had been initiated, but it was felt that more needed to be done in those specific areas.

The intensive interventions in math and reading were considered to be transformations that were essential to any type of reform for achievement. Increasing the emphasis on writing skills also was viewed as a positive in any scenario, and the importance that was stressed by teachers of these subjects being practiced at home was 
also related as positive. Also, continued school level staff development was indicated as imperative during any type of transformation. Leslie explained that in any situation, "I think that if you want to have a more successful school, I think you've got to train your people." It was explained that this has taken place at B.R.E..

Another necessary school level adjustment that was highlighted as constructive for any type of achievement improvement were the expectations of parents shouldering part of the responsibility for their child's learning and the ensuring of cooperative planning among teachers. These concepts were reported as evident as the school, but at the same time it was felt that more need to be done in this area. Leslie explained:

Parents are expected to work with their kids...I mean, that's just what education should be all about. It is not just the teacher sitting there during the day working with the child, but it should continue on and parents need to do that too.

Tracy believed that in order to get the parents more involved they may need to be educated more. Maria declared:

If you're in a community where you have a big E.S.O.L. [English for Speakers of Other Languages] population, they are afraid to come to school, they don't speak the language; they don't have the money to pay for many things. So, if you make them feel that the school is giving the parent something, they will become greatly involved with it.

It seemed that participants believed that the more parental involvement and school acceptance of this involvement at the school level, the more positive an experience the reform might be.

A final issue that was identified as being a critical component of any successful attempt at reform was the concentration of delivering a concrete foundation to students in the primary grades before trying to inundate them with sophisticated advanced critical 
thinking. This meant introducing concrete skills to students before higher order thinking questions were asked. Atalia explained:

I have another issue about these higher level thinking skills with very young kids, and they don't get the basics. I don't care if they can think like Einstein, if they can't read, what difference does it make. I think in the primary grades, I would throw out all the higher level thinking stuff and make it reading and math, reading, writing, and math, reading, writing, and math. And you know, throw in science and social studies.

This adjustment was not just geared to B.R.E., but was considered a must for all schools. Assignment of a School Grade Versus Real Indicators of Success

According to the accounts given by study participants, it seemed as though the underlying theme was that the scores on a single test cannot be used to determine the overall success of a school. They insisted that many different elements must be taken in to consideration when determining whether or not a school has met its responsibility in educating children. Some factors that were spoken about included looking at the overall curriculum and monitoring success in what children were learning. Also addressed were the issues of understanding each school as an individual entity, determining the level of satisfaction of key stakeholders, examining the population of children being educated at the school site, and looking at the accomplishments of an entire school year.

In addressing the monitoring of student achievement throughout the year, Rouben stated:

I definitely think to see each student's progress is the best indicator. Whatever level they're on at the beginning of the school year until the end of the school year is the best way to indicate whether they've done well or not.

A general standardized test, a norm referenced test to compare them to the rest of the state or the rest of the country to me, personally, I don't believe in it. Because, if you're seeing progress in them, no matter what level they're at, that's 
a successful student and they've had a successful year. So, the most important thing I believe that officials should look at is whether each student has progressed.

Others made similar statements concerning individual growth. "I think it's more important to see the growth of the individual and be able to grade [the school] based on that rather than just on the whole grade level," affirmed Gigi. Considering each student's progress seemed to be considered the best indicator of accomplishment.

Understanding each school as its own entity and examining the population attending the school were also earmarked as benchmarks to be used in determining accountability. Carole claimed, "I think you have to understand that different children learn different ways and different children bring different things to school, and somehow they have to take that into account when they're grading a school." Mar believed, "This child improved from one year to the next. That would be more of a fair way of grading somebody, but not necessarily as a school in total because you have to look at so many variables." Gigi summarized these feelings in her reaction.

If you're going to grade the school, you have to look at what the school has, what is the school composed of, and what programs are available for those students that have the need. Because if its students do not qualify for the very few programs that we have, and they are in a classroom getting instruction at a level that they don't understand, that is not fair to them. And, it's not fair to the school to be graded based on what the child is performing because he is not labeled anything else; therefore he is a regular student. And yet, that child needs different instruction in order to succeed. So, the school can't succeed in that manner. And the schools are graded and one year it's okay and the next year it's not. It's like saying you didn't do your job, and that may not be it.

It was considered that different schools serviced different populations and testing did not take that into consideration.

Participants felt that "a successful school isn't just a school that is an A school" (Barry). Jo emphasized, "I think that school success has to do with student satisfaction, 
parent satisfaction, which comes from many factors, and teacher satisfaction." Patti

defined a successful school in this way:

I would definitely say a combination of test scores, grading, teacher input, and I would have more than one assessment, not just the FCAT, not norm-referenced, but a combination of assessment. And I just don't think that you can be objective about children. When you're dealing with children, there's just so much objective [information] you can use, and I think that the teacher input is very important.

It was expressed numerous times that success was more than a test score.

Positive achievement in the teaching and learning environment was described to be much more intensive than just formulating a school grade that was primarily configured on one set of scores from a specific test. Consuela expressed her beliefs in this manner:

Right now, basically, I think we're being successful is if you're an A+; successful is how well you did on those tests, and it is not, that is not the case. We're seeing that here. We're seeing that an A+ school, that the children, it's not anything to be proud of what we're seeing in the children. There's no retention whatsoever. We're cramming, so I do not, I don't consider that successful.

Whereas the Miami-Dade County Public Schools, for the Florida Governor would consider that we're a very successful school, I don't believe we are. I believe we were much more successful before, regardless of the grade we had. The kids were learning more, the teachers were actually teaching more, and that is a successful school.

Political agendas seemed to be viewed by most of the participants as the keys to what defined school success.

\section{Other Issues of Perceived Importance}

The role of political perspectives on education and accountability was a common thread found in the final statements of the study participants. One perspective came from the principal: 
The A+ Plan, okay, let me take the A+ Plan and the grading cause that's pretty much in one area. That's the political side; that's the side where you know, that's where if we show improvement, that's looking good for the people in power. And if we don't, they continue the push about how we're not doing our job. The FCAT is an accountability measure and I don't think that's going to go away. And, I don't think that's necessarily a bad thing. It's what's done with [test scores] that is what I have a problem with, and what's done with that is what the $\mathrm{A}+$ Plan is all about.

What I have to say about it is nothing that you haven't heard before, which is that it is arbitrary, it's not fair, there are components of it that don't make any sense, that you don't compare apples and oranges, the criteria have no business in that, in the A+ Plan. I think it's a total political agenda, and I don't think politics has any place in education. (Patti)

The impression of the role of politics and other related issues constituted the final impressions of constructive and long-lasting change as perceived by study participants.

In defining success in terms of the A+Plan, interviewees believed that politicians do not understand what educators do, and the A+ Plan and administration of the FCAT have more to do with a political agenda and less to do with real achievement.

I think the whole purpose of grading the school is a way to have numbers, a way to have numbers that you can then point and say, this school is not making the numbers and have some kind of numbers that you can point to. I really don't think the emphasis of FCAT is to measure how much kids are learning, and I don't think it has much to do with education. I think it has everything to do with numbers needed by politicians, and so they can say there are so many numbers.

I think that any time you have numbers and statistics, you can play with numbers, and so truly it isn't a, to me it's not a fair way of putting, of measurement of the kids. Plus what I really see it as is numbers; it's numbers you can point to. Does it show if kids are really learning? No, I don't think it does because you can always play with numbers. You can always play with statistics. And, I also think it only measure a very limited scope of intelligence and knowledge in the kids. So again, to me it's not real. It's not a real account, and it needs to be other ways. If you need measurement, then it needs to be other ways of measuring kids and assessing kids. (Laura)

Comparable comments came from others. Barry related his conviction. 
You know, I'm usually a very cool and even mannered person, but when you talk to me about FCAT and grading schools A through F, that really gets me going... Why they ever instituted the FCAT plan, it must be political? Why would you start a program where you already know which schools will be labeled $\mathrm{F}$ or $D$ ? And then insult those neighborhoods and communities and have them working against you; I don't know why... So why they would even have a program where you would label someone an F, it's not good public relations; it's not a surprise.

In continuing with this theme, Tracy said:

I think that basically all those things that are there are a bunch of politicians trying to label or trying to prove that which school is better, which system is better. I don't know if it's for their egos or if it's for bureaucracy or for whatever the case. I think it's important that we do have some justification on the things that we do. I just think that it's becoming abundant, and I think that is reliable for the kids' education, and I think that we're being put against the wall that everything is accountability. We have some very good teachers, and we have some very good students, and we have some very good parents, but sometimes it just doesn't work out, and I don't think it's fair for everybody to always be putting such an accountability [angle on] every moment of the day every time of the day.

A final thought on the issue on the idea of political agenda versus success came from Leslie.

Well, I believe in public education. My parents were teachers and in the school system. I'm a product of the public school system. My husband is also a product of the public school system, and his parents were teachers in the schools. I feel like this grading thing of schools is a very Bush driven, and it's very political, and people that don't know are attracted to that. It's real easy for the politicians to come up with this rhetoric that, "Oh we've gotta improve the schools, these lousy schools," and parents they say, "Hey that sounds good." What should they say, "Oh our schools are great; we don't need to do a thing." Well, that's not true either, but I just think that this is just an easy thing for them to say to get elected. That's how I feel about the whole grading thing. I think it's a stupid thing; it could very well be the death knell of public education.

Individuals questioned whether there really was an accurate measurement of success within the political structure of the A+Plan.

Following along the lines of political motives creating and refining the A+Plan, interviewees brought up concerns about maintaining what was defined as success and the 
continual shift in criteria for school grades from year to year. Trepidation evolved from not knowing how the criteria would change and how the public would react if the grade of the school fell.

Moving away from the political side of accountability, participants indicated that school success was in some part directly related to the overcrowded situations in many classrooms. They felt that especially in the lower grades, achievement might escape due to the fact that overcrowded classes do not allow for the individual attention many students need to obtain a strong foundation for learning.

Finally, educators believed that success was best determined by those who had a large investment and interest in the school teaching and learning environment, and that their expertise should be valued.

I personally believe that teachers are the biggest impact on kids' education. So, I would look at the teachers. I would look at teachers that care, that feel empowered, that are continuing on their professional growth, that are good communicators and are happy... So, if you want to help kids and you want to help education, then you have to empower teachers and help teachers, and listen to teachers and look at teachers and reward teachers. You know, I would say put the responsibility on teachers, but then give the teachers authority, compensate teachers, don't blame, don't necessarily just point your finger at teachers, but really empower teachers, and that's the way education is going to happen. And to me, that's the biggest indicator. (Consuela)

Participants believed that teachers have the experience to determine success in the teaching and learning environment. Gigi's remarks summarized this sentiment.

I don't know who is making these decisions. I don't know if they are educators that are coming up with all of this, but I think that teachers that are involved need to have a voice in this because they have first hand knowledge in what works and what doesn't.

For these teachers and administrators it appeared as if the educators' voices were key in determining a significant and lasting thriving teaching and learning environment. 


\section{Summary of Results}

The interpretation of the flow of change and the effects from the implementation of the A+ Plan and FCAT testing for school accountability were developed through the themes that evolved from the analysis of the comments of study participants. Since the schools have become graded, participants statements concerning the A+Plan seem to have fallen into two major categories of outcomes. These are general changes and school level changes. These modifications, along with the A+ Plan itself have produced a variety of effects. Some participants viewed a few of these alterations as positive including looping students with the same teacher for two years, increased parent informational workshops on the FCAT, and the school's provision of additional tutoring to those students who were weak in certain skills areas. Participants also perceived a variety of the changes as negative including pulling students out of special area classes, redirecting staff to FCAT affected grade levels only, and the persistent increase in the levels of stress and anxiety. In addition, some changes were interpreted as intended by the state such as an increased focus on test related skills. Others, such as the omission of certain subject areas not covered on the test were interpreted as not meant to be outcomes of the school accountability system.

Many of the concerns and statements expressed by the educators participating in this study reflected what was described as the building blocks for transforming teaching and learning, what works in transforming schools, and what is seen by Lieberman and Miller, through their research, as fundamental for school improvement and subsequently defines what constitutes effective and long-lasting change. 
Study participants outlined what they felt were the characteristics of successful schools. These included perspectives on curriculum, instructional strategies, parental and community involvement, and many other areas affecting the teaching and learning environment. They felt that the most important characteristic was that students were showing academic growth, which was not necessarily indicated by scores on a standardized test. Participants also identified needed themes of change to make Blue Ribbon Elementary truly successful. 


\section{CHAPTER V}

\section{FINDINGS, CONCLUSIONS, RECOMMENDATIONS AND IMPLICATIONS}

The purpose of this study was to ascertain educators' perceived changes in the overall teaching and learning environment that were instituted at Blue Ribbon Elementary School in response to the implementation of Florida's A+ Plan high stakes accountability system. Furthermore, it was the intent of this study to discover what they perceived was the impact these changes had on the teaching and learning environment at the school. In addition, a goal of the study was to appreciate the viewpoint and response of school educators and administrators to the A+ Plan accountability measures and the changes in teaching and learning that have occurred, and discover whether "making the grade" rather than achieving meaningful and enduring changes (Lieberman \& Miller, 1999) had become the overall quest of the school. Significant and lasting changes are brought about through rethinking curriculum and instruction to improve quality and promote equality, and rethinking the structure of the school. Also, effective changes involve adopting a focus dealing with teachers and students, making connections outside of the school, and encouraging increased attention by parents and the community.

Twenty-one educators, including 17 teachers and four administrators were interviewed. Interviewees' statements were coded and grouped according to their similarities. An analysis of these groups led to the emergence of the four main categories described in the results.

\section{Findings}

Through the statements garnered from study participants during their interviews, the discoveries made on the perceived impact of the A+Plan are best understood when 
grouped into three distinct categories. The first category is comprised of the identified changes that have taken place since the inception of Florida's high-stakes accountability system. This grouping is further characterized by three sub-categories including general change, school site change, and consistency in the school teaching and learning environment beginning prior to the employment of school grades through the present. Table 2 displays this information. The data is organized according to the frequency of statements given by participants. Interviewees' comments that occurred at the highest rate appear at the beginning of each list and those with the lowest number of statements are indicated at the bottom of the table.

Many of the identified areas of change were reported by different people under all three subsections, which indicated that there was a perceptual difference among participants as to whether or not certain aspects of the teaching and learning environment had (a) stayed the same, (b) had been a general alteration of the A+ Plan, or (c) had been a specific modification at Blue Ribbon Elementary. In the cases where there were conflicting opinions as to whether change was evident or continuity was apparent, and there were very few, the points of discrepancy usually had to do with the focus on obtaining an A grade for accountability purposes. An example of this was where participants indicated that B.R.E. has continued its tradition of high expectations and academic achievement, but at the same time has focused this goal toward high scores on the FCAT.

Study participants expressed their views as to the value of the changes that took place due to the implementation of the A+ Plan. The majority of the comments 
Unchanged in Teaching

General Change*

School-site change* and Learning

Environment*

- Learning in spite of physical plant limitations and plant size

- Care and concern

- Instructional needs met

- Administrative support

- Respect and civility

- Camaraderie

- Parental and community Involvement

- Making a good situation better
- More 1-1 Instruction

- Students must grow up faster

- Revised teacher assessment system

- Teacher-proof instructional strategies

- Shift in workshop delivery and content

- Emphasis on testing

- Instructional blocks of time

- Problem-oriented mathematics

- Textbook adoption focusing on FCAT

- Tighter control of funds

- Other changes
- Time management

- Curriculum

- Administrative

- Grade level configurations

- Teaching style

- Parent involvement

- Staff assignments

- Student needs

- Resource allocation

- Staff development content and delivery

- Other changes

*Items in each list are in descending order of frequency in interviewees' comments. 
pertaining to the infusion of programs to help students strengthen their skills in reading and mathematics, including the provision of extra one-on-one and small group tutoring, were regarded as positive changes. Pulling students from special area classes, utilizing paraprofessionals and certain instructional personnel for duties that did not enhance the teaching and learning environment for all grade levels, altering curriculum to "teach to the test," and using funds to primarily purchase FCAT enhancement materials were seen as points of negativity.

As described by study participants, after the changes were initiated, the second area of impact related to the implementation of the Florida high-stakes accountability system was the effects of the A+ Plan itself, along with the effects of the general and school site changes that accompanied the plan. Many of the interviewees conveyed their impressions of what effects were noticed as a function of the changes made at the school site. They spoke about what had taken place due to the emphasis by the state on the need for accountability via the A+Plan and the results of the FCAT. The comprehended impact included alterations in the curriculum, overall school atmosphere, time utilization, delivery and content of staff development, and the classroom teaching and learning environment; similar ideas that were stated as changes due to the implementation of the A+ Plan. In addition, participants described the influences that were made on staff, students, parents, and the school community in which increased levels of stress seemed to be the main point of focus.

The interviewees spoke about the influences that the A+Plan and the related changes have had on the teaching and learning environment in both positive and negative terms. Participants felt that the most positive effects were seen in the areas of teachers 
rising to the occasion of exhibiting their best efforts and the alignment of educators when it came to focusing upon the same skills in the classroom. However, participants believed that a good portion of the consequences were destructive, especially in the areas of curriculum where they believed to be a lack of a broad knowledge base being covered and in the increased anxiety and stress exhibited by students and educators.

Significant and long-tem change was the final category that emerged as part of the understood impact of the implementation of the A+ Plan. Characteristics of a successful school and their relationships with high-stakes accountability, whether they were in evidence at B.R.E. or not, were components of this category. Effective changes for all types of school reform, real indicators of success as opposed to assigning a school grade, and other pertinent issues completed the list of elements that comprised the overall theme of what defined significant and long-term change. Ideas indicated by participants concerning the characteristics of positive significant change most times sounded very much like the terms of meaningful and enduring change described by Lieberman and Miller (1999). Table 3 illustrates this relationship. The middle and right columns relate to the building blocks for transforming schools, as indicated by Lieberman and Miller in the left column, and this relationship can be seen when moving horizontally across the table.

Many of the characteristics of successful schools that were delineated by interviewees were also reported as being evident at B.R.E. These qualities were either in place before the establishment of the A+ Plan or came about as a result of some of the changes made after the criteria of the reform went into effect. Examples of those evident at the school included the emphasis on strengthening the skills of weak students, the 
Building Blocks for Transforming Schools and Teaching (Lieberman \& Miller)
Participants Perceived Characteristics of a Successful School
Participants Perceived Effective Changes for all School Reform
- Rethinking curriculum and instruction to improve quality and promote equality (content and process)

- Rethinking the structure of the school (balancing action and reflection)

- Adopting a twopronged focus: students and teachers

- Making connections outside the school

- Encouraging increased participation by parents and the community
- Focus on total school curriculum vs. concentration for specific grade levels

- Positive approach to teaching vs. lack of enthusiasm

- Need for respect and a safe environment

- Continued assessment of changes

- Positive, supportive administration vs. inflexibility

- Staff cohesiveness

- Preparation of students for real life

- Continual staff development

- High expectations for all

- Increased parent and community involvement
- Concrete foundation in primary grades

- Development of grade level between $\mathrm{K}$ and $1^{\text {st }}$

- Lower class size

- Analysis of school demographics to assist in accountability

- Focus on individual child

- Strengthen individual student skill weaknesses

- Continual school and district level staff development

- Visitation of state officials when determining accountability

- Expectation of parents to share in achievement goal 
focus on staff development, and the push to involve parents in the understanding of what was necessary for their children to achieve academically, although it was noted that these areas needed further development. The strengthening of students' skills and the focus on staff development reflect the provisions of Lieberman and Miller's building block of focusing equally on teachers and students. Parent understanding fits the building block of encouragement of greater community and parent participation.

Participants described other attributes of a successful school that were lacking at B.R.E. Individuals believed that much more needed to be done to provide a solid foundation at the primary grade levels. Class size reduction was also viewed as an area of weakness at the school, as average class size at each grade level had increased each year. These two attributes reflect elements of the building blocks of rethinking curriculum and instruction for quality and equity and reviewing the school structure.

Changes that were considered effective for all types of reform covered alterations that needed to be made at the state and local levels, as well as at the school site. Most people felt that the change needed to come at the state and district levels as they would then, in turn, affect what changes were made at the school. This was evident in the statements made by participants concerning what real changes indicated success as opposed to the change in the letter grade that the school received each year.

A final issue that emerged from the accounts of study participants was that the entire atmosphere of school change, academic success and accountability is for the most part politically driven. It was felt that this was true concerning the establishment of the A + Plan and the changes and effects that resulted from its high-stakes accountability criteria. The continual shift of the requirements showing school success was a main 
concern of all the participants. Equal importance was placed on the need for those involved in education on daily basis to have input into what defines true success at a school along with their determining what changes are necessary to insure growth for students.

\section{Conclusions}

Subject to the constraints set forth in this study and to the caveats of being the sole researcher, the responses of the study participants with respect to changes and the effects related to the implementation of the Governor of Florida's A+ Plan for School Accountability, I have come to understand how the teaching and learning environment at Blue Ribbon Elementary School has been decisively impacted. The distinct areas of influence consist of general and school site changes, the effects of the A+Plan and of the specific noted changes, and the idea of school success and the significance and durability of what takes place in and around the teaching and learning environment.

\section{Change}

According to Fullan (1991), "When we ask which aspects of current practice would be altered, if given educational changes were to be implemented, the complexity of defining and accomplishing actual change begins to surface" (p. 37). He goes on to explain that the complexity is that change in education is not comprised of a single entity, but that it must be viewed as multidimensional. For the achievement of specific new educational goals to be realized, the three aspects of innovation that are part of Fullan's theoretical framework become necessary occurrences: (a) the use of new or revised instructional resources, (b) the utilization of new teaching methodologies, and (c) the alteration of convictions. The responses of the study participants illustrate that specifying the changes 
that took place since the inception of the A+ Plan was a problematic task. This was due in part to their beliefs that most meaningful and long lasting implemented procedures and ideas had been in place before the $\mathrm{A}+$ Plan held schools accountable.

Changes that were identified by the participants were also described as somewhat disconnected events. Therefore, as expressed by many interviewees, real change, which according to my analysis meet the criteria of Lieberman and Miller's definition of meaningful and enduring change, did not take place. The use of a variety of new instructional resources and some alternative instructional strategies were incorporated, but a true shift of principles and educational values by educators, of their fundamental beliefs in what teaching and learning should be, did not take place. These principles and values included ideas that teachers still are the professionals and know what their students need. In addition, school site educators can assess the academic achievement of their students more comprehensively than a standardized test.

It is my conclusion that the changes that were highlighted by those individuals whom I interviewed were believed to be the means by which attaining an A grade would be accomplished and according to participants may not be applicable to other types of school reform. Although there were indications of mixed feelings as to the value of the overall and school site changes, it is my conclusion that the changes were met with negativity. This may be in part due to the notion of many educators that the entire highstakes A+ Plan is viewed with quite a bit of disapproval. Effects

Many of the effects were reported to have been both results of school level changes of the implementation of the A+ Plan including the administration of the FCAT 
to formulate a school grade. Figure 1 provides a graphic display of the B.R.E. educators' understanding of the interaction of causes and effects. The implementation of the A+ Plan produces overall system changes, school site changes and general effects at the state and district levels. In turn, the overall changes are part of the effects of the A+Plan and along with this high-stakes accountability system produce school site changes. Effects of the school site changes may resemble the effects of the A+Plan as well as be site specific.

The identified effects of change on the teaching and learning environment were perceived to be, on an overall basis, detrimental. According to the perceptions of those educators interviewed, a conclusion of this study is that the curriculum at B.R.E. has been narrowed, anxiety and stress have dominated the teaching and learning environment, a situation that has been described in the literature. "More and more, there is only one real class being taught in American public schools: test prep" (Wagner, 2002, p. 6).

Furthermore, according to the data student and teacher motivation to learn new things has been undermined. Finally, time for more reflective student-teacher dialogue has all but been eliminated.

Characteristics of Success, Meaningful and Enduring Change

When analyzed by the criteria established by Lieberman and Miller for meaningful and enduring change, participants' impressions about (a) the changes made since the A+Plan, (b) their ideas of the as to what constitutes a successful school, and (c) the effects that were produced by the Plan and the various changes indicate that the overall picture of alterations and their consequences at B.R.E. is not one of meaningful and long lasting change. This is evident through the expression of a variety 


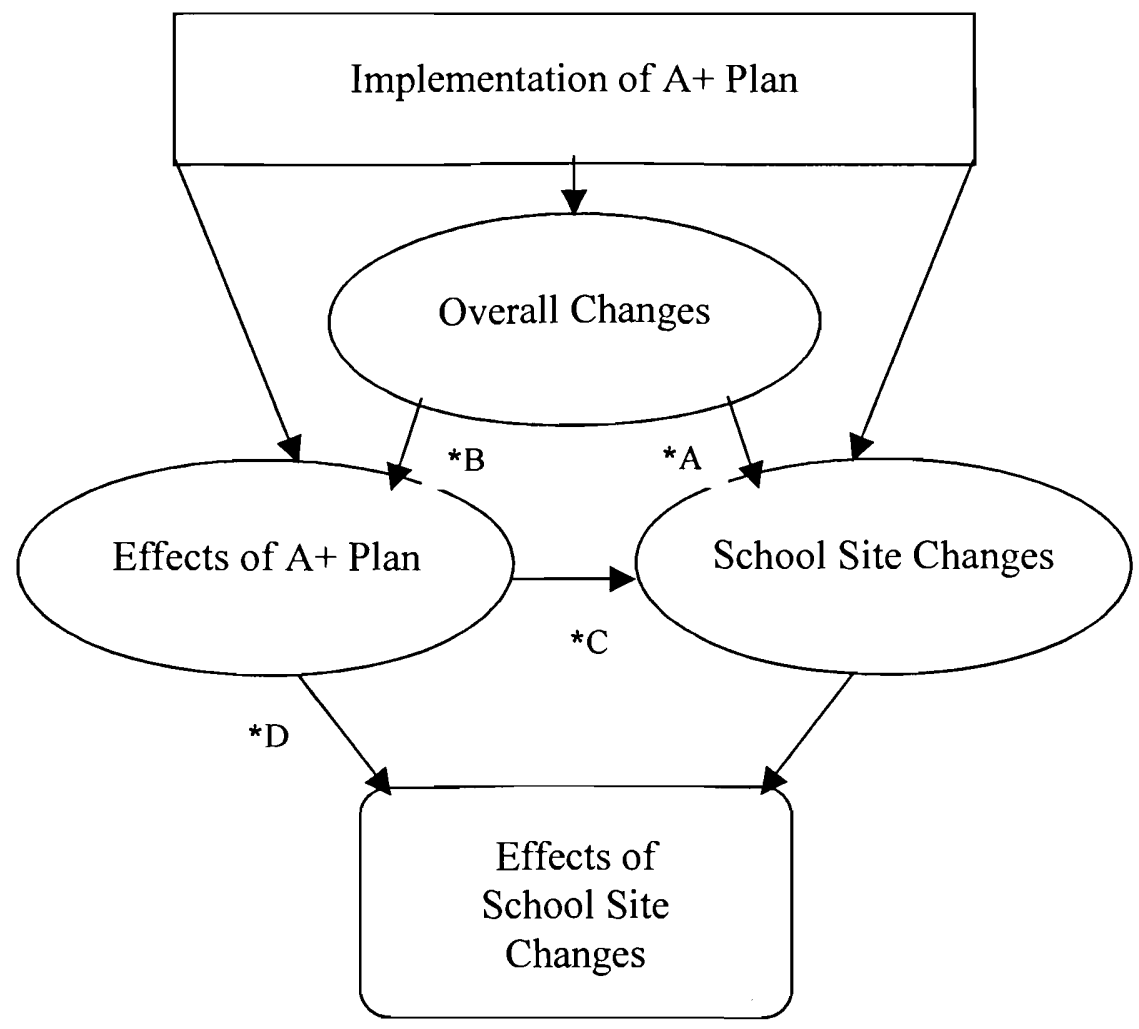

*A Some reported school site changes were general changes at the district level.

*B Overall changes are effects of the A+ Plan.

${ }^{*} \mathrm{C} \quad$ School site changes are effects of the A+ Plan.

*D Some reported effects of school site changes are general effects of the A+Plan.

Figure 1. Participants' understanding of A+ Plan changes and effects.

of thoughts by the participants. These ideas include, but are not limited to ideas alluding to the fact that changes were made to target the test and not made to provide a well rounded curriculum and notions that the state continually switches the criteria for accountability and the school does not know which way to turn next. In addition, participants believe that stress and anxiety abound in the total school environment and there exists a redirection of the focus of resources allocation, time management, and staff 
allocation. Other areas of priority have been geared toward grades that are assessed by the FCAT and count towards the school's grade.

Characteristics of a successful school, as identified by participants in the study, do meet with the criteria established by Lieberman and Miller for meaningful and enduring change. This is apparent in the interview responses, which focused on students and not what is needed to meet grading criteria. Participants spoke about watching the growth of individuals versus comparing school to school; utilizing proven teaching strategies; opening direct lines of communication between administration, staff, parents and the community; continually providing and attending staff development activities and working together as a team.

In the eyes of the participants, the changes they had been experiencing and their effects do not make the school successful; most felt the school had been on the right road before the implementation of the A+Plan and many of the changes and consequences actually hurt the school's efforts. Examples include the utilization of staff for duties other than enhancing the teaching and learning environment and omitting subject material not covered on the FCAT. Some individuals even questioned whether they were really doing their job once they directed their attention to meeting the criteria to reach the "A." Participants believed success is not defined as significant and long lasting by a grade; it is so characterized by the continual achievements of staff and students and the satisfaction of the key stakeholders.

Educational Accountability and Politics

A final conclusion based upon the responses of the participants in this study incorporates the concept that politicians do not comprehend the genuine meaning of 
school achievement and success and that the A+ Plan, FCAT and their associated changes and effects are a reflection of political agenda and have a minimal relationship to significant and enduring educational change and school success. With the year-to-year modifications in the accountability criteria, it seems to these educators that there is no real stability in what signifies a flourishing school except for the letter grade it receives. Instead, according to the educators interviewed, those who have the most interest in the school teaching and learning environment best determine success and significant and lasting change. The key stakeholders include educators, parents, and the community. Summary of Conclusions

Relationships among the four themes that emerged from the data can provide an understanding of what conclusions were drawn from this study. The first relationship showed that the changes that took place at the school site and their effects, along with the effects of the A+ Plan, were linked. Sometimes they were inseparable or one and the same. A second relationship that existed was the similarity of B.R.E.'s consistent procedures and principles and what the participants delineated as characteristics of a successful school. Third, the responses of B.R.E. educators helped to determine the conclusion that most changes and their effects did not related to what these participants perceived to be positive consistent principles, procedures and characteristics of a successful school. In turn, these changes and effects did not reflect Lieberman and Miller's characteristics for effective and long-term transformation. The values and procedures identified by participants as being in place before the implementation of the A+ Plan showed a positive relationship to Lieberman and Miller's criteria for transforming teaching and learning. In addition, B.R.E. educators' criteria for a 
successful teaching and learning environment positively relate to what was discussed by Lieberman and Miller. Figure 2 provides a graphic representation of these relationships. From the point of view of long-term educators at B.R.E., the changes that occur as a result of high-stakes accountability system may show positive outcomes in the form of higher test scores and an increase in students' knowledge of isolated skills. On the other hand, possible destructive consequences appear including a narrowed curriculum, which focuses upon material stressed on standardized tests, an increase in the displeasure of learning among students and teaching among educators, an uneven allocation of resources, time and personnel at a school, and an ultimately negative regard for public education.

Educators who took part in this study believe that if a high-stakes accountability system is to maximize its expected benefits above and beyond raising test scores, then there are a number of essential issues that should be taken into account. Their ideas reflect the statements of King and Mathers (1997) who point out that policymakers must develop guidelines utilizing a suitable balance of state and local jurisdiction over reform goals. King and Mathers also state that those in power must guarantee fairness in comparing schools and districts of differing socio-economic standing. Individuals who set policy must also delineate the type of support and penalties for schools not meeting performance expectations. Moreover, participants think that educational policymakers must understand that without ensuring sufficient staff development, leadership, and all forms of resources including personnel and materials, a high-stakes accountability system such as the A+ Plan, may do little to advance positive educational reforms and promote increases in academic achievement in-low performing schools. 


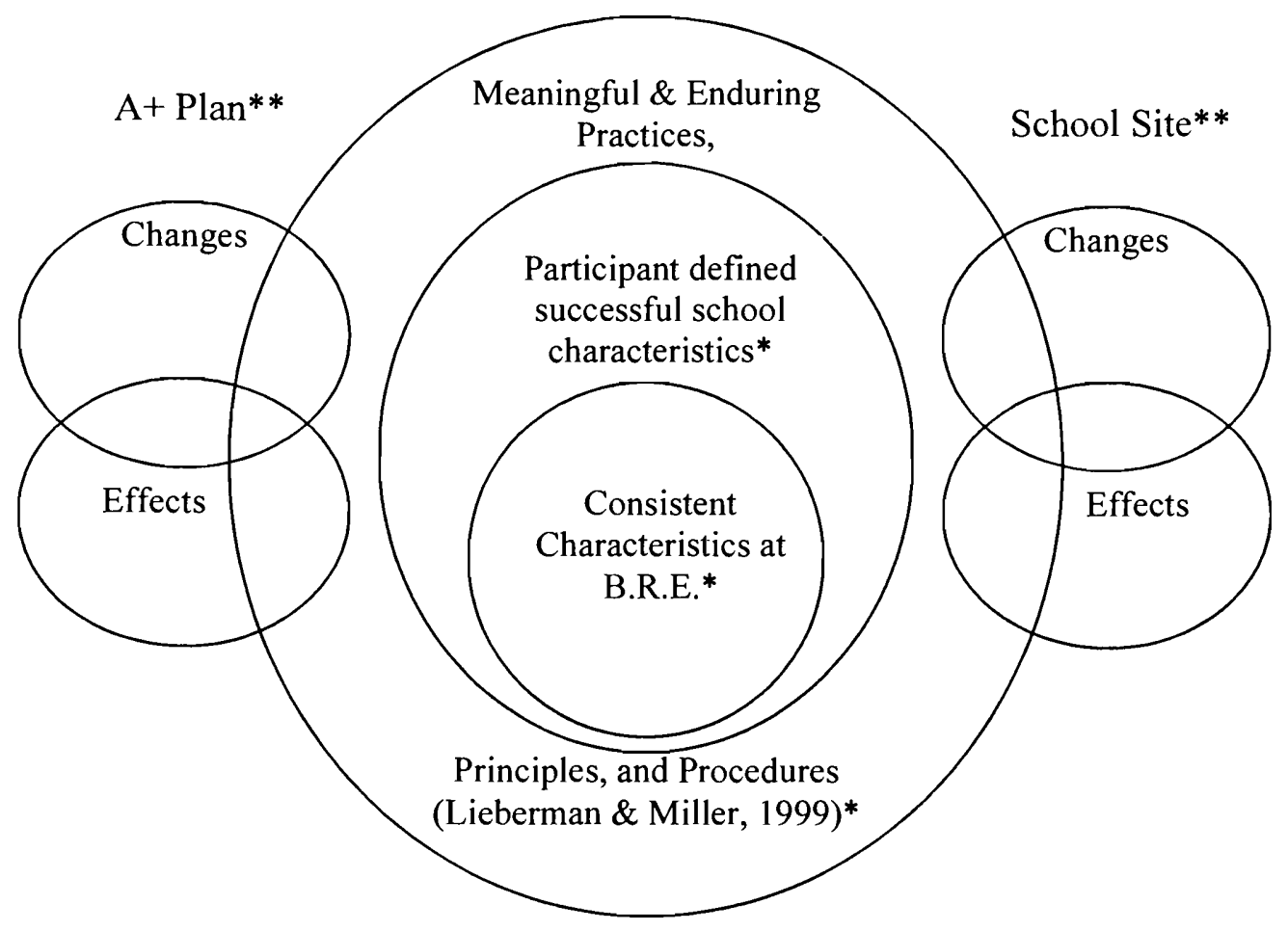

* Focus on the entire teaching and learning environment.

** Focus on student achievement and accountability.

Figure 2. Participants' perceptions of a successful school.

\section{Contributions of the Study}

High-stakes testing and accountability systems have been reported to produce stress, tension, increased standards, higher test scores, and other general effects on schools. This study adds to the understanding of specific changes and their explicit effects on a particular school to the literature. It also relates their relationships to what educational researchers, such as Lieberman and Miller, find necessary to promote effective and lasting transition in schools. 
This study provides a look at the transformation of a specific school after the implementation of Florida's A+ Plan. It looks at this transformation through the eyes of teachers and administrators who had experienced "teaching to the test," stress, increased test scores, and other general changes. It highlights the changes in curricular programs, the manipulation of time, schedules, and resources that occurred and reported effects on students and parents as well as the educators themselves.

The analysis of the data indicates that there is a relationship established between what study participants indicate as perceived changes and effects. These are analyzed in terms of Lieberman and Miller's (1999) characteristics found in a school that has experienced meaningful and enduring change. A link between the declarations from interviewees, the themes that have been developed from these reports, and the building blocks for changing teaching and learning in schools has been established.

Although many of the issues indicated by participants did not explicitly address Lieberman and Miller's ideas, educators' perspectives on what constitutes a successful school directly did reflect many of the criteria established by these educational researchers. These criteria included staff development, collaboration, parent involvement, meeting student needs, and a balance among content and process, students and teachers, and accountability and responsibility.

An analysis of the information provided by study participants reveals that B.R.E. followed many of Lieberman and Miller's principles both before and after the implementation of the A+ Plan, yet many of the changes and effects produced by the A+ implementation did not meet these principles for effective and enduring change. These 
results add insight into the impact of the A+ Plan on the decision-making a school may go through when having to deal with a high-stakes accountability system.

The findings related to the changes and their effects, along with the relationship they have to Lieberman and Miller's criteria for what produces a significant and longlasting transformation, establishes what has been previously cited in the literature on high-stakes testing and accountability in schools. As seen through the eyes of those directly affected by the process, this study adds another dimension to what possible roles high-stakes accountability plays in public education.

Finally, the establishment of a relationship between what educators in the study viewed as essential criteria for a successful school, the consistent characteristics of B.R.E., and the indicators of meaningful and enduring change as delineated by Lieberman and Miller lends itself to the formulation of a model of how schools ought to define their teaching and learning environments. The perceptions of the participants speak to the point that the focus should be teachers and students, curriculum and instruction to advance equity and equality, and more parent involvement as opposed to a sole concentration on standardized test scores for accountability purposes.

Implications for Decision Makers

This study has allowed the ideas and opinions of educators concerning the implementation of the A+Plan, its effects and the changes that have taken place to be voiced. The case study gives political officials the opportunity to understand what goes on in a particular school as an outcome of their decisions concerning school accountability. Insight into the changes and effects on the teaching and learning environment may provide those in the state capitol a broader scope of what needs to be 
addressed to ensure high quality public education and greater academic achievement for all students.

\section{Recommendations for Educational Policymakers}

The following suggestions are those state educational decision makers are encouraged to take when acting upon issues of school accountability:

1) Provide the opportunity for school site staff to collaborate in order to determine the value of changes to be made and the continued assessment as to the validity and effectiveness of these changes.

2) Include the responsibility of parents in the accountability of schools as well as the professionals in the field of education.

3) Incorporate school visitations as part of the accountability system in order to truly understand what defines school success.

4) Provide an organized orientation and the availability of a staff development program prior to any more changes in the grading criteria.

Recommendations for Research

Although this study focused upon one particular school, the interview questions can be utilized at other sites to ascertain the viewpoints of the educators who have a vested interest in their schools. This may provide insight as to the similarities and differences among schools when comparing the changes and effect brought about by the implementation of the A+ Plan. Therefore, the following recommendations for further qualitative research are being suggested:

1) Utilization of the same interview questions and techniques at one or more other elementary school sites within the same school district to compare 
and contrast the perceived changes and effects and whether they are considered meaningful and enduring.

2) Utilization of the same interview questions and techniques at a secondary school site to identify the changes and effects that take place at the secondary level.

3) Utilization of the same interview questions and techniques at one or more elementary school sites in different districts to compare and contrast the perceived changes and effects among different districts.

4) Repetition of the study at the same site may be in order to determine if the new criteria set forth for accountability, since this study was conducted, has caused a change in the opinions of the participants and to determine if any similarities exist between the findings of the present study and the new one.

5) Implementation of a study involving legislators and educational policymakers to ascertain their awareness of what school site changes have been instituted in relationship to the A+ Plan.

6) Implementation of a study ascertaining the opinions of the general public concerning the effectiveness of the A+Plan and the impact it has had upon Florida's public schools.

In addition to qualitative studies, it is suggested that quantitative research methods may be used to measure the effects of the A+ Plan on issues such as school attendance, levels of stress and anxiety and degree of teacher dissatisfaction. It may be especially interesting to look at the state grading system changes that have taken place since this 
study was implemented and recalculate the 2001-2002 school grade according to the original criteria to see whether the different formulas made a difference in the grade the school received. A study may be conducted to establish whether the A+ Plan measures the impact of the changes or their effects on student achievement and/or teacher performance. These studies may be combined with interviews in order to secure verbal data along with numerical data.

Further research on the impact of the A+ Plan upon the teaching and learning environment will help educators, parents, the community, policymakers, and state leaders understand the changes and effects that a high-stakes accountability system causes in public schools. This knowledge can ultimately enable those in power to make sound decisions when dealing with the education of children and the continued increase of academic achievement within the public schools of the State of Florida. 


\section{References}

Association for Effective Schools, Inc. (1996). What is effective schools research? Retrieved December 1, 2003, from http://www.mes.org/esr.html

Adams, L., \& Karabenick, S. A. (2000, April). Impact of state testing on students and teaching practices: Much pain, no gain? Paper presented at the meeting of the Annual Meeting of the American Educational Research Association, New Orleans, LA. (ERIC Document Reproduction Service No. ED443870)

Archer, J., \& Hoff, D. J. (2000, September 27). Teaching and learning: High-stakes tests. Education Week, 20(4), 14.

Bailey, B. (2000). The impact of mandated change on teachers. In N. Bascia \& A. Hargreaves (Eds.), The sharp edge of educational change: Teaching, leading and the reality of reform (pp. 112-128). London: RoutledgeFalmer.

Barksdale-Ladd, M., \& Thomas, K. F. (2000). What's at stake in high-stakes testing: Teachers and parents speak out. Journal of Teacher Education, 51, 384-397.

Barton, P. E. (1999, Summer). Tests, tests, tests. American Educator, 23(2), 18-23, 44.

Bauer, S. C. (1999, November). Should achievement tests be used to judge school quality? Paper presented at the Annual Meeting of the American Evaluation Association, Orlando, FL. (ERIC Document Reproduction Service No. ED435760)

Beck, B. (1995). State-mandated test score accountability: Its usefulness and meanings for school districts (Doctoral dissertation, University of Utah, 1995). Dissertation Abstracts International, 56, 4370.

Bell, M. (2000, October 8). Dropout teachers add to shortage. Sun Sentinel, pp. 1A, 26A.

Berliner, D. C., \& Biddle, B. J. (1995). The manufactured crisis. White Plains, NY: Longman.

Boser, U. (2000, June 7). Teaching to the test? Education Week, 19(39), 1, 10.

Boser, U. (2001). Quality counts: Pressure without support [Special issue]. Education Week, 20(17), 68-71.

Bracey, G. W. (2000). The 10th Bracey report on the condition of public education. Phi Delta Kappan, 82, 133-144. 
Bradley, A. (2000, March 22). L. A. proposes linking teacher pay to tests. Education Week, 19(28), p. 3.

Cheating to the test. (2000, March). School Reform News, 4(3), p. 10.

Clayton, M. (1999, April 6). Do high-stakes tests change a school? Yes. Christian Science Monitor, 15.

Coleman, A. L. (2000, August 2). Rejecting the false choice about high-stakes testing. Education Week, 19(47), 42-45.

Coles, A. D. (2001, January 11). Quality counts: Tennessee - Education officials slowly implement standards-based tests and accountability [Special issue]. Education Week, 20(17), 181.

Conley, D. T., \& Goldman, P. (1998, April). How educators process and respond to state-level education reform policies: The case of Oregon. Paper presented at the Annual Meeting of the American Educational Research Association. (ERIC Document Reproduction Service No. ED421773)

Creswell, J. W. (1994). Research design: Qualitative and quantitative approaches. Thousand Oaks, CA: Sage.

Creswell, J. W. (1998). Qualitative inquiry and research design: Choosing among five traditions. Thousand Oaks, CA: Sage.

Datnow, A., \& Castellano, M. (2000). Teachers' responses to success for all: How beliefs, experiences, and adaptations shape implementation. American Educational Research Journal, 37, 775-799.

Dorn, S. (1998, January 2). The political legacy of school accountability systems (1st ed., Vol. 6). Retrieved from Education Policy Analysis Archives: http://olam.ed.asu.edu/eppa/v6n1.html

Eisner, E. W. (2001). What does it mean to say a school is doing well? Phi Delta Kappan, 82, 367-372.

Feldman, S. (2000, September). The uproar over testing. American Teacher, 5.

Ferrechio, S. (2000, February 5). FCAT Preparation reaches fever pitch in area schools. The Herald, pp. 1A, 20A.

Ferrechio, S. (2000, February 14). Anxiety heightens as FCAT nears. The Herald, pp. 1B, $2 \mathrm{~B}$. 
Flick, U. (1998). An introduction to qualitative research. London: Sage.

Florida Department of Education. (1999). Florida's system for high quality school 19992000. Tallahassee, FL: Office of Policy Research and Accountability and the Division of Public Schools.

Florida Department of Education. (2001). FCAT briefing book. Retrieved January 8, 2001, from http://www.firn.edu/doe

Florida Department of Education. Florida Administrative Code Rule 6A-1.09981. Retrieved January 8, 2001, from http://www.firn.edu/doe/rules/69-1-11.htm

Fullan, M. G. (1991). The new meaning of educational change $\left(2^{\text {nd }}\right.$ ed.). New York: Teachers College Press.

Gehring, J. (2001, January 11). Quality Counts: Massachusetts [Special Issue]. Education Week, 20(17), p. 143.

Gold, S., \& Talalay, S. (1999, May 16). Educators express fears of teaching "to the test". Sun Sentinel, pp. 1A, 11A.

Gratz, D. B. (2000). High standards for whom? Phi Delta Kappan, 81, 681-687.

Helfand, D. (2001, September 4). Stakes get personal in school reform accountability: By using special funds to help raise test scores, teachers agree failure can mean reassignment. The Los Angeles Times, p. A1.

Hess, F. M., \& Brigham, F. (2000). None of the above. American School Board Journal, 187, 26-29.

Hirschman, B. (1999, November 5). Teachers flee failing schools, educators say. Sun Sentinel, pp. 1A, 26A.

Hirschman, B. (2000, August 13). "I don't think anybody can relax or let up": Test pressure from FCAT is likely to remain intense. Sun Sentinel, p. 23A.

Hirschman, B., Hall, H., \& Patrick, K. (2000, February 13). Pressure, tension fuel FCAT drills. Sun Sentinel, pp. 1A, 13A.

Hoff, D. J. (1999, September 12). Standards at crossroads after decade: High-stakes testing is chief worry. Education Week, 19(3), pp. 1, 9.

Hoff, D. J. (1999, December 15). N.Y.C. probe level test-cheating charges. Education Week, 19(16), 3. 
Hoff, D. J. (2000, June 21). As stakes rise, definition of cheating blurs. Education Week, 19(41), 1, 14-16.

Holdzkom, D. (1999, April). Be careful what you ask for: The impact of an accountability system on student achievement, school achievement and teachers. Paper presented at the meeting of the Annual Meeting of the American Educational Research Association, Montreal, Quebec, Canada. (ERIC Document Reproduction Service No. ED435114)

Jacobson, L. (2001, January 11). Quality counts: Georgia [Special Issue]. Education Week, 20(17), 128-129.

Janesick, V. J. (1998). "Stretching" exercises for qualitative researchers. Thousand Oaks, CA: Sage.

Janesick, V. J. (1998). The dance of the qualitative research design. In N. K. Denzin \& Y. S. Lincoln (Eds.), Strategies of qualitative inquiry (pp. 35-55). Thousand Oaks, CA: Sage.

Jehlen, A. (2001, January). Can the standards movement be saved? NEA Today, 19(4). 89.

Jones, K. J., \& Whitford, B. L. (1997). Kentucky's conflicting reform principles: Highstakes school accountability and student performance assessment. Phi Delta Kappan, 79, 276-281.

Jones, M. G., Jones, B. D., Hardin, B., Chapman, L., Yarbrough, T., \& Davis, M. (1999). The impact of high-stakes testing on teachers and students in North Carolina. Phi Delta Kappan, 81, 199-203.

Jones, S. L. (1999, November 8). Gateway grade to be set this week: More protests expected at board meeting. The Atlanta Journal and Constitution, p. 1.

Kannapel, P. J., Coe, P., Aagaard, L., Moore, B. D., \& Reeves, C. A. (2000). Teacher responses to rewards and sanctions: Effects of and reactions to Kentucky's highstakes accountability program. In B. L. Whitford \& K. Jones (Eds.), Accountability, assessment \& teacher commitment: Lessons from Kentucky's reform efforts (pp. 127-146). Albany, NY: State University of New York Press.

Keller, B. (2001, January 11). Quality counts: Texas - A much-debated system is gearing up for changes that will give educators even more to talk about [Special Issue]. Education Week, 20(17), 182, 184. 
Kentucky Institute for Education Research (1995, October). Statewide education reform survey: The judgments, opinions and perspectives of local school board members. Frankfort, KY. (ERIC Document Reproduction Service No. ED394974)

King, R. A., \& Mathers, J. K. (1997). Improving schools through performance-based accountability and financial rewards. Journal of Education Finance, 23, 147-176.

Kleiner, C. (2000, June 12). Test case: Now the principal's cheating. U.S. News and World Report, 130, 24.

Knowles, R., \& Knowles, T. (2001). Accountability for what? Phi Delta Kappan, 82, 390-392.

Kohn, A. (2000a). Burnt at the high stakes. Journal of Teacher Education, 51, 315-327.

Kohn, A. (2000b). The case against standardized testing: Raising the scores, ruining the schools. Portsmouth, NH: Heinemann.

Kohn, A. (2001a, January). Education in a dark time. ASCD Education Update, 43(1), 1, 4.

Kohn, A. (2001b). Fighting the tests: A practical guide to rescuing our schools. Phi Delta Kappan, 82, 349-357.

Lezotte, L. W. (2001). Revolutionary and evolutionary: The effective schools movement. Retrieved November 27, 2003, from http://www.effectiveschools.com

Lieberman, A., \& Miller, L. (1999). Teachers: Transforming their world and their work. New York: Teachers College Press.

Lindsay, D. (2000a, April). Call to arms. Teacher Magazine, 11(8), 24-31.

Lindsay, D. (2000b, April 5). Con test. Education Week, 19(30), 30-37.

Linn, R. L. (2000). Assessments and accountability. Educational Researcher, 29(2), 4-16.

Manzo, K. L. (2000, December 13). New N.C. report card sizes up state's education system. Education Week, 20(15), 28.

Marsh, M. S. (1999). Life inside a school: Implications for reform in the $21^{\text {st }}$ century. In D. D. Marsh (Ed.), Preparing our schools for the $21^{\text {st }}$ century (pp. 185-202). Alexandria, VA: ASCD.

Marshall, T., \& Hall, H. (2000, June 26). FCAT focus draws flak. Sun Sentinel, pp. 1B, $2 \mathrm{~B}$. 
McColskey, W., \& McMunn, N. (2000). Strategies for dealing with high-stakes state tests. Phi Delta Kappan, 82, 115-120.

McNeil, L. M. (2000). Creating new inequalities: Contradictions of reform. Phi Delta Kappan, 81, 729-734.

Miami-Dade County Public Schools. (2000). Promoting continuous school quality improvement. Miami, FL.

Mid-Content Research for Education and Learning. (2000, April). High-stakes testing: Trends and issues (Policy Brief). Aurora, CO: Anne Lewis. (ERIC Document Reproduction Service No. ED442806)

Mitchell, K. J. (1997). What happens when school reform and accountability testing meet? Theory into Practice, 36(4), 262-265.

Moores, D. F. (2000). High-stakes testing: Are the stakes too high? American Annals of the Deaf, 145, 235-236.

Moss, P. A., \& Schutz, A. (2001). Educational standards, assessment, and the search for consensus. American Educational Research Journal, 38, 37-70.

My Florida. (2000). A+ plus plan for education. Retrieved January 8, 2001, from http://www.myflorida.com/myflorida/government/learn/aplusplan/ planEducation.html

Natriello, G, \& Pallas, A. M. (1998, December). The development and impact of highstakes testing. Paper presented at the High-Stakes K-12 Testing Conference. Retrieved February 26, 2001 from http://www.law.harvard.edu/groups/ civilrights/conferences/testing98/drafts/natriello99.html

Nazareno, A. (2000, July 1). Focus on FCAT might help students learn. The Herald, pp. 1B, 2B.

Nazareno, A., Brecher, E. J., \& Robinson, A. (2000, June 29). Scores have teachers jumping for joy. The Herald, pp. 1B, 2B.

O’Connor, L. (2000, March 11). “A-plus” uproar gaining volume. Sun Sentinel, pp. 1A, $6 \mathrm{~A}$.

Ohanian, S. (2001). News from the test resistance trail. Phi Delta Kappan, 82, 363-366.

Olson, L. (2001, January 31). Few states are now in line with Bush testing plan.

Education Week, 20(20), 1, 25. 
Quality counts: A better balance [Special issue]. (2001). Education Week, 20(17).

Ramirez, A. (1999). Assessment-driven reform: The emperor still has no clothes. Phi Delta Kappan, 81, 204-208.

Rosenstein, P. D. (2001, March 7). The politics and practice of student assessment: Solution or fad? Education Week, 20(25), 42, 46.

Rothman, R. (1995). Measuring up: Standards, assessment and school reform. San Francisco, CA: Josey-Bass.

Rubin, H. J., \& Rubin, I. S. (1995). Qualitative interviewing: The art of hearing data. Thousand Oaks, CA: Sage.

Schleisman, J. (1999). An in-depth investigation of one school district's responses to an externally mandated, high-stakes testing program in Minnesota. Paper presented at the Annual Meeting of the University Council for Educational Administration, Minneapolis, MN. (ERIC Document Reproduction Service No. ED440465)

Sheldon, K. M., \& Biddle, B. J. (1998). Standards, accountability, and school reform: Perils and pitfalls. Teachers College Record, 100, 164-180.

Shepard, L. A. (2000). The role of assessment in a learning culture. Educational Researcher, 29(7), 4-14.

Slaton, D. B., Attwood, V. A., \& Shake, M. C. (1999). Experienced teachers' reactions to mandated reform and nongraded primary school programs [Electronic version]. Journal of Research in Childhood Education, 12, 5-15.

Smith, M. L., \& Fey, P. (2000). Validity and accountability in high-stakes testing. Journal of Teacher Education, 51, 334-344.

Stake, R. E. (1998). Case Studies. In N. K. Denzin \& Y. S. Lincoln (Eds.), Strategies of qualitative inquiry (pp. 86-109). Thousand Oaks, CA: Sage.

Stiggins, R. J. (1999). Assessment, student confidence, and school success. Phi Delta Kappan, 81, 191-198.

Suarez, T. M., \& Gottovi, N. C. (1992). The impact of high-stakes assessment on our schools. NASSP Bulletin, 76, 82-88.

Tuch, W. A. (1996).The impact of high-stakes performance assessment on teachers and learning (Doctoral dissertation, Arizona State University, 1996). Dissertation Abstracts International, 57, 4220. 
Van den Berg, R., \& Ros, A. (1999). The permanent importance of the subjective reality of teachers during educational innovation: A concerns-based approach. American Educational Research Journal, 36, 879-906.

Wagner, T. (2002). Making the grade: Reinventing America's schools. New York: RoutledgeFalmer.

Wallace, D. (2000). Results, results, results. Educational Leadership, 57, 66-68.

Wheelock, A. (2000). A new look at school accountability. In B. L. Whitford \& K. Jones (Eds.), Accountability, assessment \& teacher commitment: Lessons from Kentucky's reform efforts (pp. 179-198). Albany, NY: State University of New York Press.

Whitford, B. L., \& Jones, K. (Eds.). (2000). Accountability, assessment, \& teacher commitment: Lessons from Kentucky's reform efforts (pp. 9-24). Albany, NY: State University of New York Press.

Willis, S. (1999, November). The accountability question. ASCD Education Update, $41(7), 1,4-5,8$.

Wolf, S. A., Borko, H. Elliot, R. L., \& McIver, M. C. (2000). “That dog won't hunt!”: Exemplary school change efforts within the Kentucky reform. American Educational Research Journal, 37, 349-393.

Wolk, R. A. (1999). Who will lead? Teacher Magazine, 11(1), 7-8.

Wolk, R. A. (2000). Crash test. Teacher Magazine, 12(2), 3.

Young, T. A. (1996). A study of the perceptions of Tennessee teachers, principals, superintendents, legislators, and Department of Education representatives regarding the impact of the Tennessee value-added assessment system (Doctoral dissertation, University of Alabama, 1996). Dissertation Abstracts International, $57,2317$. 
APPENDICES 
2000-2001 Procedures for Grading Florida's Public Elementary Schools

Criteria for Grades A-F**

\begin{tabular}{|c|c|c|c|c|c|}
\hline Grade & $\underline{\mathrm{C}}$ & $\mathrm{D}$ & $\mathrm{F}$ & B & A \\
\hline Criteria & $\begin{array}{l}\text { Current year } \\
\text { data in } \\
\text { reading, } \\
\text { writing, and } \\
\text { math at or } \\
\text { above } \\
\text { minimum } \\
\text { criteria.* }\end{array}$ & $\begin{array}{l}\text { Current year } \\
\text { data in } \\
\text { reading, } \\
\text { writing, or } \\
\text { math below } \\
\text { minimum } \\
\text { criteria. }\end{array}$ & $\begin{array}{l}\text { Current year data } \\
\text { in reading, } \\
\text { writing, and } \\
\text { math below } \\
\text { minimum } \\
\text { criteria. }\end{array}$ & 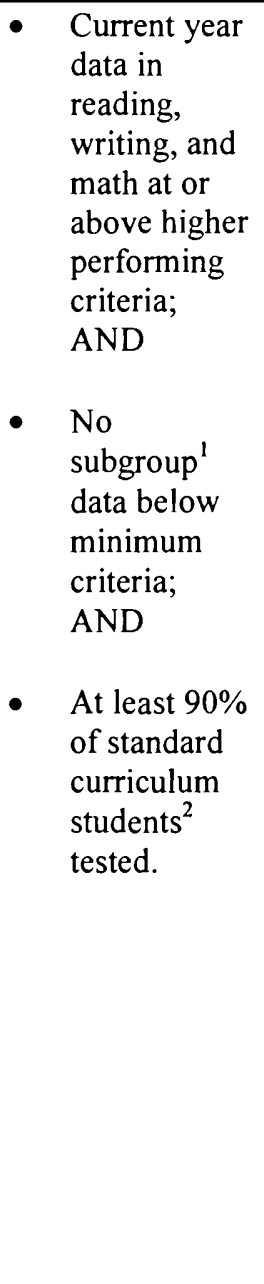 & $\begin{array}{l}\text { - } \begin{array}{l}\text { Meets "B" } \\
\text { requirements; } \\
\text { AND }\end{array} \\
\text { - } \begin{array}{l}\text { Percent of } \\
\text { students } \\
\text { absent more } \\
\text { than } 20 \text { days } \\
\text { and percent of } \\
\text { outdoor } \\
\text { suspensions } \\
\text { below state } \\
\text { means; AND } \\
\text { - Shows } \\
\text { significant } \\
\text { improvement }{ }^{3} \\
\text { in reading } \\
\text { scores; AND } \\
\text { Shows no } \\
\text { significant } \\
\text { decline in in } \\
\text { math or } \\
\text { writing } \\
\text { scores; AND } \\
\text { At least } 95 \% \\
\text { of standard } \\
\text { curriculum } \\
\text { students } \\
\text { tested. }\end{array} \\
\text { - }\end{array}$ \\
\hline
\end{tabular}

*Reading scores for fourth grade students, writing scores for fourth grade students, and math scores for fifth grade students. At least $90 \%$ of the students in a school must be tested in order to receive a grade higher than " $\mathrm{C}$. ."

'Subgroups include Hispanic, Black, Asian, American Indian, White and economically disadvantaged students.

${ }^{2}$ Standard curriculum students include language impaired, gifted, speech impaired, hospital homebound and limited English proficient students who have been in an ESOL program more than two years.

${ }^{3}$ Significant improvement in reading means an increase of more than two percentage points in the percent of students scoring at a Level 3 on the FCAT and above. If a particular school has 75\% or more of its students scoring at or above a Level 3 on the FCAT and no greater than a two percentage point decrease from the prior year, then this requirement is waived.

${ }^{4}$ Significant decline means a decline of five or more percentage points in the percent of students scoring in FCAT Level 3 and above in math OR a decline of five or more percentage points in the percent of students scoring 3 and above in writing. 
Minimum Criteria for Grade C, D, and $\mathrm{F}^{* *}$

\begin{tabular}{|c|c|c|c|}
\hline School Type & FCAT Reading & FCAT Math & Florida Writes! \\
\hline Elementary & $\begin{array}{c}60 \% \text { score } \\
\text { Level } 2 \& \\
\text { above }\end{array}$ & $\begin{array}{c}60 \% \text { score } \\
\text { Level } 2 \& \\
\text { above }\end{array}$ & $\begin{array}{c}50 \% \text { score } 3 \\
\& \text { above }\end{array}$ \\
\hline Middle & $\begin{array}{c}60 \% \text { score } \\
\text { Level } 2 \& \\
\text { above }\end{array}$ & $\begin{array}{c}60 \% \text { score } \\
\text { Level } 2 \& \\
\text { above }\end{array}$ & $\begin{array}{c}67 \% \text { score } 3 \\
\& \text { above }\end{array}$ \\
\hline High & $\begin{array}{c}60 \% \text { score } \\
\text { Level } 2 \& \\
\text { above }\end{array}$ & $\begin{array}{c}60 \% \text { score } \\
\text { Level } 2 \& \\
\text { above }\end{array}$ & $\begin{array}{c}75 \% \text { score } 3 \\
\& \text { above }\end{array}$ \\
\hline
\end{tabular}

Criteria for Grade A and $\mathrm{B}^{* *}$

\begin{tabular}{c|ccc}
\hline School Type & FCAT Reading & FCAT Math & Florida Writes! \\
\hline \multirow{5}{*}{ Elementary } & $\begin{array}{c}50 \% \text { score } \\
\text { Level 3 \& } \\
\text { above }\end{array}$ & $\begin{array}{c}50 \% \text { score } \\
\text { Level 3 \& } \\
\text { above }\end{array}$ & $\begin{array}{c}67 \% \text { score 3 } \\
\text { \& above }\end{array}$ \\
& $\begin{array}{c}50 \% \text { score } \\
\text { Level 3 \& } \\
\text { above }\end{array}$ & $\begin{array}{c}50 \% \text { score } \\
\text { Level 3 \& } \\
\text { above }\end{array}$ & $\begin{array}{c}75 \% \text { score 3 } \\
\text { \& above }\end{array}$ \\
& $\begin{array}{c}50 \% \text { score } \\
\text { Level 3 \& } \\
\text { High }\end{array}$ & $\begin{array}{c}50 \% \text { score } \\
\text { Level 3 \& } \\
\text { above }\end{array}$ & $\begin{array}{c}80 \% \text { score 3 } \\
\& \text { above }\end{array}$ \\
& & & \\
\hline
\end{tabular}

**As determined and reported by the Florida Department of Education 


\section{Appendix B}

\section{Interview Questions}

1. What do you think are the characteristics of a successful school?

2. Tell me about your experiences when you first came to B.R.E. How would you describe the school environment (instructional programs, accountability, staff development, budget, extra curricular activities, test prep, teacher professionalism issues, relationship with the parents, community, etc.)?

3. Tell me about the A+ Plan, the purpose of the FCAT, and the grading of schools in Florida.

4. Since the implementation of the A+ Plan, how have the goals, students, community, \& needs of B.R.E. changed? Describe the teaching and learning environment at B.R.E. since the grading of schools began.

a. Include changes dealing with staff, students, instructional strategies, teaching, learning, instructional support, budgets, staff development, curriculum, time management, and parental involvement.

b. Have these changes impacted your teaching style; has their been a change in administrative style? If so, please give examples.

c. What effect do you feel these changes have had on staff, students, instructional strategies, teaching learning, instructional support, budgets staff development, curriculum, time management, parental involvement.

d. What changes have been effective and/or ineffective?

5. Our school received a grade of " $C$ " for the $1^{\text {st }}$ two years and an " $A$ " the third. What changes do you think had the greatest effect on raising the school grade?

6. Do you feel these changes warrant continuation in light of new grading criteria? Why or why not?

7. Do you feel that the changes that have been made at B.R.E. are significant for any type of school reform that may come along, or do you feel they are only relevant for meeting the requirements of the $\mathrm{A}+$ Plan? Please explain your response.

8. Which changes that have been made at B.R.E. do you feel are worthwhile to share with other schools?

9. What changes do you feel need to be implemented at B.R.E.?

10. What would you tell state officials are the best indicators of school site success in teaching and learning? 


\section{Appendix C}

\section{Participant Letter of Consent*}

\section{CONSENT TO PARTICIPATE IN A RESEARCH STUDY}

\section{MAKING THE GRADE: THE PERCEIVED IMPACT OF FLORIDA'S A+ PLAN ON THE LEARNING ENVIRONMENT OF ONE ELEMENTARY SCHOOL}

I freely and voluntarily consent to be a participant in the research project listed above, to be conducted at Florida International University, with Robin Behrman as principal investigator. I have been told that my participation will require me to respond to various questions, during a taped interview, regarding Florida's A+ Plan and the Florida Comprehensive Assessment Test and change at my school. I am told that my participation will require about 2 hours total of my time. I will be participating in this study with approximately 20 other faculty members.

I understand that the purpose of this research is to study the impact of Florida's A+ Plan on teaching and learning. I understand that the procedures will be as follows. 1) The researcher will obtain some background information about me including my education, number of years as an educator, and number of years at this school; 2) I will be asked questions pertaining to my perceptions of change at my school since the inception of the FCAT and A+ Plan; 3) I am aware that the interviews will be audio-taped; 4) The researcher will follow-up with me after the interview in order to clarify any responses or to further ascertain any information relating to the study.

I understand that there are no risks involved in being a participant in this research, as all I need to do is respond to questions dealing with teaching and learning. I understand that my participation will assist with the researcher gathering knowledge in this area of study. Participation in this study is of no cost to me, and I also understand I will not receive any tangible rewards after completing the interview.

I understand that I may withdraw my consent and discontinue participation in this research project at any time with no negative consequences. All information pertaining to this study and participation will be kept in a locked cabinet off of the school site. A number and/or pseudonym will be used; no names will be disclosed. My responses are strictly confidential and would only be disclosed as required by law.

I have been given the right to ask questions concerning the procedure, and any questions have been answered to my satisfaction. I understand that if any new discoveries are developed during the time that I am in this study, which may affect my willingness to be in the study, I will be notifies as soon as possible.

I have read and I understand the consent form.

Signature of Participant

Printed Name

Date

I have explained and defined in detail the research procedure in which the participant has agreed to participate and have offered him/her a copy of this informed consent form.

Signature of Witness

Date

*This is a modified version of the original form. The original appears on university letterhead. 
Appendix D

Background Information on Blue Ribbon Elementary School 2001-2002 School Year

\section{School Characteristics}

Blue Ribbon Elementary (B.R.E.), lies in the northwest region of Miami-Dade County, is surrounded by a middle class neighborhood, and is under the jurisdiction of the Miami-Dade County Public School System. At the time when data was gathered for the study, B.R.E. housed pre-kindergarten through grade five, and was at $171 \%$ of 1311 capacity utilization. The school was made up of a main building, an annex, two primary learning centers, and twenty portables. After school care was provided.

\section{Staff Characteristics}

The staff at Blue Ribbon Elementary, at the time of data collection, was comprised of 137 full-time staff and 27 part-time staff. Administrative staff was made up of one white female principal, two white, female assistant principals, two black female assistant principals, and one Hispanic female assistant principal. Instructional staff, which was comprised of classroom teachers, exceptional student teachers, special area teachers, guidance counselors, and librarians, was composed of fourteen males and ninety-six females. Thirty-one members of the instructional staff were classified as White, non-Hispanic; twenty-seven were classified as Black, Non-Hispanic, and fifty-two were classified as Hispanic. The average number of years of experience, in the State of Florida, for the members of the instructional staff was twelve. Forty-three percent of the instructional staff had earned a Masters Degree and eight percent had obtained a Specialists Degree. 
Appendix D

Cont'd

Student and Educational Program Information

The student membership for the 2001-02 school year was 2242; 264 were classified as White, Non-Hispanic, 181 as Black, Non-Hispanic, 1732 as Hispanic, and 65 as Asian/Indian or Multiracial. Out of the entire student population, 128 students were classified as Gifted, sixty-six as Speech and/or Language Impaired, and 103 were covered under a variety of other exceptional student education programs. The Bilingual Program enrollment included 468 students in the English for Speakers of Other Languages (ESOL) Program. Students participating in the Federal Free/Reduced Lunch Program made up $47.4 \%$ of the student population.

\section{Student Achievement}

The 2001-02 Blue Ribbon Elementary School profile provided by the MiamiDade County Public Schools delineated student achievement by providing normreferenced test information for the 1999, 2000, and 2001 spring administrations. Also provided were the scores for the grade 4 FCAT Writing Assessment for both the 2000 and 2001 spring administrations. In addition, 2001 grade four reading and grade five math FCAT information were supplied. The following charts summarize that data. 
Appendix D

Cont'd

2000 and 2001 FCAT Writing Assessment Results

\begin{tabular}{c|cccc} 
Prompt Type & \multicolumn{3}{|c}{ Average Score } & \multicolumn{2}{c}{ Percent Scoring 3 and } \\
& 2000 & 2001 & Above (combined) \\
\hline Expository & 3.5 & 3.4 & $2000:$ & 93 \\
Narrative & 3.3 & 3.5 & $2001:$ & 94 \\
Combined & 3.4 & 3.4 & &
\end{tabular}

1999, 2000, and 2001 Norm-Referenced Test Data*

\begin{tabular}{c|ccccccccccccc} 
Grade & \multicolumn{2}{|c}{$\begin{array}{c}\text { Reading } \\
\text { Comprehension } \\
\end{array}$} & \multicolumn{2}{c}{$\begin{array}{c}\text { Mathematics } \\
\text { Computation }\end{array}$} & \multicolumn{2}{c}{ Mathematics } & \multicolumn{2}{c}{ Science } \\
\hline 2 & 52 & 58 & 60 & 85 & N/A & N/A & 63 & 53 & 52 & & & & \\
3 & 49 & 58 & 57 & 78 & N/A & N/A & 61 & 56 & 51 & 49 & N/A & N/A \\
4 & 47 & 50 & 56 & 86 & N/A & N/A & 66 & 49 & 62 & & & \\
5 & 46 & 42 & 45 & 58 & N/A & N/A & 69 & 67 & 64 & 46 & 41 & 41
\end{tabular}

*Median percentile given

2001 FCAT Results*

\begin{tabular}{|c|c|c|c|c|c|c|c|c|c|c|c|c|c|c|c|c|c|c|}
\hline \multicolumn{10}{|c|}{ Reading-Grade 4} & \multicolumn{9}{|c|}{ Mathematics - Grade 5} \\
\hline \multicolumn{2}{|c|}{ Level 1} & \multicolumn{2}{|c|}{ Level 2} & \multicolumn{2}{|c|}{ Level 3} & \multicolumn{2}{|c|}{ Level 4} & \multicolumn{2}{|c|}{ Level 5} & \multicolumn{2}{|c|}{ Level 1} & \multicolumn{2}{|c|}{ Level 2} & \multicolumn{2}{|c|}{ Level 3} & \multicolumn{2}{|c|}{ Level 4} & Level 5 \\
\hline 00 & 01 &, 00 & 01 & ${ }^{\prime} 00$ & 01 & '00 & 01 & .00 & 01 & 00 & '01 & 00 & ${ }^{\circ} 01$ & 00 & 01 & 00 & 01 & $\begin{array}{ll} & \prime \\
\end{array}$ \\
\hline 33 & 26 & 22 & 21 & 28 & 32 & 15 & 16 & 2 & 5 & 20 & 20 & 29 & 27 & 25 & 23 & 21 & 24 & 66 \\
\hline
\end{tabular}

*Indicated in percent 
Appendix D

Cont'd

School grades for Blue Ribbon Elementary were also available. The school received a grade of $\mathrm{C}$ for 1998-1999, another C for 1999-2000, and an A for 2000-2001. The 2001-2002 grade was not available at the time of data collection from participant interviews, but was released at the end of the school year. Blue Ribbon Elementary received a grade of B for the 2001-2002 school year.

School Climate Survey

Parents, staff, and students were given a chance to complete a survey indicating their perceptions about the school. For the 2001-2002 school year, parents gave the school a grade of $\mathrm{B}+$ and students and staff rated the school as an A-. 
Appendix E

\section{Participant Questionnaire}

Please use the following to identify my responses in the dissertation document:

$\square$ Initials - Place initials here

$\square$ Pseudonym - The name I'd like you to call me is:

$\square$ Use my real first name

Number of years as an educator

Number of years at Blue Ribbon Elementary

$1^{\text {st }}$ year at Blue Ribbon Elementary

Grade level this year

Subject(s) taught this year

Other grade levels taught throughout professional career

Other subject areas taught throughout professional career

Degrees

Areas of Certification

Thank you for your input! 
Appendix F

\section{Profile of Participants*}

\begin{tabular}{|c|c|c|c|c|c|}
\hline Participant & Interview Date & $\begin{array}{l}\text { \# Years in } \\
\text { Education }\end{array}$ & $\begin{array}{l}\text { \# Years at Blue } \\
\text { Ribbon Elem. }\end{array}$ & $\begin{array}{c}2001-02 \\
\text { Assignment } \\
\end{array}$ & Degree(s) \\
\hline Rochelle & $3 / 29 / 02$ & 24 & 5 & Gr. 3 Language Arts & $\begin{array}{l}\text { B.S. in Elementary } \\
\text { Education }\end{array}$ \\
\hline Carla & $4 / 1 / 02$ & 27 & 5 & $\begin{array}{l}\text { Gifted Education } \\
\text { Grades 2-5 }\end{array}$ & $\begin{array}{l}\text { B.A. in Elementary } \\
\text { Education; M.S. in } \\
\text { Elementary Education }\end{array}$ \\
\hline Rouben & $4 / 1 / 02$ & 5 & 5 & $\begin{array}{c}\text { Grade } 5 \\
\text { Math and Science }\end{array}$ & $\begin{array}{l}\text { B.S. in Elementary } \\
\text { Education }\end{array}$ \\
\hline Patti & $4 / 2 / 02$ & 27 & 10 & Principal & $\begin{array}{l}\text { B.S. in Elementary } \\
\text { Education; M.S. in } \\
\text { Elementary Education; } \\
\text { pursuing Ed.D. }\end{array}$ \\
\hline Leslie & $4 / 2 / 02$ & 26 & 13 & $\begin{array}{l}\text { Giffed Education } \\
\quad \text { Grades 2-5 }\end{array}$ & $\begin{array}{l}\text { B.A. in Special } \\
\text { Education; M.S. in } \\
\text { Special Education }\end{array}$ \\
\hline Linola & $4 / 3 / 03$ & 25 & 14 & $\begin{array}{c}\text { Grade } 5 \\
\text { Math and Science }\end{array}$ & $\begin{array}{l}\text { B.S. in Elementary } \\
\text { Education; M.S. in } \\
\text { Elementary Education }\end{array}$ \\
\hline Atalia & $4 / 9 / 02$ & 17 & 8 & $\begin{array}{l}\text { Assistant } \\
\text { Principal }\end{array}$ & $\begin{array}{l}\text { B.S. in Elementary } \\
\text { Education; M.S. in } \\
\text { Educational Leadership }\end{array}$ \\
\hline
\end{tabular}




\section{Appendix F (Cont'd)}

\begin{tabular}{|c|c|c|c|c|c|}
\hline Participant & Interview Date & $\begin{array}{l}\text { \# Years in } \\
\text { Education }\end{array}$ & $\begin{array}{l}\text { \# Years at Blue } \\
\text { Ribbon Elem. }\end{array}$ & $\begin{array}{c}2001-02 \\
\text { Assignment }\end{array}$ & Degree(s) \\
\hline Spring & $4 / 9 / 02$ & 9 & 9 & $\begin{array}{l}\text { Assistant } \\
\text { Principal }\end{array}$ & $\begin{array}{l}\text { Bachelors in Business; } \\
\text { M.S. in Elementary } \\
\text { Education }\end{array}$ \\
\hline Carole & $4 / 14 / 02$ & 39 & 19 & $\begin{array}{c}\text { Grade } 3 \\
\text { All Subject }\end{array}$ & B.A. in Education \\
\hline Mar & $4 / 18 / 02$ & 5 & 5 & $\begin{array}{c}\text { Grade } 4 \\
\text { Math, Science, and } \\
\text { Social Studies }\end{array}$ & $\begin{array}{l}\text { B.S. in Elementary } \\
\text { Education }\end{array}$ \\
\hline Barry & $4 / 23 / 02$ & 34 & 20 & $\begin{array}{l}\text { Grade } 5 \text { Math and } \\
\text { Science }\end{array}$ & $\begin{array}{l}\text { B.S. and M.Ed. in } \\
\text { Elementary Education } \\
\text { and certification in } \\
\text { Leadership }\end{array}$ \\
\hline Jo & $4 / 26 / 02$ & 13 & 8 & $\begin{array}{l}\text { Assistant } \\
\text { Principal }\end{array}$ & $\begin{array}{l}\text { B.S. in Elementary } \\
\text { Education, M.S. in } \\
\text { Educational } \\
\text { Leadership; pursuing } \\
\text { Ed.D. }\end{array}$ \\
\hline Maria & $5 / 2 / 02$ & 20 & 10 & Spanish Grades 1-5 & $\begin{array}{l}\text { B.S. and M.S. in } \\
\text { Elementary Education; } \\
\text { Ed.S. in Leadership }\end{array}$ \\
\hline Gigi & $5 / 3 / 02$ & 15 & 8 & $\begin{array}{c}\text { Grade } 4 \\
\text { Language Arts }\end{array}$ & $\begin{array}{l}\text { Bachelors in Design; } \\
\text { Elementary Education, } \\
\text { Middle Grades Social } \\
\text { Studies and French } \\
\text { Certification }\end{array}$ \\
\hline
\end{tabular}


Appendix F (Cont'd)

\begin{tabular}{|c|c|c|c|c|c|}
\hline Participant & Interview Date & $\begin{array}{l}\text { \# Years in } \\
\text { Education }\end{array}$ & $\begin{array}{l}\text { \# Years at Blue } \\
\text { Ribbon Elem. }\end{array}$ & $\begin{array}{l}2001-02 \\
\text { Assignment }\end{array}$ & Degree(s) \\
\hline Consuela & $5 / 7 / 02$ & 10 & 5 & $\begin{array}{c}\text { Grade } 4 \text { Mathematics } \\
\text { and Science }\end{array}$ & $\begin{array}{l}\text { B.S. and M.S. in } \\
\text { Elementary } \\
\text { Education }\end{array}$ \\
\hline Lisa & $5 / 20 / 02$ & 10 & 10 & $\begin{array}{c}\text { Grade } 1 \\
\text { All Subjects }\end{array}$ & $\begin{array}{l}\text { B.S. in Business } \\
\text { M.S. in Educational } \\
\text { Leadership }\end{array}$ \\
\hline Laura & $5 / 23 / 02$ & 6 & 5 & $\begin{array}{c}\text { Art } \\
\text { Grades 2-5 }\end{array}$ & $\begin{array}{l}\text { B.F.A.; Masters in } \\
\text { Art Education }\end{array}$ \\
\hline Tracy & $5 / 24 / 02$ & 9 & 9 & $\begin{array}{l}\text { Kindergarten } \\
\text { All Subjects }\end{array}$ & $\begin{array}{l}\text { B.S. in Elementary } \\
\text { Education }\end{array}$ \\
\hline Julio & $5 / 28 / 02$ & 7 & 7 & $\begin{array}{l}\text { First Grade } \\
\text { All Subjects }\end{array}$ & $\begin{array}{l}\text { B.S. in Elementary } \\
\text { Education; M.S. in } \\
\text { Computer Education; } \\
\text { Ed.S.- Educational } \\
\text { Leadership }\end{array}$ \\
\hline Chris & $5 / 31 / 02$ & 30 & 6 & $\begin{array}{l}\text { Kindergarten } \\
\text { All Subjects }\end{array}$ & $\begin{array}{l}\text { B.S. in Elementary } \\
\text { Education; M.Ed. }\end{array}$ \\
\hline Peggy & $6 / 4 / 02$ & 20 & 9 & $\begin{array}{c}\text { Grade } 1 \\
\text { All Subjects }\end{array}$ & $\begin{array}{l}\text { B.S. in Elementary } \\
\text { Education; M.S. in } \\
\text { Educational } \\
\text { Technology }\end{array}$ \\
\hline
\end{tabular}




\section{ROBIN L. BEHRMAN}

November 20, 1953

1975

$1979-1983$

1981

$1983-1992$

$1992-2000$

1996

1998

2000

$2000-2002$

2002 - Present
Born, New York, New York

B.S. in Elementary Education

Florida International University

Miami, Florida

Teacher

Toras Emes Academy

Miami Beach, Florida

M.S. in Counseling Psychology

Nova University

Davie, Florida

Teacher

Skyway Elementary

Opa Locka, Florida

Teacher

"Blue Ribbon Elementary"

Hialeah, Florida

Ed.S. in Educational Leadership

Florida International University

Miami, Florida

Who's Who Among America's Teachers

Temporary Assistant Principal

Mae M. Walters Elementary

Hialeah, Florida

WLRN - NTTI Master Teacher of the Year

Assistant Principal

"Blue Ribbon Elementary"

Hialeah, Florida

Assistant Principal

Bob Graham Education Center

Miami Lakes, Florida 